\title{
LAMINAR FLOW OF DILUTE POLYMER SOLUTIONS AROUND CIRCULAR CYLINDERS
}

\author{
Thesis by \\ David Fielding James \\ In Partial Fulfillment of the Requirements \\ For the Degree of \\ Doctor of Philosophy
}

California Institute of Technology

Pasadena, California

(Submittod May 24, 1967) 


\section{ACKNOWLEDGMENTS}

In the course of his work the author benefited from the advice, guidance and encouragement of Professor A. J. Acosta to whom he wishes to express his sincere thanks. Thanks are also due to other members of line Inslitule facully, especially Professor R. H. Sabersky, with whom the author had occasion to discuss his work.

The partial support of this research under the Department of the Navy Contract N 00014-66-C0009-A 02 is gratefully acknowledged. Financial assistance was afforded the author by a Ford Foundation Summer Fellowship and by Graduate Teaching and Research Assistantships.

Special thanks are due to Mr. E. F. Daly, Mr. R. L. Greenway and Mr. C. Eastvedt for their technical assistance. The author is also grateful to Mrs. Hhyllis Henderson, Miss Julle Wright, Miss Cecelia Lin and Mrs. Madeline Fagergren for the assistance in preparing the manuscript.

Furthermore, the author wishes to express his deepest gratitude to his wife for her encouragement and understanding. He also wishes to thank her for the technical assistance she rendered during the course of the experiments. 


\section{ABSTRACT}

Experimental results are presented for heat transfer by free and forcod convection at low velocities from small heated cylinders in dilute solutions of polyethylene oxide in water. The experiments were conducted for a range of velocities (less than $1.0 \mathrm{ft} / \mathrm{sec}$ ) and polymer concentrations, with several cylinder diameters, and for several polymer molecular weights. Experimental results are also presented for the drag of a small cylinder in similar liquids and for a comparable range of velocities.

The heat transfer and drag results at low velocities were identical to those for a Newtonian liquid; at high velocities, the measured values departed considerably from Newtonian results. These departures result from the viscoelastic nature of the polymer solutions. Visualization studies of the flow around a cylinder and of a minute laminas jel were conducted to determine the gross magnitude of the viscoelastic effects. Due to the liquid's elasticity, a significant enlargement of the flow field was observed for both configurations above a critical Reynolds number. An allempl is made lo explain the lieal transfer and drag results in light of these observations.

Photographic materials on pp. $111-149$ are essential and will not reproduce clearly on Xerux cupies. Pholographic cupies should he ordered. 
TABLE OF CONTENTS

ABSTRACT _ i ii

LIST OF TABLES viii

IIST OF FIGURES ix

I. INTRODUCTION

A. Preliminary Remarks 1

B. Survey of Previous Investigations 4

C. Objectives of Present Investigation 6

II. EXPERIMENTAL EQUIPMENT - HEAT TRANSFER 9

A. Viscometric Measurements 9

B. Polymer Solutions 10

C. Heat Transfer 14

1. General Scheme 14

2. Anemometer 14

3. Heated Cylinders 16

4. Electronic Squaring Circuit. 17

5. Tow Tank 18

III. EXPERIMENTAL PROCEDURE - HEAT TRANSFER 20

A. Viscometric Measurements 20

1. General Procedure 20 
2. Calibration 21

3. Temperature Correction 23

B. Polymor Solutiona 25

1. Concentration Range 25

2. Measurement of Intrinsic Viscosity 27

3. Polymer Degradation 27

C. Heat Transfer Measurements · 29

1. Preliminary Measurements 29

2. Procedure for a Heat Transfer Rum 30

3. Air Bubbles 37

4. Sensor Stability 37

5. Free Convection Studies 40

IV. HEAT TRANSFER RESULTS . 43

A. Computation of Dimensionless Parameters 43

B. Free Convection $\quad 46$

C. Combined Free and Forced Convection 47

1. Distilled Water 47

2. Polymer Solutions 48

V. DRAG MEASUREMENTS $\quad 52$

A. Preliminary Remarks $\quad 52$

B. Experimental Apparatus $\quad 52$

1. Arrangement of Equipment 52

2. Rotating Tank 53 
3. Travelling Stage Microscope 53

4. Cantilever Wire 54

C. Experimental Procedure 54

1. Viscometric Measurements 54

2. Preparation of Polymer Solutions 55

3. Calibration of Cantilever Wire 56

4. Design Considerations $\quad 57$

5. General Procedure for Deflection 58

Measurements

6. Deflection Meásurements 59

7. Calibration of Microscope Counter 60

D. Results 61

E: Flow Visualization 62

VI. JET EXPERIMENTS 65

A. Preliminary Remarks 65

B. Experimental Equipment 66

$\begin{array}{ll}\text { C. Procedure } & 67\end{array}$

D. Results 68

$\begin{array}{ll}\text { VII. DISCUSSION OF RESULTS } & 71\end{array}$

A. Pure Water Data 71

1. Free Convection 71

2. Combined Free and Forced Convection 72

3. Drag Measurements 73 
vii

$\underline{\text { page }}$

B. Results in Polymer Solutions 74

C. Viscoelastic. Effects $\quad 76$

D. Summary 81

SYMBOLS AND ABBREVIATIONS

REFERENCES

APPENDIXI - Calibration of Anemometer 91

APPENDIX II - Drifl Correction 94

APPENDIX III - Load Function for Cantilever Wire 99

$\begin{array}{ll}\text { TABLES } & 105\end{array}$

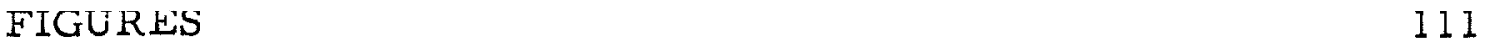


viii

LIST OF TABLES

TABIE

1

2

3

4

5

6

7
TITLE

PAGE

23

Representative Viscosity Data of Four Dilute Solutions

Polymer Degradation

28

Critical Reynolds Numbers for Drag and Heat Transfer Measurements for Dilute Polymer Solutions

80

Supplementary Data for the Combined Free and Forced Convection Heat

Transfer Results

105

Calibration of Cantilever Wire

108

Summary of Data for Calibration of Anemometer

109

Drift Corrections

110 
Fig. 1 Cannon-Fenske Viscometer. 111

Fig. 2 Circuit Diagram of Shapiro \& Edwards Model 112

$\begin{array}{lll}\text { Fig. } 3 \text { Photograph of probe equipment. } & \text { I13 }\end{array}$

Fig. 4 Photograph of 0.006 in. dia. platinum hot-film 114

Fig. 5 . Drawing of commercial hot film sensor. I15

Fig. 6 Photograph of tow tank and carriage. 116

Fig. 7 Intrinsic viscosity analysis for Polyox WSR-301 117

Fig. 8 Representative data relating resistance and 118

Fig. 9 Heat transfer by free convection from a $0.001 \quad 119$

Fig. 10 Heat transfer by free convection from a $0.002 \quad 120$

Fig. 11 Heat transfer by free convection from a 0.006 inch sensor.

Fig. 12 Heat transfer by free convection from the long 122 $(L / D=96) 0.006$ inch sensor.

Fig. 13 Heat transfer by combined free and forced convection from a. 001 inch sensor in water.

Fig. 14 Heat transfer by combined free and forced con124 vection from a. 002 inch sensor in water.

Fig. 15 Heat transfer by combined free and forced convection from a. 006 inch sensor in water. 
Fig. 16 Heat transfer by combined free and forced convection from a. 001 inch sensor in dilute and moderately concentrated solutions of Polyox WSR-205 in water.

Fig. 17 Heat transfer by combined free and forced convection from a. 002 inch sensor in dilute and moderately concentrated solutions of Polyox WSR-205 in water.

Fig. 18 Heat transfer by combined free and forced convection from a. 006 inch sensor in dilute and moderately concentrated solutions of Polyox WSR-205 in water.

Fig. 19 Heat transfer by combined free and forced convection from a. 001 inch sensor in dilute and moderately concentrated solutions of Polyox WSR-301 in water.

Fig. 20 Heat transfer by combined free and forced convection from a. 002 inch sensor in dilute and moderately concentrated solutions of Polyox WSR-301 in water.

Fig. 21 Heat transfer by combined free and forced convection from a. 006 inch sensor in dilute and moderatcly concontrated solutions of Polyox WSR-30l in water.

Fig. 22 Heat transfer by combined free and forced convection from a.00l inch sensor in dilute and moderately concentrated solutions of Polyox Coagulant in water.

Fig. 23 Heat transfer by combined free and forced convection from a. 002 inch sensor in dilute and moderately concentrated solutions of Polyox Coagulant in water.

Fig. 24 Heat transfer by combined free and forced convection from a. 006 inch sensor in dilute and moderately concentrated solutions of Polyox Coagulant in water. 
Fig. 25 Arrangement of equipment for drag

Fig. 26 Photograph of equipment for drag measurements. 136

Fig. $27 \quad$ The travelling stage microscope. 137

Fig. $28 \quad$ Photograph of cantilever wire and its mounting 138 support.

Fig. 29 Drag measurements for a.005 inch circular

Fig. 30 Drag measurements for a .005 inch circular

Fig. 31 Drag measurements for a .005 inch circular cylinder in moderately concentrated solution of WSR-301.

Fig. 32 Arrangement of dye injection tube for visualization of flow around a horizontal circular cylinder.

Fig. 33 Observed dye patterns around a .005 inch $\quad 143$ circular cylinder.

Fig. 34 Arrangement of equipment for jet experiment. 144

Fig. 35 Laminar jet of water. Mean velocity $=0.2 \mathrm{ft} / \mathrm{sec} . \quad 145$

Fig. 36 Laminar jet of water. Mean velocity $=0.4 \mathrm{ft} / \mathrm{sec} . \quad 145$

Fig. 37 Laminar jet of water. Mean velocity $=1.5 \mathrm{ft} / \mathrm{sec} . \quad 116$

Fig. 38 Laminar jet of a dilute polymer solution. 146 Mean velocity - $1.0 \mathrm{ft} / \mathrm{sec}$.

Fig. $39 \quad$ Laminar jet of a dilute polymer solution. $\quad 147$

Fig. 40 Laminar jet of a dilute polymer solution. $\quad 147$ Mean velocity $=2.6 \mathrm{ft} / \mathrm{sec}$. 
xii

page

Fig. 41 Representative data taken during the anemometer 148 calibration.

Fig. 42 Correlation of the corrections for the readout voltage when the sensor resistance is charging. 


\section{CHAPTER I}

\section{INTRODUCTION}

\section{A. Preliminary Remarks}

For the past five or six years considerable attention has been focussed on the fluid mechanics of dilute polymer solutions. This interest has been motivated by a phenomenon often described as the Toms Effect, the reduction of wall friction in turbulent flow when minute amounts of a high molecular-weight polymer are present. In pipe flow, drag reductions by as much as 80 percent have been reported (19) ${ }^{1}$. The polymers used for the Toms Effect typically have $10^{5}$ monomer units; they are highly flexible, linear molecular chains. The dissolved molecules are said to be "randomly coiled", meaning that the molecular chain has a random walk configuration. The effectiveness of a polymer for drag reduction depends on its molecular weight and its concentration in solution. In general, the concentration of solute required for maximum drag reduction in a given flow is so minute that the solution can be considered "dilute"; viz., the spatial separation of polymer molecules does not permit physical interaction.

1. Numbers in parentheses designate references. 
In order to understand the mechanism whereby such "macromolecules" alter the wall shear stress, various types of polymers in different solvents have been tested to find the importance of the poiymer length, linearity of the molecular chain, and flexibility of the molecule. The Reynolds number and shear rate of the flow, as well as the solution concentration and temperature, have been varied to ascertain their separate influence on drag reduction and on the inception of drag reduction.

In contrast to the many experimental studies on drag reduction in turbulent flow, very little experimental work has been done to find suitable "constitutive" relations for dilute polymer solutions. This is understandable because of the uncertainty of the usefulness of such relations; since wall turbulence does not lend itself to theoretical treatment even for Newtonian fluids, it is not obvious that a properly set constitutive equation for dilute polymer solutions would aid in the explanation of the anomalous skin friction reduction.

Nevertheless, whatever the constitutive equation for a dilute polymer solution might he, a proposed relation should include the "elasticity" of the liquid solution. It is well known that polymer solutions are elastic as well as viscous $(6,24)$. One well-known manifestation of the elastic property is shown when the fluid is poured from a container and the stream is cut two or three inches below the lip of the container; the top part of the stream then snaps back into the container much like a severed rubber band. This elastic recovery is 
clearly shown in a photograph on the cover jacket of Lodge's book (24). The elastic effect of the fluid is a result of the preferred configuration of the microscopic polymer molecules $(33,50)$. It is argued that in a stagnant fluid, the randomly coiled molecular chain assumes a roughly spherical equilibrium configuration. The long-chain molecule can be thought of as a series of beads and springs which when stretched from the equilibrium shape by the flow of the surrounding solvent creates restoring forces within the molecule. When the stress causing the fluid deformation is removed, the molecular restoring forces return the molecule to its equilibrium configuration; this molecular reorientation makes itself known at the macroscopic level as an elastic "recoil". This and other such elastic effects are clearly visible and easily measured when the polymer solution is concentrated, but when the solution is dilute the liquid's elasticity is difficult to detect by standard experimental techniques.

While considerable experimental work has been done on turbulent flows of dilute polymer solutions, it appears that laminar flows of such solutions have received relatively little attention. This is perhaps understandable since ordinary viscometric measurements of such laminar flows indicate a fluid behavior similar to that for a Newtonian liquid. It is not clear whether the study of laminar flows would lead to a better understanding of the drag reducing effect in turbulent flow. Tet there have been indications that laminar flows subject to convective acceleration are altered by the presence of long-chain molecules. 
Several experimental investigators, for example, using thermoanemometers and Pitot tube velocity-measuring devices have noted that the sensitivity of these instruments is decreased in polymer solutions even in laminar flow. In fact the present work was motivated by the finding that hot-film probes became insensitive to velocity in polymer solutions. Subsequently Fabula (13) has reported that his hot-film sensors likewise became insensitive to the free stream velocity. Goren (17) also mentioned a discrepancy in Pitot tube calibrations between pure water and a polymer solution. From a survey of the literature it has been found that, to date, there has been no systematic investigation of these abnormal results in laminar flow.

\section{B. Survey of Previous Investigations}

As mentioned, turbulent flow drag reduction in dilute polymer solutions was first reported by. Toms (43): His research was carried out with polymethyl methacrylate in chlorobenzene; it went largely unnoticed until the $1960^{\prime}$ s, when several investigators experimented with a variety of polymers in a water solution. The pioneer work of hydrodynamic interest was conducted by Hoyt and Fabula (19) who measured the pressure drop in pipes for water-soluble polymers and found that the most effective polymers for reducing the wall friction consisted of linear, long-chain molecules. Their pipe flow exporiments indicated that the maximum drag reduction depended on the flow Reynolds number, as well as on the molecular weight and concentration of the polymer. 
The significant drag reduction in pipe flow suggested that the velocity profile for the flow of dilute polymer solutions is considerably altered. Two investigations $(10,17)$ have examined the turbulent velocity profile, but the results differ in the value of the Kármán constant k. Elata ế. al. (10) found no change in the constanl for all concentrations of guar gum, while Goren (17) finds that k decreases with an increasing concentration of polyethylene oxide for the outer fourth of the profile. To date no velocity measurement has been made in the region of most interest - the viscous sublayer. Both Elata and Goren employed small Pitot tubes to measure the velocities in the turbulent core. Goren reports that, at the same velocity, there was a discrepancy in the Pitot tube reading between clear water and a dilute polymer solution; this discrepancy increased with polymer concentration and decreased with the Reynolds number.

Diminished sensitivity with another velocity-measuring device was experienced by Fabula (13) in his work with hot-film sensors. To measure the fluctuating velocities in the turbulent flow behind a grid, Fabula employed a hot-film anemometer. He found that circular and wedge-shaped sensors exhibited flat calibration curves in the high velocity ranges; i.e., at the higher velocities, the heat loss from the sensors became independent of the free stream flow velocity. Virk (46) also reported a similar calibration curve with a cylindrical hot-film sensor. His data with polymer solutions is incomplete, but the characlerislics are sumewhal similar lo Fabula's. Fur example, di luw 
speeds, the sensor heat loss is identical to that for the solvent alone, but at higher speeds a significant reduction in the heat transfer occurs. Lindgren (23) detected a slight decrease in sensitivity with hot-film sensors in a polyethylene oxide solution; however, his velocities did not extend to the regime where Fabula observed the flat calibration curve with a wedge senanr.

It should be mentioned that several theoretical papers $(21,32$, $38,39)$ have treated the flow of a viscoelastic fluid near a stagnation point. The analyses differ in the choice of constitutive equation, but none of these investigators extended their calculations to the regime where elastic effects are expected to be significant. Consequently the computed boundary layer thickness in all cases differs only slightly from that with an equally viscous Newtonian Iiquid.

Rouse's (33) model of a randomly-coiled macromolecule has provided an important theoretical contribution to the work in polymer mechanics. He considered the dissolved polymer molecule to be a series of beads and springs, and found that when the molecule was disturbed from an equilibrium position, the return into the original configuration was associated with a series of discrete relaxation times. His theory shows that the relaxation times depend on the length of the molecule, and on the molecular forces between solute and solvent.

\section{Objectives of the Present Investigation}

The Toms Effect is associated with wall turbulence, and as already indicated none of the above investigations has measured the 
velocity profile in the critical viscous layer next to the wall. The original intention of the present research was to examine the characteristics in this region by use of hot-film sensors.

The feasibility of this technique for measurement of turbulent boundary layers in water has been established by Townes (44) who measured velocities to positions within. 004 inches of the wall corresponding to a $\mathrm{Y}^{*}$ value of 1.0 . Similar measurements were planned for the present work with dilute polymer solutions, but the aforementioned difficulty appoared in calibrating the hot-film scnsors in the polymor solutions. (Fabula's difficulties with the hot-film sensors were not yet known.) At low velocities the heat transfer-velocity relationship was found to be similar to that of pure water; but at higher velocities (on the order of $0.2 \mathrm{ft} / \mathrm{sec}$ ) the heat transfer became independent of the velocity. This indicated, of course, that the hot-film sensors would be useless for velocity measurements whether the flow was turbulent or not. At the same time it was realized that this insensitivity of heat transfer to velocity was itself a significant phenomenon and might provide an interesting research problem in its own right.

As a result the present study was directed towards the heat transfer characteristics of circular cylinders in polymer solutions for laminar flow in the hope that such measurements would provide additional insight into the mechanics of the flows of dilute polymer solutions. Heat transfer measurements were planned for a range of concentrations and velocities, with several cylinder diameters and several polymer 
molecular weights. It was hoped that these results could be correlated with the characteristics of the polymer solution. The peculiar heat transfer results mentioned suggested that the flow field around the cylinder had been altered in a major way by the presence of the polymer molecules. To gain additional insight into the nature of the altered flow field, a furthor cxperiment was carried out to measure the drag of a small cylinder of a size similar to that of the heat transfer experiments and over an equivalent range of velocities and polymer concentrations. 'l'hese investigations were augmented by flow visualization experiments on small jets and on the flow around a small cylinder, both with and without the polymer. The following chapters describe the experimental set-up for the heat transfer measurements, the procedure that was used to make these measurements, and their results. A similar description is given for the drag experiments and results. The observations of the visualization experiments are then presented to make plausible the heat transfer and drag results. The experimental results are compared to studies of the Toms Effect, and are discussed with reference to the viscoelastic nature of a polymer solution. 
CHAPTER II

\section{EXPERIMENTAL EQUIPMENT}

\section{A. Viscometer}

The viscosities of the liquids used in the heat transfer and drag experiments were measured simply yet accurately by use of

a Cannon-Fenske viscometer, a picture of which appears in

Figure 1. The viscosities of the polymer solutions varied between 0.9 and 3.4 centipoise; the ASTM Standards (1) recommends a size 50 viscometer for viscosities ranging from 0.8 to 3.2 , and, accordingly, a size 50 was used for the present work.

To ensure that the liquid sample contained in the viscometer remained at a constant temperature during the viscosity measurement, the viscometer was immersed in a bath, a Lucite tank 11-1/4 inches in diameter and 18 inches deep, filled with water. The viscometer was supported vertically in the tank by a rubber clamp which closed around the viscometer tubes. The clamp was arranged so that only the top inch of the viscometer was not immersed in the water bath. $\mathrm{A}-15^{\circ}$ to $32^{\circ} \mathrm{C}$ thermometer was suspended in the bath, and located about two inches.from the viscometer. 
B. Polymer Solutions

A considerable number of high-weight, water-soluble polymers have been used in the experimental studies of turbuient drag reduction. The polymers tested by Shaver and Merrill (40) produced pseudo-plastic solutions, viz., the solution viscosity decreased with increasing shear rate. Typical solute concentrations for these "non-Newtonian" solutions were 0.3 percent by weight. Hoyt and Fabula (19) also tested a number of water-soluble polymers; they found that, with the polymers of the highest molecular weight, much lower solute concentrations were required for significant drag reduction. 'Typical solution concentrations for these high-weight polymers were 0.005 percent, or equivalently, 50 parts per million by weight (wppm). Two of these long-chain, highly effective polymers were polyethylene oxide (PEO) and guar gum, and viscometry measurements of solutions of both polymers were made over a range of shear rates. The viscosity of guar gum solutions, for concentrations less than 500 wppm, was slightly greater than that for water, and was independent of shear rate over the range of shear rates tested, $2 \times 10^{-2}$ to $4 \times 10^{-5} \mathrm{sec}^{-1}$. The range of shear rates was extended for the PEO solutions, and it was found that the viscosities of two PEO solutions, $10 \mathrm{wppm}$ and $100 \mathrm{wppm}$, were constant for shear rates between $10^{-1}$ and $5 \times 10^{-5} \mathrm{sec}^{-1}$. The constant viscosity of these solutions is considerably different from the non-Newtonian behavior of the solutions tested by Shaver and Merrill. Almost all subsequent investigations used either PEO 
or guar gum because (a) PEO and guar gum solutions are highly effective drag reducers, (b) they have viscosities which differ slightly from water, and (c) their viscosities are independent of shear rate. It was for these same reasons, plus the desirability of comparing the present laminar studies with turbulence work, that the choice of polymer in this investigation was limited to polyethylene oxide and guar gum. PEO was preferred over guar gum for two basic reasons: (1) Only one grade of guar gum is commercially available, while $\mathrm{PEO}$ is available in four molecular weights (the Union Carbide Company produces PEO under the brand name Polyox); and (2) the molecular character of PEO is better known than that of guar gum. This latter factor requires some explanation, and to. do so, it is necessary to introduce the parameters commonly used to describe polymers and polymer solutions.

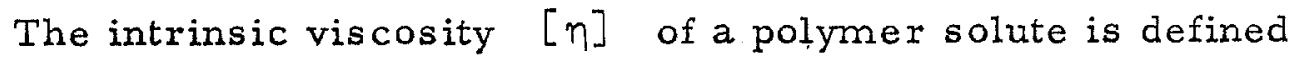
as

$$
[\eta]=\lim _{c \rightarrow 0} \frac{\eta-\eta_{s}}{\eta_{s} c}
$$

where

$$
\eta \quad=\text { viscosity of solution }
$$$$
\eta_{s}=\text { viscosity of solvent }
$$$$
c=\text { concentration of solute }
$$

Since the concentration $c$ is usually expressed in $\mathrm{gm} / 100 \mathrm{ml}$, or $\mathrm{gm} / \mathrm{d} l,[\eta]$ has units of $\mathrm{d} l / \mathrm{gm}$. This parameter is experimentally determined by measuring $\left(\eta-\eta_{s}\right) / \eta_{s} c$ at various solution concentrations and extrapolating to $c=0$. 
The intrinsic viscosity is a measure of the hydrodynamic influence of the dissolved macromolecule on the flow of solvent. It is an indication of the force required to drag the molecule through the solvent, and consequently the larger the molecule, the higher the intrinsic viscosity. This relationship is usualiy given by

$$
[\eta]=k^{\prime} M^{a}
$$

where $M$ is the molecular weight of the solute, and $\mathrm{k}^{\prime}$ and a are constants whose values depend on the temperature and on the nature of the solute and solvent. If the polymer sample is heterogeneous, i. e., if it consists of several molecular weights, then an average molccular woight must bo oubstituted for $M$; by definition this quantity is the viscosity-average and its symbol is $\bar{M}_{\nu}$. If the distribution of molecular weights is unknown, then $\bar{M}_{\nu}$ must be determined independently to find the constants for the above equation. The usual method is to measure the intensity of light passing through the polymer solution (42). Analys is of the light scattering data at various concentrations yields the weight-average molecular weight $\overline{\mathrm{M}}_{\mathrm{W}}$, which can be used in the relation

$$
[\eta]=l^{\prime} \bar{M}_{w}^{a}
$$

where $a$ and $k^{\prime}$ would be different from the former values. From light scattering measurements, Shin (4I) and Bailey et al (2) have found the correlation for Polyox to be 


$$
\left.[\eta]=1.03 \times 10^{-4} \overline{\mathrm{M}}_{\mathrm{W}} 0.78 \quad \text { Shin, at } 25^{\circ} \mathrm{C}\right\rangle
$$

or

$$
[\eta]=1.25 \times 10^{-4} \overline{\mathrm{M}}_{\mathrm{W}}^{0.78} \quad \text { (Bailey et al, at } 30^{\circ} \mathrm{C} \text { ) }
$$

Both investigators tested commercial unfractionated samples of $\mathrm{PEO}$, and consequently the difference in the constant ' $k$ ' is probably due to the variation in the distributions of the molecular weights. Sñin's correlation thus allows the molecular weight of PEO to be determined by simple viscometric measurements. From light scattering measurements, Deb and Mukherjee (9) found the molecular weight of an unspecified commercial sample of guar gum. They did not measure the intrinsic viscosity of the sample, and they did not test other samples of guar gum. Consequently an equation such as $[\eta]=k^{\prime} \bar{M}_{\mathrm{w}}{ }^{a}$ is not available for this polymer, and the molecular weight cannot be computed from viscosity measurements. The molecular weight is, of course, the most important property of a polymer; the simple means of determining this parameter for $\mathrm{PEO}$ was a considerable factor in its choice for the present work in dilute polymer solutions.

Three grades of Union Carbide's Polyox were obtained for the experiments: WSR-205, WSR-301, and Coagulant. All were samples of industrial blends donated by the Union Carbide Company and were used as received. A commercial grade of Polyox is required to have a viscosity, at 5 percent concentration in water, which falls between two specified values. If a batch does not meet 
the specification, PEO of a different molecular weight is combined with the batch until the specification is met. Consequently each polymer sample used in the heat transfer experiments had an uniknown distribution of molecular weight. The molecular weight can be computed from the intrinsic viscosity data for each grade, and this value must be regarded as an estimate of the molecular character of the heterogeneous polymer.

\section{Heat Transfer}

\section{General Scheme}

The basic equipment for the heat transfer measurements from circular cylinders consisted of hot-film sensors, a constanttemperature anemometer, an electronic squaring circuit, and a towing tank. This equipment was originally intended for a research problem of a different nature; as mentioned in Chapter I, the author planned to examine velocities in the viscous sub-layer of a turbulent boundary layer, but the insensitivity of the hot-film sensors in dilute polymer solutions discouraged the planned research and suggested a more interesting problem in heat transfer. Consequently, the anemometer and sensors were employed for measurements of heat transfer instead of velocity. The heat transfer data were recorded while the sensor was towed at a series of velocities through a variety of polymer solutions in the tow tank.

\section{Anemometer}

Hot-wire anemometers are generally designed around two 
basic principles: the constant-current type maintains a fixed current through the sensor and detects changes in heat transfer (i. e., velocity) by changes in the sensor resistance; the constanttemperature type maintains the sensor at a constant resistance (i.e., temperature) and detects the corresponding changes in the sensor current. The anemometer used in the present studies was the latter type, and was a modification of Shapiro and Edwards Model 60-B. Since the set was originally made for Townes' (44) velocity measurements in water, it was considered to be suitable for the present study in aqueous polymer solutions. The anemometer circuit diagram is shown in Figure 2.

The 0-300 ma ammeter of the anemometer directly measured the current through the sensor, i. e., through the fourth leg of the set's Wheatstone bridge. The resistances of two other legs of the bridge are, of course, fixed and the third leg is made variable in order to balance the bridge when sensors of different resistances are inserted as the fourth leg. The resistance of the third leg was varied by manually adjusting the resistance dial on the face of the anemometer. This variable resistor is actually a wire-wound potentiometer, and its numerical values were designed to correspond to the resistance of the fourth leg. When the anemometer is used to measure resistance, the appropriate circuit switch is momentarily closed, and the anemometer ammeter functions as a null meter. If the meter needle doesn't deflect when the switch is closed, the reading on the resistance dial corresponds to the resistance of the fourth leg of the bridge. 


\section{Heated Cylinders}

A shielded low-resistance cable connected the anemometer to the probe holding the sensor. The probe and sensors were standard products of Thermo-Systems Inc., and a photograph of the probe assembly, and two sensor holders, is shown as Figure 3 . The probe, a TSI Model NTID, was combined with a N45 locking sleeve and ' $O$ ' ring to prevent water leaking around the electrical connection between the probe and sensor holder. More details of this watertight locking arrangement can be found in TSI Bulletin N16A.

Figure 4 is a closer photographic examination of the sensor and the legs of the sensor holder. TSI fabricates these sensors in diameter sizes of $.001, .002$, and .006 inches, and a detailed drawing of the sensor construction is presented in Figure 5. The quartz coating shown in Figure 5 is applied around the platinum by sputtering in a vacuum chamber; its application is necessary to prevent the electrolysis which would result if the insulating quartz were not present and electrical paths were established in the conducting liquid. The platinum film in Figure 5 is deposited by firing, the thickness being approximately $1000 \AA$ to produce a sensor resistance between 6 and 9 ohms. The range of the sensor resistance is limited; a large resistance places considerable demands on the circuit anemometry to supply the power for the $I^{2} R$ heat loss from the sensor. On the other hand, a low resistance does not permit an accurate "overheat ratio" to be determined. More will be said about the overheat ratio in the procedural details 
of Chapter III; for the present, it is sufficient to understand that this ratio involves reading values from the anemometer resistance dial which differ by as little as 2 percent. A 2 percent change in the resistance of $6.00 \mathrm{ohm}$ sensor corresponds to a change of $.12 \mathrm{ohm}$ on the resistance dial. Since this dial can be read to $\pm .005 \mathrm{ohm}$, the error in the reading is $5 / 120$ or \pm 4 percent. This error would increase and become unacceptable if the sensor resistance were less than 6.0 ohms. Consequently the platinum film sensors are produced with a minimum sensor resistance of 6 ohms.

The length-to-diameter ratio of the standard TSI hot-film sensors varied between $12: 1$ and $22: 1$. In order to estimate the importance of end effects on heat transfer, a 0.006 inch sensor was custom made by TSI with a length-to-diameter ratio of 96:1。 This sensor is included in the photograph in Figure 3.

\section{Electronic Squaring Circuit}

The anemometer supplied a voltage output which was the product of the current through the hot film and a 10.00 resistor. As it was desired to measure heat flux, the output terminal was connected to an electronic squaring circuit to facilitate the measurement of the dissipated energy. This additional circuitry was convenient because in a typical experimental situation, the anomometer current varied between 90 and $120 \mathrm{ma}$ while the velocity of the fluid past the sensor varied from zero to a maximum. A squaring circuit was already available and found to be very suitable for amplifying the anemometer signals in this work. This squaring circuit amplified and then 
squáfed an input voltage signal; a bias system was also available in the circuitry so that any specified voltage could be subtracted from the amplified-and-squared voltage. For the present work, the bias voltage was always used to suppress the zero-velocity outpul from the anemometer. Consequently the output from the squaring circuit, e, for a particular velocity, was proportional to $I^{2}-I_{0}^{2}$, where I equaled the ammeter current at the particular velocity and $I_{0}$ equaled the ammeter current at zero velocity. The squaring circuit voltage output, e, was measured with a Hewlett-Packard Model 425A DC Micro Volt-Ammeter. The suppression of the zerovelocity current, $I_{0}$, is the essential feature in facilitating the measurement of heat flux for the convection flow.

The accuracy of the electronic operations of the squaring circuit was cherked by Townes (44), who found an accuracy of \pm 3 percent for the operations of the squaring circuit. The circuit amplifier was a Philbrick Model UPA-2, and the electronic squaring was performed by a Douglas Quadratron, Type A, Model 10.

\section{Tow Tank}

An overall view of the tow tank and carriage employed for the heat transfer studies is exhibited in Figure 6. The inside dimensions of the wooden tank were 95-1/2 $\times 11 \times 18$ inches, and the 3-wheel carriage shown in the figure was fastened to a cable loop driven by a $1 / 15$ horsepower, $173 \mathrm{rpm}$ speed-reducer mulur. Combined with the motor was a Minarik Model SH 56 E speed control to provide carriage speeds between .08 and 1.0 feet per second. 
Since lower velocities were desired for the investigation, an additional shaft was mounted above the motor shaft and a removable pulley system was arranged between the two shafts to permit carriage velocities between 0.01 and 0.10 feet per second with the existing motor and speed control. Limit switches for the carriage were installed near the ends of the tank, and a scale was mounted along the rail to measure the carriage travel. Also shown in Figure 6 is the clamp mounted on the carriage to hold the probe and sensor ass embly. 
CHAPTER III

\section{EXPERIMENTAL PROCEDURE}

\section{A. Viscometric Measurements}

The ASTM Standards (1) for the Cannon-Fenske viscometer served as a guideline for cleaning the viscometer, and for introducing and testing a liquid sample.

The viscometer was cleaned by thoroughly rinsing with a technical grade of acetone and drying with dehumidified air. Before the viscometer was calibrated, it was soaked in chromic acid to ensure a perfectly clean instrument. The calibration of the viscometer was periodically checked with several liquids of known viscosities. No discrepancies from the original calibration were noted, and it was concluded that the acetone rinse provided a satisfactory cleaning technique.

1. General Procedure

A measured amount of liquid was introduced into the viscometer (Fig. 1) by (a) attaching a short hose to the larger tube of the viscometer, (b) inverting the viscometer and placing the end of its smaller tube into the liquid to be tested, (c) applying suction through the hose to cause the sample liquid to rise through both small bulbs to etched line $\mathrm{E}$, marked in Figure 1 , and (d) turning the viscometer back to its normal vertical position. The hose was 
then removed, the viscometer was inserted in the clarnp, placed in the constant-temperature bath, and vertically aligned by eye.

Before measuring the sample viscosity, a five-minute waiting period was allowed while the viscometer and its contents reached the bath temperature. After this interval, suction was applied to the smaller viscometer tube to bring the sample above the etched line $C$ (see figure 1). The liquid was allowed to fall, and the time was recorded while the liquid meniscus passed from line $C$ to line $E$. This time interval is known as the "efflux time", and was measured to within 0.1 second with a stopwatch. 'The bath temperature was recorded to $.01^{\circ} \mathrm{C}$ before and after the efflux time was measured, and the average of these temperatures was taken as the liquid temperature during the viscosity measurement.

\section{Calibration}

The viscometer was calibrated by measuring the efflux time of fresh distilled water and 16 water-glycerol solutions of various proportions. These proportions were designed so that their viscosities varied from 0.9 to $3.2 \mathrm{cp}$, the viscosity range of the dilute polymer solutions used in the heat transfer experiments. The viscosity of each solution was determined from the Handbook of Chemistry and Physics (18), which provides viscosity data for all concentrations of glycerol in water for the temperature range, $20^{\circ}$ to $30^{\circ} \mathrm{C}$. The kinematic viscosity of each test liquid was plotted against its efflux time, and the combined data of all liquids provided the calibration curve for the viscometer. 
Maintaining a fixed temperature for the viscometric readings provided an unforeseen difficulty. The water bath is equipped with a constant-temperature device positioned several inches from the thermometer. Thermal gradients produced by the heater caused inconsistent viscometer readings at identical thermometer temperatures. Consequently the heating apparatus was not employed for the viscometric work, and all measurements were taken of the prevailing bath temporature. The prevailing temperature fluctuated between $21.8^{\circ} \mathrm{C}$ and $23.6^{\circ} \mathrm{C}$, but its maximum rate of change was observed to be $0.20^{\circ} \mathrm{C} / \mathrm{hr}$. Since approximately seven minutes were required for a viscosity measurement, the bath temperature was essentially constant for the measurement period.

The above viscometric procedures provided an accuracy of .001 centipuise fur a viscusily measurenent. This accuracy is evident in Table 1, which gives the repeated viscosity measurements of four polymer solutions. In addition, the occasional viscosity measurement of fresh distilled wațer corresponded to within $.0005 \mathrm{cp}$ of the value listed in the Handbook of Chemistry and Physics.

This accuracy was necessary since the difference in viscosity between a polymer solution and pure water is required to characterize the dissolved polymer. The description of this characterization will be presented in the section on polymer solutions. 
TABLE 1

Representative Viscosity Data of Four Dilute Solutions

\begin{tabular}{|c|c|}
\hline $\begin{array}{c}\text { Concentration of } \\
\text { WSR-301 }\end{array}$ & $\begin{array}{c}\text { Viscosity } \\
\mathrm{cp}\end{array}$ \\
& corrected to $23.00^{\circ} \mathrm{C}$ \\
\hline 30 wppm & 0.996 \\
& 0.996 \\
& 0.988 \\
& wppm \\
10 wppm & 0.988 \\
& 0.969 \\
5 wppm & 0.970 \\
& .962 \\
& .962 \\
\hline
\end{tabular}

\section{Temperature Correction}

The computations for the heat transfer results require the viscosity of the polymer solutions at the tow tank temperaturc. Since the solution viscosity was usually measured at a temperature different from that in the tow tank during heat transfer runs, it was necessary to find some procedure for estimating the viscosity of lhe same solution at the tow tank temperature. The following equation was used to correct for this temperature difference, and is based on the assumption that the dissolved molecules increase the viscosity by the same ratio at all temperatures.

$$
\frac{\eta_{1}\left(T_{1}\right)}{\eta_{s}\left(T_{1}\right)}=\frac{\eta\left(T_{2}\right)}{\eta_{s}\left(T_{2}\right)}
$$


where

$$
\begin{aligned}
& T=\text { temperature } \\
& n=\text { solution viscosity } \\
& \eta_{S}=\text { solvent viscosity }
\end{aligned}
$$

For polymer solutions, the viscosity dependence on concentration is usually expresser in terms of the relation

$$
\left(\frac{\eta-\eta_{s}}{\eta_{s} c}\right)=[\eta]+K[\eta]^{2} c
$$

or

$$
\eta=\eta_{s}\left(1+[\eta] c+K[\eta c]^{2}\right)
$$

where $K$ is known as the Huggins constant and has a value near 0.35 for flexible polymer molecules $(20)$. Since $\left[\eta^{2} c<1\right.$ for most solutions used in the present work, the temperature dependence of $\eta$ is mainly related to the temperature dependence of $\eta_{s}$, and consequently Equation ( 1 ) is fully acceptable: When $[\eta] \sim 1$, the variation of $[\eta]$ with temperature is of importance. Pruitt and Crawford found that

$$
\frac{\Delta[r]}{[\eta] \Delta \mathrm{T}} \simeq .28 \times 10^{-2} o_{\mathrm{F}}^{-1}
$$

for Polyox Coagulant at $70^{\circ} \mathrm{F}$. Since the temperatures of the tow tank and of the bath were always close to room temperature, the maximum temperature difference between the two was $4^{\circ} \mathrm{F}$. For this temperature difference, the change in $[\eta]$ would be 1.0 percent and consequently the change in solution viscosity $\eta$ is roughly 0.8 percent. 
This error is considered acceptable and therefore correction Equation (1) was employed for polymer solutions of all concentrations.

\section{B. Polymer Solutions}

1. Conccntration Rangc

The polymer concentrations in the heat transfer and drag reduction studies are usually in the dilute regime, viz., the physical separalion of the dissulved macromulecules shouid the large enough to prevent mechanical interaction. The concentration at which molecular interference is certain is termed the critical concentration, $c_{c}{ }^{*}$ In general, $c_{c}[\eta]=1,(47)$, and for PEO, Shin (41) computes that $c_{c}[\eta]=0.62$ using the Kirkwood-Riseman theory. This difference in the critical concentration is not large, and consequently either can serve as a criterion for dilution. For the solutions used in the heat transfer and drag measurements, the maximum concentration of the polymer approached $c_{c}$ for each molecular weight of PEO. The most dilute solution employed for the experiments was the lowest concentration which would produce deviations from the pure water.

Distilled water was the solvent for all polyethylene oxide solutions in this thesis. McGary (27) has observed that PEO solutions are most stable when the solution is prepared with distilled water; tap water solutions had lower initial viscosities and degraded more quickly. It was also anticipated that distilled water would have a smaller air content than tap water, and thus would be less likely to generate air bubbles on the heated surface of the hot-film sensors. 
This difficulty is explained in more detail in the section on "Air Bubbles".

The series of concentrations for a particular grade of $\mathrm{PEO}$ were designed to be geometrically increasing, viz., each concentration was half the previous value. In practice, the most concentrated solution was made first and the less concentrated solutions were derived from it by continual dilution. The preparation of the most concentrated solution for the 25 gallon tow tank required the use of a master polymer solution. A solution of several gallons was prepared whose concentration was 5 to 10 times that of the maximum desired in the tow tank. This concentrated solution was thoroughly mixed with the water in the tow tank, and the resulting solution was allowed to sit overnight. The heat transfer measurements were taken the next day, during which a sample was removed for viscosity analysis. The next lower concentration was prepared by emptying half of the prevailing liquid from the tank, and adding distilled water to the original level. The solution was again completely mixed and the measurements with the hot-film sensor were taken the following day. The viscosity, as well as several dilute solutions derived from it, were measured to find the intrinsic viscosity of the dissolved polymer, and consequently to check on molecular degradation.

To check on the homogeneity of the tow tank solution, samples were withdrawn at various positions and viscometrically tested. The procedure was repeated at several concentrations and the 
rosults indicated uniform polymor donoity.

2. Measurement of Intrinsic Viscosity

The intrinsic viscosity of each $\mathrm{PEO}$ grade was determined by combining the measured viscosities of all solution concentrations, viz., $\left(\eta-\eta_{s}\right) / \eta_{s} c$ was computed at several concentrations and extrapolated to $c=0$ to yield $[\eta]$. To check on the accuracy of this procedure an additional solution of WSR-301 was prepared and thoroughly tested; the polymer was taken from the same manufacturer's sample which was used in the WSR-301 heat transfer measurements. A 500 wppm solution was prepared, from which three 100 wppm solutions were derived. After determining the viscosity of these liquids, the three solutions were diluted to 75 wppm and the viscosities remeasured. This dilution process was repeated ecveral times to provide the data for Figurc 7. The figure indicates $[\eta]=9.9$, which corresponds closely to the value of 9.6 which was measured from the solutions used in the heat transfer results. Of more significance is the data scatter; $[\eta]$ cannot be determined more closely than \pm 0.6 (or \pm 6 percent), even though the solutions were carefully prepared and handled. Similar scatter of $\left(\eta-\eta_{s}\right) / \eta_{s} c$ at the lower concentrations was observed with the three grades of PEO used in the experiments. Consequently the accuracy of \pm 6 percent has been assigned to all intrinsic viscosity values.

3. Polymer Degradation

The question of polymer degradation naturally arises in the heat transfer investigations since the polymer solutions were 
contained in an open tank. Usually seven days were required to complete the heat transfer measurements for all concentrations and cylinder sizes. To ascertain whether the character of the polymer remained constant for this period, the intrinsic viscosity was checked frequently during the WSR-301 data runs, the results of which are presented in Table 2 .

TABLE 2

Polymer Degradation

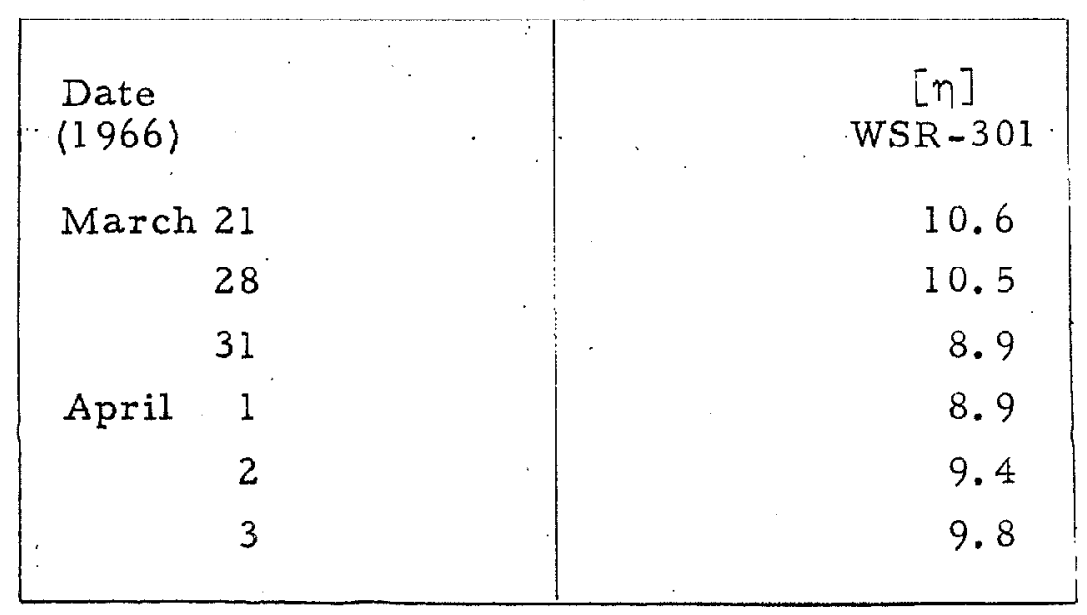

The time variation of $[\eta]$, is probably due to a slight polymer degradation and to considerable data scatter. The heat transfer measurements with WSR-301 solutions were taken during the period

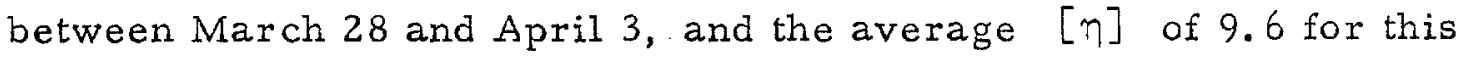
period has been assigned to all WSR-301 runs. Polyox WSR-2Ob and Coagulant solutions were exposed to the atmosphere for only half the above duration, and thus degradation was not considered a problem for the present work. 
C. Heat Transfer Measurements

1. Preliminary Measurements

The temperature coefficient of resistivity for each platinum sensor was determined prior to its use in the heat transfer exper. iments. This coefficient was found by immersing the sensor in water at various temperatures and using the anemometer as a potentiometer to measure the corresponding resistance. (As explained in Chapter II, the resistance dial of the anemometer functions as a potentiometer.) Typical data from such a measurement are presented in Figure 8, which shows the expected linear relationship between resistance and temperature. The temperature coefficient of resistivity for all platinum sensors averaged $0.0026^{\circ} \mathrm{C}^{-1}$, which closely corresponds to the value of $0.003{ }^{\circ} \mathrm{C}^{-1}$ for platinum given in the Handbook of Chemistry and Physics.

An optical comparator was employed to measure the diameter of all sensors to within. 0001 inch; the length of the heated portion, viz., the distance between the gold-platinum interface at either end (Fig. 5), was measured to within $0.03 \mathrm{~mm}$ with a travelling stage micros cope.

The resistance, $R$, for the heated portion of each hot-film sensor could not be precisely determined. The resistance measured by the anemometer includes the resistance of the wire cable, probe, sensor holder, gold connections and the sensor itself. Shorting the probe indicated the resistance of the first two items was $0.75 \mathrm{ohm}$ and the resistance of the steel legs of the sensor holder was 
calculated to be $0.25 \mathrm{ohm}$. The resistance of the gold bonding, which varies with each sensor, cannot be determined since the commerciallymade sensors are coated with insulating materials, epoxy and quartz, that prohibit measurement of the metal resistance underneath (Fig. 5). Since the gold thickness, 0.0002 inch, is much greater than that for the platinum, $2000 \AA$, and since gold has a high conductivity, the resistance of the sensors' gold bonding was assumed to be negligible. Thus the sensor resistance, $R$, was estimated to be the measured resistance minus $1.00 \mathrm{ohm}$.

2. Procedure for a Heat Transfer Run

The torm "run" will be used in this thesis to designate the set of measurements recorded for a series of towing velocities with a given sensor in a particular fluid. Usually three runs were made with a given fluid, each with a different size of sensor. The preceding section on polymer solutions explained the criteria for the range of polymer concentrations, and the geometric progression of the continued dilution; these guidelines allowed about six different concentrations for each grade of PEO. Since three molecular weights of PEO were tested, there were approximately 60 heat transfer runs in all.

Prior to the measurements in the PEO solutions, runs were made in distilled water with the three sensor sizes. The data from these measurements will be compared to previous investigations for Newtonian liguids, and thus will serve as a check on the present experimental technique. The distilled water data will also serve as 
the frame of reference for the heat transfer measurements in polymer solutions.

Each run was preceded by the preparation of the desired polymer solution in the tow tank, as explained in Section B of this chapter. The probe assembly was mounted vertically on the carriage so that the sensor was at least two inches under the surface of the liquid, and equidistant from the tank walls. The sensor was horizontal and visually aligned to be normal to the approaching flow. Figure 6 shows a mounted probe assembly, and the cable connection to the anemometer.

The temperature of the tow tank liquid was recorded, and the resistance of the sensor assembly for this temperature was measured by the anemometer. For this procedure, the anemometer ammeter functions as a null motor; tho resiotanco dial (potentiomoter) of the anemometer was adjusted so that the null meter did not deflect when the appropriate circuit switch was momentarily closed. The reading of the resistance dial corresponding to this mull condition is known as the cold resistance, $R_{c}$. The dial setting was then increased to the operating resistance, $R_{o p}$, the desired sensor resistance for the heat transfer run. The value of $R_{o p}$ is determined by the selected temperature difference between the sensor and the ambient fluid; since the sensor resistance is linearly related to the temperature, the temperature difference is proportional to the resistance difference, $R_{\text {op }}-R_{c}$. In hot-wire terminology, the difference $R_{o p}-R_{c}$ is incorporated in a term known as the overheat ratio, O.R., which is 
defined as

$$
\text { O.R. }=100 \frac{R_{o p}-R_{c}}{R_{c}}
$$

The value of the overheat ratio for each run depended upon several criteria. In general, the lowest possible overhcat was used to avoid the associated difficulty with air bubbles; more details of this particular problem will be presented in a later section of this chapter. At the same time, a high overheat ratio was necessary to provide reasonable sensitivity from the anemometer.

Sensitivity, in this case, refers to the difference, $I_{m}-I_{0}$, between the maximum and minimum current through the sensor. The larger this difference, the more easily changes in current can be detected and recorded. Since a squaring circuit was part of the recording system in the present work, sensitivity in practice referred to the difference $I_{m}^{2}-I_{0}^{2}$, rather than to $I_{m}-I_{0}$. It will be helpful to examine how $I_{m}^{2}-I_{0}^{2}$ depends on the cylinder diameter, $D$, and the temperature difference, $\Delta T$; King's Law will be used for this purpose:

$$
N u=N u_{0}+B R e^{\frac{1}{2}}
$$

For an electrically heated cylinder, this equation is

$$
\frac{I_{m}^{2} R}{\pi L k \Delta T}=\frac{I_{0}^{2} R}{\pi L k \Delta T}+B\left(\frac{V_{m}^{D}}{v}\right)^{\frac{1}{2}}
$$

where $k=$ thermal conductivity

L $\quad=$ length of cylinder 


$$
I_{m}^{2}-I_{0}^{2}=\text { const } \Delta T D^{\frac{1}{2}}
$$

The equation indicates that the sensitivity increases linearly with $\Delta T$, or equivalently, with the overheat ratio; it also shows that the smaller the cylinder diameter, the larger the temperature difference required to achieve the same sensitivity. Consequontly different overheat ratios were used for the three sizes of sensors in the heat transfer work. The minimum overheat ratio will of course apply to the largest sensor, and the description of the anemometer in Chapter II has indicated that the error in measuring $O . R$. is acceptable if the minimum $O . R$. is 2,0 . The overheat ratio for the .006 inch diameter.sensor in water was 2.0 , and to provide comparable sensitivity with the smaller sensors, overheat ratios of approximately 3.0 and 5.0 were used for the 0.002 and 0.001 inch sensors respectively.

These overheat values had to be increased for the measurements in the dilute polymer solution. A glance at the heat transfer results (Eigs. 16-24) for these fluids indicates that the heat loss appoare to follow King's Law for valuco bclow some critical Reynolds number. To see how this behavior affects the sensitivity, King's Law will again be used; for purposes of discussion, the subscript $k$ refers to the maximum conditions at which King's Law approximates the heat transfer results in polymer solutions: 


$$
\begin{gathered}
\mathrm{Re}<\mathrm{Re}_{k} \quad \mathrm{Nu}=\mathrm{Nu} u_{0}+\mathrm{BRe^{ \frac {1 } { 2 } }} \\
\frac{\mathrm{I}_{\mathrm{k}}^{2} \mathrm{R}}{\pi \mathrm{L} \Delta \mathrm{T}}=\frac{\mathrm{I}_{0}^{2} \mathrm{R}}{\pi \mathrm{Lk} \Delta \mathrm{T}}+\mathrm{B}\left(\frac{\mathrm{V}_{k} \mathrm{D}}{\nu}\right)^{\frac{1}{2}}
\end{gathered}
$$

or

$$
I_{k}^{2}-I_{o}^{2}=\text { const } \Delta T V_{k}^{\frac{1}{2}} D^{\frac{1}{2}}
$$

The heat transfer results indicate that $\mathrm{V}_{\mathrm{k}}$ is typically $1 / 10 \mathrm{~V}$, where $V_{m}$ is the maximum possible velocity; thus the sensitivity in dilute polymer solutions, $I_{k}^{2}-I_{0}^{2}$, will equal that in water, $I_{m}^{2}-I_{0}^{2}$, only if $\Delta T$ is increased by $10^{\frac{1}{2}}(=3.2)$. Increases in the overheat ratio by this amount were unacceptable because of the allied problem with air bubbles. Consequently, sensitivity was sacrificed, and for the work in the more concentrated polymer solutions, the overheat ratio was roughly twice the value used in water.

Once the overheat ratio for a particular run had been determined, the anemometer was balanced. This procedure basically balanced the set's Wheatstone bridge by passing enough current through the sensor so that the sensor temperature became the desired value (i.e., its resistance increased to $R_{o p}$, the operating resistance). If the sensor resistance tended to deviate from its value, due to a change in sensor heat loss, a feedback system in the anemometer supplied more or less current, as the case may be, 
to maintain the sensor at a resistance of $R_{o p}$. This, in theory at least, is the design of the anemometer operation; in practice, it did not hold true. The anemometer did not maintain the sensor resistance at $R_{o p}$ for all heat losses, but rather allowed it to deviate in a systematic way. The anemometer was calibrated to avoid this exror, and the details of the method and results of the calibration are presented in Appendix I.

The conditions under which the anemometer was balanced were dictated by the results of the anemometer calibration. The current through the sensor when the anemometer is balanced is Lermed $I_{b}$ and ils value dependis on llie sensor lieal luss, i.e., un the corresponding sensor towing velocity, $V_{b}$. In general, the higher the sensor velocity, $V_{b}$, during the balancing, the larger the heat loss and the greater the required balance current $I_{b}$. If the anemometer were capable of maintaining the sensor resistance at a prescribed value for all heat losses, then the balance conditions, $I_{b}$ and $V_{b}$, would have no effect on the current, $I$, at velocities different from $V_{b}$. But the anemometer was not capable of this performance and Appendix I notes that the current deviation from the correct values decreased as the balance current, $I_{b}$, increased. Thus the anemometer was balanced while the sensor was towed at the velocity which was expected to provide the highest current through the sensor. In plain water, this velocity corresponded to the highest available velocity; in dilute polymer solutions, the heat transfer results to be presented show that the maximum sensor 
current occurred at intermediate velocities, and consequently the anemometer was balanced at these velocities. In each case, the balance current, $I_{b}$, and the corresponding value at zero velocity, $I_{0}$ were recorded for the run.

After the balancing procedure, the anemometer output was connected to the electronic squaring circuit which was adjusted to give a zero voltage output when the sensor was idle. The sensor was towed through the tank liquid over a range of velocities, and for each speed the voltage output of the squaring circuit, e, was recorded. The reading exror for this voltage was estimated to be \pm 0.5 percent. Halfway through each run, the pulley system at the motor was changed to permit an additional series of velocities. Each sensor velocity was measured by timing the carriage over a given distance with a stopwatch, a procedure that provided an accuracy of \pm 0.5 percent. For each speed, the voltage reading, e, was recorded during the carriage traverse over the given distance.

After the heat transfer data were completed with a given fluid, samples of the liquid were removed for viscometric measurements. Measurements of the liquid temperature at various positions in the tow tank indicated that the temperature was uniform throughout. In order to check that the anemometer ammeter accurately monitored the current through the heated cylinder, a second ammeter, a Hewlett Packard Model 425A DC Micro Volt-Ammeter with a 1000:1 reducer probe, was placed in series with the cylinder. The readings of both ammeters were compared at severai currents and 
found to be identical.

\section{Air Bubbles}

Even at the lowest overheat ratios, air bubiles formed on the surface of the heated cylinder. Distilled water was used for the tow tank solutions, but nevertheless, the water was saturated with air. When heated, the air comes out of solution and forms bubbles on the cylinder surface, causing a reduction in heat transfer. These bubbles were removed by carefully brushing the sensor with a camel-hair brush. The frequency of this cleaning depended on the overheat ratio and on the tomporaturo of the liquid, but in gencral, the sensor was brushed often enough to reproduce the voltage reading at a given velocity. In some instances it was possible to cover the entire range of carriage velocities without brushing more than twice; in others it was necessary to brush just before the start of the carriage travel, so that the heat transfer measurements were recorded bofore bubbles wero generated.

\section{Sensor Stability}

Each platinum hot-film sensor was. used as long as its resistance reinained constant. The operating life of a sensur varied between one and fifty hours, and the end of its us eiulness was signaled by a slight increase in cold resistance. After this change was first detected, the resistance appeared to increase monotonically - even exponentially - with usage. A small change in the cold resistance appeared as a relatively large change in Lle vollage readoul from lhe squaring circuil. This relationship can be readily seen as follows: 
The overheat ratio

$$
O \cdot R \cdot=100 \frac{R_{o p}-R_{c}}{R_{c}}
$$

where

$$
\begin{aligned}
R_{c}= & \text { sensor resistance at the temperature of the } \\
& \text { ambient fluid } \\
R_{o p}= & \text { operating resistance of the sensor }
\end{aligned}
$$

from which

$$
\frac{d\left(O . R_{.}\right)}{O \cdot R_{.}}=-\left(\frac{K_{o p}}{R_{o p}-R_{c}}\right) \frac{d R_{c}}{R_{c}}
$$

Since the sensor resistance is linearly related to its temperature, i.e., since

$$
R_{c}=a T+b
$$

therefore

$$
R_{o p}-R_{c}=a \Delta T
$$

where

$$
\begin{aligned}
\Delta \mathrm{T}= & \text { temperature difference between the sensor } \\
& \text { and the surrounding fluid. }
\end{aligned}
$$

Cons equently

$$
\frac{d_{c}}{R_{c}}=\frac{d(\Delta T)}{\Delta T}
$$

Using King's Law as an approximation for heat loss from a circular cylinder 


$$
\mathrm{Nu}=\mathrm{Nu} u_{0}+B R e^{1 / 2}
$$

or

$$
\frac{I^{2} R}{\pi L k \Delta T}=\frac{I_{0}^{2} R}{\pi L k \Delta T}+B\left(\frac{V D}{V}\right)^{1 / 2}
$$

For a given sensor operating at a fixed velocity

$$
I^{2}-I_{0}^{2}=b \Delta T
$$

and

$$
\frac{d\left(I^{2}-I_{0}^{2}\right)}{I^{2}-I_{0}^{2}}=\frac{d(\Delta T)}{\Delta T}
$$

Since the voltage readout, e, from the squaring circuit was always adjusted to be proportional to $I^{2}-I_{0}^{2}$, then

$$
\frac{d(e)}{e}=\frac{d\left(I^{2}-I_{0}^{2}\right)}{I^{2}-I_{0}^{2}}
$$

Combining Equations (2), (3), (4) and (5) yields

$$
\frac{d(e)}{e}=-\left(\frac{R_{o p}}{R_{o p}-R_{c}}\right) \frac{d R_{c}}{R_{c}}
$$

Typical values for $R_{c}$ and $R_{\text {op }}-R_{c}$ are 6.00 and 0.18 ohrzz, respectively. Thus if $R_{c}$ increases by only $0.01 \mathrm{ohm}$, a change of 0.16 percent, the voltage readout is reduced by 5.7 percent, a change that can be more readily detected. 
During the recording of the heat transfer data, the voltage readout at a reference velocity (usually the balanco volocity) was periodically checked. The deterioration of a sensor was always signaled by a steady but slight decrease in this reference voltage; thus tine reasom for the term "drift". If the observed drifl remained small compared to the maximum voltage, the recording of the heat transfer data was continued until the completion of the run.

In order to utilize the information which was recorded while the sensor resistance was changing, drift corrections were applied to the measured voltages. 'L'he method and results of the procedure for finding the drift correction are presented in Appendix II. The data in this Appendix indicate that the general correction curve was determined using corrections as high as 60 percent of the reference (or maximum) voltage. Voltage drifts of this magnitude were not tolerated for the heat transfer runs. In general, the data were not retained unless the maximum voltage drift was no greater than 30 percent of the highest voltage reading. Of the 59 runs in the heat transfer results, two required 30 percent drift corrections, three required 10 percent corrections, and seven had corrections of less than 5 percent.

\section{Free Convection Studies}

Up to now, this chapter has been concerned with the heat transfer from circular cylinders by forced convection. Since the data from these measurements indicated that the heat transfer at 
high velocities is significantly altered by the presence of the macro. molecules, a separate investigation was undertaken to determine the polymer effect on heat transfer at zero velocity. This information could be obtained from the zero velocity Nusselt number, Nu。, which is contained in the forced convection data. However, the $\mathrm{Nu}_{0}$ 's from this data rely on the anemometer calibration of Appendix I, viz., the value of $I_{0}$ must be corrected in order to be used in computing $N u_{0}=\frac{I_{0}^{2} R}{\pi L k \Delta T} \cdot$ The appendix indicates that the accuracy of $\mathrm{Nu}_{0}$, after the necessary corrections, is \pm 4 percen More precise results can be obtained by balancing the anemometer at zero velocity, since this procedure eliminates the need for the correction curve. This balancing at zero velocity was one of the two differences in procedure from that used in the forced convection measurements. The other difference was that the overheat ratio, for each of the three sensor sizes, was varied from 1.0 to 10.0 . In order to check on end effects, i.e., to estimate the heat loss by conduction through the sensor ends, the extra-long ( $L / D=96)$ sensor was also employed for the free convection investigation. The heat transfer measurements were made while the four sensors were immersed in fresh distilled water and in polymer solutions contained in a four-litre beaker. Six concentrations of WSR -301 , ranging from 10 to 304 wppm, were prepared. Tine results in the next chapter indicate that the polymer did not affect the free convection heat transfer, and consequently only one grade 
$-42-$

of PEO was used. The WSR-301 used for this study was drawn from the sample used in the furced cunvecliun hed lidisfer measufentents. 


\section{CHAPTER IV}

\section{HEAT TRANSFER RESULTS}

\section{A. Computation of Dimcnsionlcss Paramctcrs}

The parameters used to correlate the heat transfer data are the Reynolds number Re, Nusselt number Nu, Grashof number Gr, and Prandtl number Pr. The calculation of these dimensionless parameters is not straightforward in some instances, and consequently this section will be concerned with the computational details.

All forced convection data have been correlated by the Reynolds number, $R e=\frac{V D \rho}{\mu}$. The procedure of Chapter III has described the straightforward measurement of the velocity $V$ and the cylinder diameter D. The absolute viscosity, $\mu$, is the product of the measured kinematic viscosity and the solution density, $\rho$. Since the maximum polymer concentration in this work is 0.3 percent, the solution density $\rho$ has been set equal to that for water in all cases. Each viscosity measurement has been corrected to the ambient tow tank temperature by means of the method in Chapter III, Section A-3.

The Nusselt number, Nu, for an electrically heated circular cylinder is $\frac{I^{2} R}{\pi L k \Delta^{T}}$. The section on Preliminary Measurements in

${ }^{1}$ The symbol for viscosity in the fluid flow is $\mu$, while $\eta$ has been previously introduced as viscosity in the section on polymer solutions. Both are standard notation in their respective fields of fluid mechanics and polymer chemistry. Since this thesis overlaps in the two disciplines, it is not surprising to find an overlapping in notation. 
Chapter III has described the estimation of the sensor resistance, $R$, and the measurement of the cylinder heated length, I. Knowing the operating overheat ratio, the temperature difference, $\Delta T$, for a particular sensor can be found from the measured coefficient of resistivity for that scnsor (e.g., Figurc 8). The pure water value for the thermal conductivity, $k$, has been used in all cases. No information apparently exists relating $k$ to the concentration of PEO in water. It 15 reasonable to assume that the relative change in $k$ is equal to the ratio of solute to solvent; the solution viscosity, $\mu$, changes by a far greater amount, but $\mu$ is associated with flow and deformation, while the thermal conductivity has no dependence on the motion of the fluid. Thus for dilute solutions, $k$ is altered to the same extent as the density, $\rho$, and since the magnitude is negligible, the solvent value for $k$ has been substituted.

The value of I for the Nusselt number calculations was determined from the equation

$$
\frac{I^{2}-I_{0}^{2}}{I_{b}{ }^{2}-I_{0}}=\frac{\dot{e}}{e_{b}}
$$

where

$$
\begin{aligned}
I_{0} \quad- & \text { anemometer current at zero volocity } \\
I_{b}= & \text { anemometer current at the balance condition } \\
\mathrm{e} \quad= & \text { voltage readout from the squaring circuit } \\
e_{b}= & \text { voltage readout from the squaring circuit at } \\
& \text { balance conditions }
\end{aligned}
$$


This equation was used after any necessary drift corrections (Appendix II) had been applied to e. After computing I from the preceding equation, the result was adjusted to take the anemometer calibration into account. The appropriate adjustment can be found from the correction equation in Appendix I.

The Prandtl number, $\operatorname{Pr}=\frac{\mathrm{C}_{\mathrm{p}} \mu}{\mathrm{k}}$, has been used. in both the free and forced convection data. The method of computation for $\mu$ and $k$ has been mentioned in the preceding paragraphs. Since the specific heat. $\mathrm{C}_{\mathrm{P}}$ is a solution property not dependent on the flow of the liquid, the same assumption will apply here as was applied earlier for $k$, viz., the change in $C_{p}$ will approximate the corresponding minute change in $\rho$ and conservently the pure water value will be used.

The computation of the Grashof number, $\operatorname{Gr}=\frac{\rho^{2} \beta \Delta^{\prime} l^{3} D^{3}}{\mu^{2}}$, is necessary for the presentation of the free convection data. The values for $\rho, \Delta T, D$ and $\mu$ have been discussed in the preceding paragraphs. The pure water value for the coefficient of thermal expansion, $\beta$, will apply to all liquids for tho eamo roaoon that pure water values were assigned to $C_{p^{\prime}} \cdot k$, and $\rho$ in the preceding paragraphs.

Unlcss spccificd othcrwisc, the computation of fluid properties is taken at the tow tank temperature. In order to compare the present data of distilled water with previous investigations of Newtonian liquids, the liquid properties will sometimes be taken at the mean temperature, i.e., the temperature which is the arithmetic 
average of the sensor and tow tank temperatures; in these cases, the subscript $f$ will be added to the symbols.

\section{B. Free Convection}

The measurements of free convection heat transfer in WSR -301 solutions showed no change from the clear water data for concentrations ranging from 10 to $304 \mathrm{wppm}$. This result can be summarized by presenting the data for the most concentrated solution only. Figures 9, 10 and 11 show the froo convection data for throo sensor sizos at various temperature differences in pure water and in $304 \mathrm{wppm}$ of WSR-301; the data are plotted in the standard form of Nusselt number, $\mathrm{Nu}_{f}$, versus lie producl of lie Grasliof sumber, $\mathrm{Gr}_{f}$, and Prandti number, $\operatorname{Pr}_{\mathrm{f}}$. The free convection results with the extra-long $(L / D=96) 0.006$ inch sensor have been plotted in Figure 12. For purposes of comparison, the measurements of previous investigators have been included in the four graphs.

It must be noted that the computation of the Grashof number and the Prandtl number for Figures 9 to 12 requires an estimation of the solution viscosity at the mean film temperature, $T_{\hat{I}^{*}}$ None of the polymer solution viscosities were measured at temperatures higher than room temperature. Thus the high-temperature viscosities were estimated by use of the equation

$$
\frac{\mu\left(T_{f}\right)}{\mu_{s}\left(T_{f}\right)}=\frac{\mu\left(T_{I}\right)}{\mu_{s}\left(T_{I}\right)}
$$


where

$$
\begin{aligned}
\mu & =\text { solution viscosity } \\
\mu_{s}= & \text { solvent (water) viscosity } \\
T_{f}= & \text { mean film temperature } \\
T_{1}= & \text { temperature at which solution viscosity was } \\
& \text { measured }
\end{aligned}
$$

The acceptability of this approximation has been discussed in Chapter III, Section A3, which notes that the error in the approximation increases as the temperature difference increases. Thus the 304 wppm data at the lower temperature differences, i. e., at the lower values of the abscissa, GrPr, are correct to within several percent, and the data at the highest temperature differences may be questioned. The measured viscosity of the $304 \mathrm{wppm}$ solution was 1.82 times that of water at room temperature. If this ratio were incorrect at the mean temperature by an unrealistic 50 percent, the horizontal shift of the affected 304 wppm data would be very slight; viz., GrPr varies as $\mu^{-1}$ and a 50 percent error in GrPr results in a relatively small displacement on the 4-rycle log paper. Consequently, even if some of the data points were incorrect, the error in no way affects the basic finding that the dissolved polymer does not altcr frco convoction hoat transfor.

\section{Combined Free and Forced Convection}

1. Distilled Water

In order to check on the accuracy of the present experimental 
results the data with fresh distilled water were compared to the previous work of Davis (8) and Piret (30). Davis examined the heat loss from vertical wires in water and oils, and correlated his data by $\mathrm{Nu}_{f} /\left(\operatorname{Pr}_{f}\right)^{0.31}=.91 \mathrm{Re}_{\mathrm{f}}^{.385}$, for $0.1<\operatorname{Re}_{f}<50$. Piret measured the heat transfer from fine horizontal wires in water, and found the correlation for his results to be $\mathrm{Nu}_{f} /\left(\mathrm{Pr}_{f}\right)^{0.30}=$ $.965 \mathrm{Re}_{\mathrm{f}} \cdot 28$, for $.08<\mathrm{Re}_{\mathrm{f}}<8$. The present data for three sensor sizes have been plotted in Figures 13,14 and 15 with $\mathrm{Nu}_{f} / \mathrm{Pr}_{\mathrm{f}}{ }^{0.3}$ and $\mathrm{Re}_{\mathrm{f}}$ as co-ordinates; the correlations of Piret and Davis have been drawn on these graphs, as well as McAdams' (26) recommended relation, $N u_{f}=\left(0.35+.65 \operatorname{Re}_{f}{ }^{.52}\right) \operatorname{Pr}_{f} .30$, for this Reynolds number range.

The present data for water can be correlated by the single equation $N u_{f} / \operatorname{Pr}_{f}{ }^{30}=1.02 \mathrm{Ke}_{f}^{.35}$, for $.02<\mathrm{Re}_{f}<50$.

\section{Polymer Solutions}

The principal heat transfer results of this thesis are presented in Figures 16 to 24. Each graph shows the combined forced and free convection heat transfer for one cyclinder diameter over a range of concentrations of one PEO grade; three cylinder sizes and three grades of PEO were used for the nine graphs. The pure water results have been included in each graph in order to complete the family of polymer concentrations.

It will be noted that these nine graphs are presented in a different form than those for the distilled water, i.e., the coordinates are Nusselt number, Nu, versus Reynolds number, Re, instead of 
$\mathrm{Nu}_{\mathrm{f}} / \operatorname{Pr}_{\mathrm{f}}{ }^{0.3}$ versus $\mathrm{Re}_{\mathrm{f}}$. The plotting of the data in the latter form requires the measurement of the polymer solution viscosities at temperatures higher than room temperature. As noted in Section B of this chapter, these viscosity measurements were not taken for any solutions, and consequently the value of $\mu$, used in the calculation of $R e$, has been the solution viscosity at the tow tank temperature.

It can be shown that the plotting of the data in the form $\mathrm{Nu}$ versus $R e$, instead of the more standard $\mathrm{Nu}_{f} / \mathrm{Pr}_{f} \cdot 3$ versus $\mathrm{Re}_{\mathrm{f}}$. has very little effect on the relationship of the family of concentrations. Figures 16 to 24 indicate in general that the heat transfer data with polymer solutions merge with the pure water data at the lowest velocities. The pure water results of the present work have been correlated by

$$
\begin{aligned}
N u_{f} & =1.02 \operatorname{Pr}_{f} \cdot 30 \operatorname{Re}_{f} \cdot 35 \\
& =1.02\left(\frac{C_{p f_{f}^{\mu}}}{k_{f}}\right)^{.30}\left(\frac{\rho_{f} V D}{\mu_{f}}\right)^{.35}
\end{aligned}
$$

This can be arranged as

$$
N u_{f}=1.02\left(\frac{C_{p f}}{k_{f}}\right)^{.30}\left(\mu_{f} V D\right)^{.35} \frac{1}{\left(\mu_{f}\right)^{.05}}
$$

In this form, the heat transfer results are a very weak function of viscosity, and consequently the relative values for the Nusselt number and Reynolds number would not be greatly shifted if a 
different viscosity value were substituted. The plotting of the present data with $\mathrm{Nu}_{f} / \operatorname{Pr}_{f} \cdot 3$ and $\mathrm{Re}_{f}$ as co-ordinates would merely result in a shift of the axes of the present graphs; the relative values of the data would not be significantly changed. Thus the presentation of the polymer solution data, as Nusselt number versus Reynolds number, does not involve an unmeasured quantity and gives an accurate picture of the effect of polymer concentration on the heat transfer from circular cylinders.

The symbol at the left-hand edge of each graph is the free convection Nusselt number, $\mathrm{Nu}_{0^{*}}$ The results on free convection heat transfer demonstrated that $\mathrm{Nu}_{0}$ is independent of polymer concentration. However, for the series of concentrations which comprise a "family" graph, $\mathrm{Nu}$ o varied from run to run, probably because of errors in the anemometer calibration. These values of Nuo uoually variod $\neq 10$ percont from tho avorago Nu for that oct. Consequently to show heat transfer features of the polymer solutions as distinctly as possible, the heat transfer data for each run were adjusted slightly so that the $\mathrm{Nu}$ o matched the arerage $\mathrm{IJu}$ for the corresponding family. This adjustment invariably permitted a better matching of the dilute polymer solution data along the pure water line at low velocities. Table 4 contains $\mathrm{Nu}_{0}$ for each concentration and the average $\mathrm{Nu}_{\mathrm{o}}$ for each family graph. The table is presented as a supplement to the graphical heat transfer results, and provides, in addition to the $N u_{0}$ values, the cylinder diameter, $D$, cylinder length, $L$, temperature difference, $\Delta T$, solution viscosity, $\mu$, and 
$-51-$

the ambient fluid temperature for each run. Table 4 also includes the measured intrinsic viscosity, $[\eta]$, for each of the three grades of Polyox. and the corresponding molecular weight, $\overline{\mathrm{M}}_{\mathrm{w}}$, calculated from Shin's correlation (41). 
CHAPTER V

\section{DRAG MEASUREMENTS}

\section{A. Preliminary Remarks}

The heat transfer results in the previous section suggest that the dissolved macromolecules significantly alter the velocity field around the circular cylinder. The corollary of this assumption is that the drag on the cylinder should also be changed, and it may be anticipated that drag measurements should provide some insight into the nature of the flow field. Consequently an experimental investigation was undertaken to measure the drag of a very small cylinder at the same Reynolds numbers and polymer concentrations as in the heat transfer studies. The experimental technique was to employ a cantilevered wire whose deflection in a flow field is a measure of the drag.

\section{B. Experimental Apparatus}

1. Arrangement of Equipment

The experimental method consisted of immersing a portion of a wire, fixed at one end only, into a rotating bas in of liquid and measuring the deflection of the frec cnd with a microscope for various speeds and polymer concentrations. The equipment is shown in the drawing 
presented in Figure 25, and a photograph of the final arrangement is shown in Figuro 26.

2. Rotating Tank

The Graham variable speed drive shown in Figure 25 could provide a range of angular speeds between 3 and $600 \mathrm{rpm}$; it was mounted on $1 / 4$ inch rubber washers to dampen the vibrations transmitted to the aluminum channel base. The circular Lucite tank was removable from the turntable, but was securely positioned on it by location blocks welded to the tank bottom. The turntable was carefully levelled by shimming to prevent any surface waves in the tank which would result from a slanted turntable.

3. Travelling Stage Micros cope

The wire deflections were measured to within 0.0001 inch by a travelling stage microscope, a picture of which appears as Figure 27. The counter on the microscope indicated the horizontal displacement of the instrument, relative to its support, to within .0001 inch, thus providing the above mentioned accuracy for the wire deflections. The microscope had a magnification of about 10 , and was mounted on an clevator table; the vertical movement of the table permitted viewing along the entire length of the immersed wire. The amount of immersion was determined by measuring the elevation difference of the support table when the microscope horizontal crusshair was aligned with the wire end and then aligned with the point of immersion. 


\section{Cantilever Wire}

Several types of wires having a diameter of 0.006 inch or less were investigated for use as a cantilever beam, and all but steel music wire permanently yielded when subjected to even a slight loading. Music wire having a diameter of 0.0050 inch was available in coil form only and had to be straightened by hand; slight curves in the wire could be tolerated since these would not affect the beam deflections under loading. Because music wire is susceptible to rust, the straightened wire was dipped in a $50-50$ mixturc of Durachem Clear and its thinner; this coating was then baked, increasing the cylinder diameter by 0.0002 inch. To make sure that the end of the wire was fixed, a portion of the coated wire was frozen in a $1 / 4 \times 1 / 4 \times 5 / 8$ inch block of Cerrolow, a type of Woods metal with

a melting point of $117^{\circ} \mathrm{F}$. A photograph of the cantilever wire and its support mounting is shown in Figure 28.

\section{Experimental Procedure}

\section{Viscometric Measurements}

A complete description of the technique for viscosity measurements has been presented in Chapter III, Section A. Similar to the procedure in the heat transfer runs, the solution viscosity was determined after each set of drag measurements at a particular polymer concentration. The viscosity data for all concentrations were combined to find the intrinsic viscosity of the dissolved polymer. 


\section{Preparation of the Polymer Solution}

The wirc wajo mountcd as ohown in Figurc 25, and cxploratory runs with distilled water indicated that the cylinder drag depended on the freshness of the liquid. The deflection of the wire was measured on three consecutive days for identical flow conditions, i. e., the position of the wire was fixed and the angular speed of the turntable was maintained constant. The deflection was measured on the first day with fresh distilled water. After 24 hours, during which the tank was motionless and covered, the deflection was again measured and found to be 10 percent higher than the original reading. After two days, the deflection was 25 percent greater. Without changing any part of the experimental set-up, the "old" water was drained from the tank and fresh distilled water was added. The deflection was again measured and found to coincide with the original value. It was concluded that algae growth had caused the discrepancy in the readings, and this problem was avoided with dilute polymer solutions by the use of a master solution. A polymer solution was prepared whose concentration was several times that of the highest desired value of the experiments. Just before a data run, a small portion of the master solution was mixed with fresh distilled water to. provide a solution of the desired concentration.

Six solutions of WSR-30I were prepared for the drag measurements. Similar to the heat transfer measurements, the concentrations increased in geometric progression, and the maximum 
concentration roughly corresponded to the critical concentration, ${ }_{c}$, for that polymer.

3. Calibration of the Cantilever Wire

The cantilever wire could not be employed as a drag monitor until its load-deflection relationship had been determined. This calibration consisted of supporting the wire horizontally, placing known weights along its length, and measuring the resulting deflections. Three loading weights were made by bending lengths of fine steel wire into V-shapes; the weight of each was measured to .00005 gram, an accuracy of \pm 1 percent for the lightest weight. With one of three weights positioned on the cantilever wire, the deflection and location of the load were measured to within 0.0001 inch with an optical comparator. The diameter of the cantilever wire was measured by the comparator, and found to be $.0052 \pm .0001$ inch. The uniformity of the wire along its length was also checked, and it was found that the wire did not vary from the above diameter by more than .0001 inch.

The results of this calibration are presented in Table 5; the data indicate that, within the experimental accuracy of \pm 1 percent, the flexural rigidity, EI, of the wire is independent of the loading weight and location for deflections which are less than 6 percent of the beam length. These results indicate that the load-deflection relationship is linear for the present range of deflections. The calibration also serves to verify that the wire may be considered a cantilever beam. 


\section{Design Considerations}

The length of the cantilever wire and its immersion distance were governed by the experimental velocities. It was found that a 2 -inch cantilever wire with $1-1 / 2$ inches penetrating into the liquid permitted the deflection at the lowest steady speed available by the motor to be large enough for accurate measurement. The maximum velocity for the drag measurements was intended to be comparable to the highest speeds in the heat transfer experiments, i. e., about 1. $0 \mathrm{ft} / \mathrm{sec}$. At this maximum velocity, the wire deflection in water was 6 percent of the wire length, and thus within the range of calibration deflections. For other experimental liquids, the maximum speed was that velocity which produced a wire deflection of 6 percent.

The wire was positioned vertically in the tank of water by focussing the microscope on the free end of the wire and on the point of immersion. When the microscope did not have to be refocussed for the two positions, the wire was considered to be vertical. The error in this procedurc is the crror in refocussing the microscope on a given object. This refocussing error was found to be about 0.010 inch, and since the wire was usually located about 3 inches from the tank center, the difference in fluid velocity at the top and the bottom of the wire is about $0.010 / 3.00$ or 0.3 percent.

The preceding paragraph has mentioned that the radial distance of the wire from the center of the tank is about 3.0 inches. Since the radius of the wire is .0026 inch, the ratio of radii is about 
1000:1. Consequently the curvature of the fluid streamlines approaching the wire was considered to be negligible, and the flow was treated as a linear flow.

A simple test with dye streaks was conducted to check that the velocity profile in the tank was uniform when a steady-state condition had been reached. Very small potassium permanganate crystals were dropped into the rotating tank liquid, and the distortion of the vertical dye streaks was noted. Of course there was some distortion of the streaks at the surface due to air drag, but the magnitude was so small that the corresponding error in assuming a uniform velocity profile was negligible.

5. General Procedure for Deflection Measurements

The preceding sections have described the preparation of the liquid and apparatus for the deflection measurements. The immersed length of the wire was measured at the beginning of each run. As in the heat transfer experiments, the term 'run' here will indicate a set of measurements for a series of velocities with a given fluid. The immersed length was determined by measuring the change in elevation (relative to the channel base) of the microscope support table when the horizontal cross-hair of the microscope was aligned with the top and then with the bottom of the immersed portion. A steel scale was used to measure these elevation distances to within \pm .008 inch. Since the wire deflection was relatively insensitive to the loaded length of the wire (see Appendix III), the immersion length was measured only in the 
quiescent liquid before each run.

After the wire was positioned vertically for the run, its distance to the tank wall was measured with a steel scale. Knowing the tank radius, the radial position of the cantilever wire was computed.

The zero deflection reading for the wire was taken by aligning the vertical cross-hair of the microscope with one side of the end of the cantilever wire. Deflection readings were then recorded for a series of velocities, and each measurement was taken when the deflection of the wire was constant, viz., when the fluid velocity in the rotating tank had reached.a steady-state condition. Before and after the deflection reading for each velocity, several revolutions of the rotating tank were timed with a stopwatch. This measurement of the angular speed was determined to an accuracy of \pm 0.2 percent; this error and the previously determined error of \pm 0.3 percent in the vertical alignment result in an error of \pm 0.5 percent for the tank velocity at the radial position of interest:

6. Deflection Measurements

Because the Lucite tank could not be perfectly centered on the turntable, the wire appeared to oscillate while the tank was rotating. The travel of the wire due to this eccentricity was about 0.003 inch. Since this distance was the same order as the smallest measured deflection, it was necessary to measure all the deflections at an extremum of the oscillation. The angular tank position which coincided with the travel extremum was marked so that before each 
run the tank could $\cdots$ positioned correctly for the zero deflection reading. At the end of a set of drag measurements, wher the fluid had come to rest, the zero deflection reading was again noted. 'L'hese procedures provided for an accuracy of 0.0001 inch in measuring wire deflections at the low and moderate velocities. At high velocities the wire vibrated in the flow field, and the error in determining the oscillation extremum was increased to 0.005 inch. This vibration was apparently due to the unsteadiness of the wake behind the cylinder at the higher velocities, an expected behavior when the Reynolds number is greater than 30 (45).

Since the tank was open to the atmosphere, it was impossible to prevent dust and other particles from entering the liquid. A microscopic examination of the submerged length revealed that the wire would "catch" small fibers, especially at the highest velocitics. In fact, by continually watching the end of the wire through the microscope, it was obvious when a small particle attached itself to the wire: the wire would instantly deflect a small amount. Consequently the wire was brushed before each deflection reading; the brushing naturally disturbed the flow field and thus the deflection measurement was taken when the wire became steady in the flow. This procedure of brushing the wire and then measuring the steady deflection was repeated several times for each velocity; consistent readings indicated the absence of fibers on the wire.

7. Calibration of the Microscope Counter The travelling stage microscope was designed so that the 
numbers on the counter recorded the horizontal travel of the instrument (relative to support frame) exactly in inches. However, the circular tank wall magnified the wire and its deflection, and consequently the counter had to be calibrated. Following a data run, the cantilever wire was removed from the support while the focussing of the microscope was not disturbed. A steel scale was inserted in place of the wire and positioned to be in focus. The scale distances were then compared to the counter readings to yield a calibration factor. This factor was then used to correct all deflection readings for that particular run.

D. Results

The drag coefficient $C_{D}$ for the wire was computed assuming the cantilever wire was uniformly loaded along a portion of its length. Since the calculation of the beam deflection for this situation is not presented in standard texts on bending beams, the problem is worked in Appendix III. The solution of the problem provides the uniform load, $q$, for a measured deflection, $y$. Knowing $q$, in lbf/ft, $C_{D}$ is calculated by

$$
C_{D}=\frac{q^{\prime}}{D \rho \frac{V^{2}}{2}}
$$

where

$$
\begin{aligned}
D= & \text { wire diameter } \\
\rho= & \text { density of liquid } \\
V= & \text { velocity of liquid computed from angular } \\
& \text { speed and radius }
\end{aligned}
$$


The Reynolds number, $R e=\frac{V D}{\mu}$, was computed using the measured solution viscosity for $\mu$, and the clear water value for $\rho$. Since the maximum concentration of polymer for the present experiments is $226 \mathrm{wppm}$, or 0.02 percent by weight, the pure water value has been used for all liquids.

The results of the drag measurements for water and for six polymer solutions are presented in Figures 29, 30, and 31. Figure 29 compares the present data for fresh distilled water with Wieselberger's classic data for a Newtonian liquid (48). The solid line on the three graphs is the "best-fit" line through Wieselberger's data. Figure 30 presents the drag results for the three least concentrated (dilute) polymer. solutions, and the data for the more concentrated solutions are shown in Figure 31.

\section{E. Flow Visualization}

The heat transfer and drag measurements suggest that the flow field around a circular cylinder is considerably different in polymer solutions than in water. In an effort to visualize the flow field, a simple dye injection study was undertaken. The essential arrangement of the equipment for this investigation was identical to that for the drag measurements, with additions and modifications noted below.

The 0.005 inch cantilever wire was bent $1 / 2$ inch from the free end to form a $90^{\circ}$ angle. The wire was mounted as in the drag experiments, and the $1 / 2$ inch portion was arranged to be horizontal 
and parallel to the line of sight of the travelling stage microscope. A dye injection tube was made by drawing out one end of a standard $3 / 8$ inch glass tube, so that the tube end had an inside diameter of 0.005 inch and an outside diameter of 0.008 inch. This injection tube was mounted on a vertical rack with a fine adjustment. and the small end of the tube was positioned about 0.10 inch upstream of the now horizontal wire. The arrangement of the injection tube and wire is shown in Figure 32. $\Lambda$ blue aniline dyc solution in wator wac prepared and inserted in the injection tube. No attempt was made to match the velocity of the issuing dye streak with the speed of the external fluid flow. Since this visualization study was concerned with gross effects, the matching of velocities was not considered essential. The dye exit velocity was always lower than the fluid velocity, and thus the issuing dye streak was somewhat reduced in diameter when it reached the flow field around the wire.

Dye patterns in water and in a 50 wppm solution of WSR-301 were observed through the microscope for several velocities between 0.1 and $0.6 \mathrm{ft} / \mathrm{sec}$.

The dye streaks indicated that the streamlines in the polymer solution are considerably displaced from the pure water streamlines. Drawings of the observed dye patterns in water and in the polymer solution at $0.5 \mathrm{ft} / \mathrm{sec}$ are shown in Figure 33. It was very hard to detect the wake region in water at this velocity (Reynolds number = 20). However, ds Figure 33 indicates, there was no doubt about the wake behind the cylinder in the polymer solution; the point of 
separation appeared to be at the topmost part of the cylinder. As the fluid speed decreased, the displacement of the streamlines around the cylinder decreased in the polymer solution. At $0.1 \mathrm{ft} / \mathrm{sec}$ the maximum width of the dyed region around the cylinder was approximately twice the wire diameter. 


\section{CHAPTER VI}

\section{JET EXPERIMENTS}

\section{A. Preliminary Remarks}

The large differences in the heat transfer and drag results between water and dilute polymer solutions suggested that perhaps normal stress effects are important in these flow regimes. The measurement of these stresses is a subject of continual research for polymer rheologists $(6,24)$, and the literature on polymer solutions provides the normal stress measurements for a considerable number of fluids. These liquids are invariably concentrated polymer solutions, however, and no measurements have apparently been reported to indicate the magnitude of the stresses for dilute solutions。

There are numerous ways of demonstrating normal stresses, but the most straightforward, from our point of view, is the "die swell" of a liquid jet is suing from a smooth tube. The books by Lodge (24) and Coleman et al (6) include photographs which demonstrate this swelling for concentrated solutions. Consequently an experimental program was conducted to examine jet swelling with dilute solutions; it was hoped that the results would provide an estimate of the magnitude of the normal stress effects in these liquids. The jets were designed to produce the same flow Reynolds 
number and fluid acceleration as in the flows around the circular cylinders. These conditions necossitated a small jet diameter, and to avoid associated surface tension problems, the jet issued into a similar liquid. These minute laminar jets were examined with the did of a micruscupe fur'waler and dilule solutions of polyethylene oxide.

B. Experimental Equipment

The general arrangement of the apparatus is shown in Figure 34. The microscope was an American Optical Microstar Series 10 and the lens were arranged to provide a magnification of 35. A Polaroid film holder, mounted above the microscope, recorded the image on $4 \times 5$ inch prints. The flow nozzle was prepared by drilling a 0.004 inch hole in a 0.005 inch plate, which was cemented to a Polyflo nut. The hole was later broached and checked for concentricity and size with an optical comparator; the hole diameter was measured as .0064 inch. A $3 \times 3 \times 1-1 / 2$ inch tank constructed of $1 / 8$ inch Lucite sheets contained the stagnant liquid. One side of the tank was $1 / 4$ inch Lucite, the extra thickness being necessary to accommodate the pipe end of a $1 / 8$ inch pipe-to1/4 inch Polyflo fitting. The Polyflo end of the fitting took the nut on which the flow nozzle was cemented. The tap hole for this pipe fitting was drilled at a slight upward angle to ensure a direct view of the jet nozzle from overhead, i.e., through the microscope. One-eighth inch copper tubing was used between the wail fitting and 
valve, and between the valve and the vertical glass tube (see Figure 34). A paper scale was posted to the tube for measuring the elevation of the liquid inside the tube. Testing with drill sizes indicated that the inside diameter of the glass tube was 0.105 inch.

The jet outline was made visible by dissolving black aniline dye in the is suing liquid. A viscosity measurement indicated that the dissolved dye increased the fluid viscosity by approximately 5 percent. Several dyes were investigated and all degraded the polymer when added to a PEO solution. It was found that the black aniline dye had the slowest rate of chemical reaction and that its solution could be employed for gross effects if utilized immediately after mixing with a PEO solution.

\section{Procedure}

The liquid to be studied was injected into the vertical glass tube. To check for trapped air in the fluid lines, the tank and plumbing were removed from the microscope; the tank was tilted to $45^{\circ}$ and the valve was kept open until the black liquid continually flowed out the hole. The support table of the microscope was equipped with a clamping arrangement which firmly pasitioned the Lucite tank. Water was poured into the tank to just cover the Polyflo cap. An overhead high-intensity light, as well as the base light and condensor system of the microscope, provided the illumination of the jet. 
Before taking each photograph, and while the valve was closed, the microscope was focused on the nozzle opening. The valve was then opened, and the liquid in the tube was allowed to fall to the level which would provide the desired jet velocity. The time for the meniscus to descend a prescribed distance was measured with a stopwatch. The corresponding photograph of the jet was snapped at the mid-point of the length. The jet velocity for this photograph was computed knowing the liquid descent velocity in the glass tube, and the diameters of the glass tube and flow nozzle. The average jet velocity for the photographs varied between 0.20 and $2.5 \mathrm{ft} / \mathrm{sec}$. The liquids used in the jet experiment were water and a solution of WSR-301. The polymer solution was prepared by mixing a 120 wppm solution with a concentrated dye solution to produce an 87 wppm solution. The two solutions were combined just before insertion in the vertical glass tube.

D. Results

Polaroid prints of the jets appear as Figures $35-40$, all photographed at the same magnification. Figures 35,36 , and 37 with the water indicate the dependence of the jet shape on the fluid velocity, i. e., the divergence angle increases as the velocity decreases. The jet outline in Figure 35 appears irregular because of the undulatory nature of the jet at low velocities. Figures 38, 39, and 40 were consecutive plotographs of the 87 wppm FEO solution. Figure 38 demonstrates the immediate enlargement of the jet upon exiting, the diameter 
increasing by a factor of four. Figure 39 indicates that at low velocities the fluid flow is essentially the same as with clear water, the undulations again being present. The velocity for Figure 40 was increased to $2.6 \mathrm{ft} / \mathrm{sec}$ and the diameter effect is noticeably less. This decrease is very likely due to the reduced effectiveness of the polymer resulting from its chemical reaction with the dye. A later picture, which has not been included here, with the same liquid showed no jet enlargement at a high velocity, indicating further degradation of the polymer. It should be noted that both Figures 38 and 40 demonstrate a slight jet contraction just after the initial enlargement, similar to jet swell in concentrated solutions, as shown in Lodge (24) and Coleman et. al. (6).

The question of fluid acceleration and its importance in this particular flow situation was briefly examined. The inlet distance for a fully developed laminar profile at the entrance to a pipe is given in Schlichting (37) by

$$
\frac{\ell v}{r^{2} \bar{V}}=0.20
$$

Appropriate values for the present jet experiment are $V=1.0 \mathrm{ft} / \mathrm{sec}$, $x=0.0032$ inch,$\ell=0.005$ inch and $\nu=1.05 \times 10^{-5} \mathrm{ft} / \mathrm{sec}$, which yield

$$
\frac{l \nu}{r^{2} \bar{V}}=0.06
$$

This value indicates that the profile is not fully developed and the fluid is still accelerating. 
In order to estimate the importance of fluid acceleration on jet enlargement, liquid-into-liquid jets from a small hypodermic needle were examined with the aid of the traveling-stage microscope described in Chapter $V$. The hypodermic needle was $7 / 16$ inch Iong with an inside diameter of .0062 inch; in order to provide a symmetrical and smooth exit geometry, the end of the needle was ground flat and deburred. The needle was attached to a $10 \mathrm{cc}$. syringe, and the jet velocity was estimated by timing the decrease of fluid volume in the graduated syringe. Similar to the preceding experiment, the polymer was mixed with a concentrated dye solution just before use in the jet. The jet shapes for water at velocities between 0.1 and $2.5 \mathrm{ft} / \mathrm{sec}$ were onserved and noted. Polymer solutions of less than $50 \mathrm{wppm}$ did not affect the shape of the jet at any velocity, perhaps because of the chemical degradation of the macromolecules by the dye. With an 83 wppm solution, the jet enlarged immediately to a diameter of 0.012 inch for the higher velocities, but exhibited the same shape as pure water at low speeds. A 111 wppm solution produced similar results. A slight necking of the jet after the initial enlargement was again observed.

This latter set of observations suggests that the jet swell for a polymer solution is dependent on the fluid acceleration through the nozzle. A positive conclusion cannot be made because the polymer solution has not been carefully characterized. At this stage, it is sufficient to note that for both nozzle geometries, the normal stresses in the liquid cause a large increase in the dianneter of the issuing jet. 
CHAPTER VII

\section{DISCUSSION OF RESULTS}

\section{A. Pure Water Data}

The primary goal of this thesis is to show that the heat transfer and drag for the laminar flow around a circular cylinder are significantly affected when minute amounts of a high-weight polymer are present. Since the present research is concerned with deviations from a known behavior, it is necessary to establish that the experimental technique yields results that reproduce the findings of previous investigations for a known fluid. In the present case, the heat transfer and drag measurements in water, i. e., at zero polymer concentration, will serve as the reference point and indicate the acceptability of the experimental set-up.

1. Free Convection

The free convection heat transfer results in pure water have been presented in Figures 9 to 12. These graphs indicate that the data with the 0.006 inch and 0.002 inch sensors coincide very well wilh lhe previous neasurenents in Newtonian liquids. The neasurements with the .001 inch cylinder deviate by as much as 30 percent from previous findings, although the data merge with the prior measurements for the highest values of the abscissa, GrPr. This 
deviation is considered to be partly due to effects. Collis and Williams (7) have observed that the heat transfer coefficient increased as the cylinder length-to-diameter ratio decreased, for GrPr values in the range $10^{-3}$ to $10^{-9}$. Since the length-to-diameter ratio of the .001 inch sensor was only 14:1, end effects have likely contributed to the virtual increase in the Nusselt number. The data with the .002 sensor and the two .006 inch sensors indicate that end effects are apparently negligible at the higher Grashof numbers.

2. Combined Free and Forced Convection

The combined free and force convection measurements in water are graphically presented in Figures 13, 14, and 15; the data compare favorably with the prior correlations for water by Davis (8) and Hiret (30) which have been plotted on the same graphs. The heat transfer results with the two smallest cylinders are in excellent agreement with the previous investigations, while the data with the 0.006 inch sensor. Figure 15, are consistently high. The 20 percent offset of Nusselt number values for this sensor exceeds the sum of the experimental errors and is considered to be the result of a mistake in the cocfficicnt of rooiotivity $\frac{\Delta R}{\Delta T}$, or in the length, $L$, for that sensor. The offset of this particular Nusselt number data were examined in more detail by comparing the clear water data in Figure 15 to other heat transfer results. The "family" graphs, Figures 16 to 24, indicate that at the lowest velocities, the heat transfer from circular cylinders in dilute polymer solutions is identical to that for water. 
Thus the data from Figure 15 with distilled water were compared to runs in dilute polymer solutions taken with the same sensor. For this comparison, the free convection Nusselt numbers were not matched as in the family graphs, and the heat transfer data at the low velocities showed good agreement between water and the least concentrated solutions. The same graph was then compared to runs in diute polymer solutions taken with other sensors of the same size; again the free convection values were not matched, and in this case, the water data wcre consistently 25 percent higher than the data in dilute polymer solutions at the low Reynolds numbers. Consequently most of the heat transfer in dilute. solutions at low Reynolds numbers shows good agreement with the data of Pirct and Davis for Newtonian liquids. It may be concluded that the offset data of Figure 15 probably resulted from an incorrect measurement of a sensor parameter. Despite this defech, the bulk of the evidence for the pure water data indicatca that the experimental set-up is suitable for measurements of heat transfer from circular cylinders.

\section{Drag Measurements}

Drag measurements in pure water, Figure 29, agree weli with the classic data of Wieselberger for the drag of a circular cylinder. lhe present values for the drag coefficient $C_{D}$ vary at must 5 percent from the "best-fit" line through Wieselberger's data. Since the scatter in his measurements is about 5 percent, the errors in the present drag measurements, mostly due to end effects, are considered acceptable. 


\section{B. Results in Polymer Solutions}

The most significant aspect of this work is that large changes are observed in laminar flow when minute amounts of polyethylene oxide are present. Up to now, only turbulent wall flows have been reported to be affected by the presence of polymer molecules. It must he pointed out that the effects in both types of flows are of a similar magnitude. Investigations of turbulent pipe flows have indicated drag reduction by as much as 80 percent. Figures 16 to 24 in this report indicate that the heat loss from cylinders is reduced by at least 70 percent at the highest Reynolds number tested; Figure 31 demonstrates that the cylinder drag has increased 3.3 times its pure water value. Thus notable differences hetween solvent and solution behavior occur in laminar as well as turbulent flow.

The family of concentration curves in Figures 16 to 24 indicates tho gonoral pattern of bohavior for heat transfer in polymer solutions for Reynolds numbers below 50. The maximum heat loss from a circular cylinder depends on the concentration and molecular weight of the dissolved polymer; the higher the concentration and molecular weight, the more effectively the heat transfer is reduced at the high Reynolds numbers. The onset of the heat transfer reduction is well-defined by the series of graphs; at low Roynoldo number, the heat loss is identical to that for water, but at some critical condition, the heat transfer suddenly deviates from the pure water data and, in fact, becomes independent of the external velocity. This point of 
departure will be termed the critical Reynolds number, Re ${ }_{c}$ and the nine graphs demonstrate that $\mathrm{Re}_{\mathrm{C}}$ decreases as the cylinder size aecreases, and as the polymer concentration and molecular weight increase. The drag measurements for a circular cylinder indicate a similar dependence on the polymer concentration. At low Reynolds numbers, the drag measurements in the dilute solutions follow the pure water data but deviate to higher values for larger velocities. The critical Reynolds number again decreases with increasing polymer concentration. At high concentrations, the drag coefficient becomes independent of the Reynolds number and is comparable to the insensitivity of the Nusselt number for high Reynolds numbers.

As mentioned, pipe friction in turbulent flow is decreased with the addition of dilute polymer solutions. As in the present experiments of laminar flow about circular cylinders, the magnitude and onset of the effect on the flow depend upon polymer concentration and molecular weight $(31,46)$. It should be pointed out that the basic flows are entirely different, one being a turbulent shear flow and the other entirely laminar. The mechanism whereby the polymer solution reduces turbulent skin friction, though not entirely clear at the present time, appears to be due to viscoelasticity (15); it also appears that the effects upon heat transfer and drag in laminar flow for the present experiments on cylinders are due also to viscoelasticity as will be discussed in the next section. Unlike turbulent pipe friction, the drag on cylinders in the Reynolds number range studied is increased, rather than decreased. 
The present heat transfer measurements for a circular cylinder in a polymer solution agree well with the calibration curves of Fabula (13). He found that the heat loss from a circular cylinder in a polymer solution became independent of the sensor speed for velocities greater than about $0.25 \mathrm{ft} / \mathrm{sec}$. He does not mention the cylinder size, but his critical velocity is of the same order for the present work with a, 006 inch sensor. On the other hand, Virk's (46) data with .002 inch heated cylinder indicate a behavior that seems somewhat different from the present and Fabula's. Virk observed that the heal transfer was identical to that for water for Reynolds numbers between 0 and 25. At $R e=25$, the heat loss dropped sharply (to one-third the pure water value) and for $R e>150$, the heat loss was constantly onethird the heat loss in pure water. Therefore he found only a very small range of velocities where the heat transfer was insensitive to the external velocity. For the highest velocities, his cylinder was less sensitive to velocity but not insensitive; these highest velocities are an order of magnitude higher than those in the present work. Unfortunately, at this writing, the complete details of Virk's work are unavailable, and thus the character of his polymer solution is unknown. An exact comparison between Virk's and the present measurements is not possible; the two findings are compatible only if Virk used an extremely dilute polymer solution.

\section{Viscoelastic Effects}

The flow visualization studies and the jet experiments together 
present a reasonably complete picture which explains the heat transfer and drag measurements for a circular cylinder in a polymer sulution. The observed dye patterns in the flow visualization studies indicate that the streamlines around a circular cylinder are considerably displaced by the presence of polymer molecules, and that this displacement increases as the approaching fluid velocity increases. The enlarged flow field reduces the local velocities near the cylinder surface, thereby reducing the heal Iransferred from the cylinder. Apparently the streamline displacement increases just enough to maintain a constant heat loss from the cylinder for Reynolds numbers greater than $\mathrm{Re}_{c}$, although quantitative measurements of the strcamline displacement effect have not been carried out to verify this supposition.

Although the displacenient of the streamlines accounts for the reduction of the heat loss from the cylinder, the altered velocity field does not explain the increased drag measurements. In fact, because of the lower velocity gradient at the cylinder surfacc, the viscous contribution to the drag on the front half of the cylinder will be reduced. The explanation for the increased drag measurements cannot be sought in the flow visualization observations. Tho dye patterns monitor the velocity field, and provide no information on the pressure distribution around the cylinder. The normal stresses in a flowing polymer solution are very different from those in a Newtonian liquid, consequently the pressure distribution on the cylinder surface is unknown. The "normal stress" effects referred to in the preceding paragraph are more readily understood from the observations of the 
laminar jet flow of a dilute polymer solution. The rapid swelling of the laminar jet indicates that the axial stresses in the issuing fluid are negative and very large. The jet enlargement is a macroscopic manifestation of the recoil of the polymer molecules. The introduction of Chapter I mentioned that the equilibrium configuration of a long-chain, randomly-coiled polymer molecule in a stagnant solvent is roughly spherical and dependent only on the molecular forces between the solute and solvent. When the flow of solvent distorts the molecule from its equilibrium configuration, the intermolecular forces festore the molecule to its original shape. This return to the equilibrium condition is dictated by a series of relaxation times, according to Rouse's (33) model for the macromolecule. It may be expected that for a sufficiently high rate of fluid deformation, i. e., when a characteristic time for the fluid deformation rate is comparable to the molecular relaxation time, the molecule does not return to its original shape, but is maintained in an elongated form. If the imposed deformation rate is suddenly removed, the elongated molecule returns to the equilibrium configuration, and this return is macroscopically manifest as elastic recoil. The magnitude of this property is determined from normál stress experiments, and the standard techniques for these measurements are well known for polymer solutions $(6,24)$. The liquids which have heen used in this type of measurement have invariably been concentrated polymer solutions, and as such provide no direct indication of the elasticity of a dilute solution. The present jet observations are 
important because they do show visually that elastically induced normal stress effects are large for a dilute polymer solution.

The normal stress effects do not appear to affect the laminar jet at low velocities. Observations of the jet at low velocities indicated that the shape of the jet is similar to that when no macromolecules are present. This Newtonian behavior at low velocities can be examineci in light of Rouse's model. The characteristic time associated with the lower deformation rates is much longer than the relaxation time for the macromolecule. Consequently the molecule has time to adjust to the flow of the solvent and is disturbed very little from its equilibrium condition. In this case, elasticity is not generated and the jet flow is similar to water.

Similar elastic effects may be expected for the flow around a cylinder. When the rate of deformation becomes sufficiently large it may be anticipated that the flow field will be altered. The heat transfer and drag measurements indicate such behavior. For low velocities the heat transfer and drag measurements in a dilute solution are identical to those for water; this implies that the solutions behave as Newtonian liquids, with the polymer molecules contributing only to the viscosity. For higher approaching velocities, i. e., for larger deformation. rates, it may be expected that the elastic effects become important, and that the measurements of heat loss and drag may be changed. This is borne out by the present experimental results which indicate that the heat transfer and drag begin to deviate from the 
Newtonian results at similar values of the Reynolds number, as shown in the following table.

\section{TABLE 3}

Critical Reynolds numbers for drag and heat transfer measurements for dilute polymer solutions.

\begin{tabular}{|c|c|c|}
\hline $\begin{array}{l}\text { Conc. } \\
\text { wppm }\end{array}$ & $\begin{array}{c}\operatorname{Re}_{c} \text { for Drag } \\
\text { Measurements (Fig. 30) } \\
{[\eta]=15.0, D=.005 \mathrm{in} .}\end{array}$ & $\begin{array}{l}\begin{array}{l}\text { Interpolated Re from } \\
\text { Heat Transfer Data (Fig. 24) }\end{array} \\
\qquad[\eta] \quad=14.5, D=.006 \mathrm{in} .\end{array}$ \\
\hline 7.4 & 10 & 6 \\
\hline 15.7 & 7 & 1.5 \\
\hline 30.2 & 3.5 & 3 \\
\hline
\end{tabular}

Further comparisons are not possible because of the single polymer grade and limited velocity range in the drag measurements.

In the flow around a cylinder, lhe eldsticily of lhe liquid causes the streamlines to be displaced in the direction normal to the lines of shear. This stretching of the flow field in the normal direction is very similar to the displaced streamines in the laminar jet. The displacement increases as the fluid velocity increases, both for the jet and cylinder flows. These increased elastic effects with increasing velocity are consistent with the molecular model described above. The larger the deformation rate, the more the molecule is distorted from its equilibrium position, and the greater the molecular restoring force. This increased molecular force is manifested by a larger displacement of the flow streamline as discussed. 
It has been suggested (13) that a gelatinous film of the polymer molecules coat the cylinder therehy causing the reduction of heat transfer. Such a coating, if sufficiently thick, would also explain the increase in drag. However, the visual flow patterns about the cylinder indicate that the coating explanation is not necessary. Observation of the dye streaks shows that a coating, if present, would have to be thinner than 0.001 inch which would not he sufficient to account either for the drag or heat transfer changes.

It may be expected that the flow fields around wedges and conical sensors will also be affected by the presence of the dissolved molecules. In a similar way, it may be expected that the normal stress distribution around a Pitot tube will be altered in a dilute polymer solution and that an uncalibrated Pitot tube might provide false readings.

\section{Summary}

The results presented in this thesis show that the laminar flow around a circular cylinder can be significantly altered when minute amounts of a high molecular-weight polymer are present. Measurements of heat transfer and drag, as well as the visualization of the flow, indicate that large differences from Newtonian behavior are observed under certain flow conditions.

The results of a comprehensive set of heat transfer experiments clearly show the dependence of the heat loss on the flow Reynolds number and on the character of the polymer solution. The heat transfer 
was measured over a range of velocities and polymer concentrations, for several cylinder diameters and with several polymer molecular weights. The results for free convection and for combined free and forced convection at the lowest flow velocities were identical to those for a Newtonian liquid. At higher speeds, the heat transfer is systematically lower than Newtonian values and, in fact, becomes independent of the external flow.

Drag measurements for a circular cylinder were made under flow conditions comparable to those in the heat transfer experiments. The results also bear similarity to the heat transfer results; at low velocities, the drag measurements were identical to Newtonian values, but at higher speeds, the drag measurements were consistently greater than those for a Newtonian liquid at the same Reynolds number.

The Reynolds number at which the measured values of the heat transfer or drag in polymer solutions deviate from corresponding Newtonian values has been termed the critical Reynolds number, $R_{C}$. The heat transfer and drag results show that $R_{e}$ increases as the cylinder diameter increases, and decreases as the polymer concentration and molecular weight increase.

The explanation for the divergence of the heat transfer and drag results is found in the viscoelastic nature of a dilute polymer solution. The magnitude of the normal stress effects which can be induced in a flowing polymer solution is clearly evident from photographic observations of a minute laminar jet. The pictures show a 
jet enlargement of three to four times the nozzle diameter for fluid velocities comparable to those in the heat transfer and drag experiments. Tn addition, the flow around a circular cylinder was examined by dye injection methods. The observed flow patterns indicate that for Reynolds numbers greater than $R_{c}$ the region of the flow field influenced hy the cylinder is about two to three times larger than that for a Newtonian fluid. However at lower Reynolds numbers, both the Iaminar jet and the cylinder flows were observed to be similar to those when no polymer was present. This Newtonian behavior in the flow visualization experiments at the low speeds is consistent with the measured Newtonian val ues for the drag and heat transfer at low velocities in polymer solutions. 
SYMBOLS AND ABBREVIATIONS

a.

$\AA$

b

B

$c$

$C_{D}$

$\mathrm{C}_{\mathrm{p}}$

$\mathrm{D}$

e

f

Gr

I

$I_{m}$

Io

$\mathrm{k}$

$k^{\prime}$

$\mathrm{K}$

l

L

exponent in intrinsic viscosity - molecular weight relation Angstrom units

subscript to indicate balance conditions

constant in King's Law

concentration of solute

drag coefficient, $\frac{q}{D p \frac{V^{2}}{2}}$

specific heat

cylinder diameter

voltage output from squaring circuit

subscript indicating mean temperature, the arithmetic average of the sensor and tow tank temperatures

Grashof number, $\frac{\rho^{2} \beta \Delta T D^{3}}{\mu^{2}}$

current through sensor

maximum current through sensor

current through sensor at zero velocity

thermal conductivity

constant in intrinsic viscosity - molecular weight relation

Huggins constant $(20)$

inlet length (jet experiment)

length of cylinder 


\begin{tabular}{|c|c|}
\hline ma & milliamperes \\
\hline M & molecular weight \\
\hline$\overline{\mathrm{M}}_{\mathrm{w},}$ & weight-average molecular weight \\
\hline$\overline{\mathrm{M}}_{V}$ & $\begin{array}{l}\text { viscosity-average molecular weight } \\
\qquad T_{R}^{2}\end{array}$ \\
\hline $\mathrm{Nu}$ & Nusselt number, $\frac{T R}{\pi L k \Delta T}$ \\
\hline $\mathrm{Nu}_{0}$ & free convection Nusselt number \\
\hline O. R. & $\begin{array}{l}\text { overheat ratio defined as } \\
\qquad 100 \frac{\mathrm{R}_{\mathrm{op}}-\mathrm{R}_{\mathrm{c}}}{\mathrm{R}_{\mathrm{c}}}\end{array}$ \\
\hline PEO & polyethylene oxide $\mathrm{C}_{\mu} \mu$ \\
\hline $\operatorname{Pr}$ & Prandtl number, $\frac{p}{k}$ \\
\hline q & uniform beam load \\
\hline$r$ & radius of jet \\
\hline $\mathrm{R}$ & resistance of sensor \\
\hline$R_{c}$ & cold resistance of sensor \\
\hline$R_{\text {op }}$ & operating resistance of sensor \\
\hline $\mathrm{Re}$ & Reynolds number, $\frac{\rho V D}{\mu}$ \\
\hline $\mathrm{T}$ & temperature \\
\hline $\mathrm{V}$ & velocity \\
\hline wppm & parts per million by weight \\
\hline
\end{tabular}

\section{Greek Symbols}

$\beta$

coefficient of thermal expansion

solution viscosity 


$\begin{array}{ll}\eta_{s} & \text { solvent viscosity } \\ {[\eta]} & \text { intrinsic viscosity, defined as } \\ \mu & \lim _{c \rightarrow 0} \frac{\eta-\eta_{s}}{\eta_{s}} \\ \nu & \text { absolute viscosity } \\ \rho & \text { kinematic viscosity, } \frac{\mu}{\rho}\end{array}$


REFERENCES

1. American Society for Testing Materials, ASTM Standards, Part 5, (1955).

2. Bailey, F. E., Kucera, J. L., and Imhof, L. G. , "Molecular Weight Relations of Poly(ethylene oxide)", J. Poiy. Sci., Vol. 32 , 517 (1958).

3. Baronet, C. N., and Hoppman, W. H., "Drag Reduction Caused by High Polymer Solutions Injected Into Water Flowing Around Cylindrical Bodies", Technical Report, Dept. of Mech. Eng., Rensselaer Poly. Inst., (1966).

4. Boggs, F. W. , and Thompsen, J., "Flow Properties of Dilute Solutions of Polymers: Part I-Mechanism of Drag Reduction", Report by U.S. Rubber Co. Research Center (1966).

5. Coleman, B. D., and Markovitz, H., "Normal Stress Effects in Second-Order Fluids", J. Appl. Phys., Vol. 35, Part 1, 1 (1964).

6. Coleman, B. D., Markovitz, H., and Noll, W., Viscometric Flows of Non-Newtonian Fluids, Springer-Verlag, New York Inc. (1966).

7. Collis, D. C., and Williams, M. J., "Free Convection of Heat From Fine Wires", Australian Aero. Res. Lab. Aero Note 140, (1940).

8. Davis, A. H., "Convective Cooling of Wires in Streams of Viscous Liquids", Phil. Mag., Vol. 47, 1057 (1924).

9. Deb, S. K., and Mukherjee, S. N., "Molecular Weight and Dimensions of Guar-Gum from Iight Scattering in Solution", Indian J. Chem., Vol. 1, 413-414 (1963).

10. Elata, C., Lehrer, J., and Kahanovitz, A., "Turbulent Shear Flow of Polymer Solutions", Israel J. of Tech., Vol. 4, Number 1, 87-95 (1966).

11. Elata, C., and Tirosh, J., "Frictional Drag Reduction", Israel J. of Tech., Vol. 3, Number 1, 1-6 (1965). 
12. Emerson, A., "Model Experiments Using Dilute Poìmer Solutions Instead of Water". Northeast Coast Institution of Engineers and Shipbuilders, Inst. Trans., Vol. 81, 201 (1965).

13. Fabula, A. G. "An Experimental Study of Grid Turbulence in Dilute High-Polymer Solutions", Ph. D. Thesis, The Pennsylvania State University, University Park, Pennsylvania (1966).

14. Gadd, G. E., "Effects of Long-Chain Molecuie Additives in Water on Vortex Streets", Nature, Vol. 211, Number 5045, 169-170 (1966).

15. Gadd, G. E., "The Reduction of Turbulent Friction in Water by Long Chain Molecule Additives", Chemical Enginees (Birminglatrs Univ.), Vol. 17, Number 2, 3 (1966).

16. Gadd, G. E., "Turbulence Damping and Drag Recuction Produced by Certain Additives in Water", Nature, Vol. 206, Number 4983, $463-467$ (1965).

17. Goren, Y., Ph. D. Thesis, University of Liverpool, (1966).

18. Handbook of Chemistry of Physics, 44th Edition, The Chemical Rubber Publishing Co., Cleveland, Ohio, (1963).

19. Hoyt, J. W., and Fabula, A. G., "The Effect of Additives on Fluid Friction", NAVWEPS Report 86́36, U. S. Naval Ordnance Test Station, China Lake, Calif. (1964).

20. Huggins, M. L., "The Viscosity of Dilute Solutions of LongChain Molcculco. IV. Dopondenco on Concontration", J. Am. Chem. Soc., Vol. 64, $2716(1942)$.

21. Kapur, J. N., and Scrivastava, R. C., "Axially-Symmetric and 2-D Stagnation Point Flow of a Certain Viscoelastic Fiuid", J. Phy. Soc. Japan, Vol. 18, No. 3, 441 (1963).

22. Lang, T. G., and Patrick, H. V. L., "Drag of Blunt Bodies in Polymer Solutions", Presented at the Winter Annual Meeting and Energy Systems Exposition, New York, New York, Nov,-Lec. 1966, of the A.S. M. E.

23. Lindgren, E. R., "Friction Reduction Effects on Turbulent Flows of Water in Rough Pipes by Dilute Additive of High Molecular Weight Polymer", Tech. Report No. 1, to David Taylor Model Basin, Oklahoma State University (1965). 
24. Lodge, A. S., Elastic Liquids, Academic Press, New York (1964).

25. Lumley, J. L., "Turbulence in Non-Newtonian Fluids", Phys. of Fluids, Vol. 7, 335 (1964).

26. McAdams, W. H. , Heat Transmission, 3 rd Ed., McGraw-Hill Book Co. (1954).

27. McGary, C. W. , Jr., "Degradation of Polyethylene Oxide", J. Pulyater Sci., Vol. 46, 51-57 (1960).

28. Metzner, A. B., and Park, M. G., "Turbulent Flow Characteristics of Viscoelastic Fluids", J. Fluid Mech., Vol. 20, Part 2, $291-303$ (1964).

29. Oldroyd, J. G., "On the Formulation of Rheological Equations of State", Proc. Roy. Soc., Vol. 200, Series A, 523 (1950).

30. Piret, E. L., James, W., and Stacy, W., "Heat Transmission From Fine Wires to Water", Ind. and Engin. Chem., Vol. 39, $1098\langle 1947\rangle$.

31. Pruitt, G. T., Rosen, B., and Crawford, H. R., "Effect of Polymer Coiling on Drag Reduction", Tech. Report No. DTMB-2, by Western Company (1966).

32. Rajeswari, G. K., and Rathna, S. L., "Flow of a Particular Class of Non-Newtonian Visco-Elastic and Visco-Inelastic Fluids Near a Stagnation Point", ZAMP, Vol. 13, 43 (1962).

33. Rouse, P. E., Jr., "A Theory of the Linear Viscoelastic Properties of Dilute Polymer Solutions of Coiling Polymers", J. Chem. Phys., Vol. 21, 1272-1280 (1953).

34. Rouse, P. E., Jr., and Sittel, K., "Viscoelastic Properties of Dilute Polymer Solutions", J. Appl. Phys. , Vol. 24, Number 6, 690 (1953).

35. Rubin, H., and Elata, C., "Stability of Couette Flow of Dilute Polymer Solutions", Phys. of Fluids, Vol. 9, Number 10, 1929 (1966).

36. Savins, J. G., "Drag Reduction Characteristics of Solutions of Macromolecules in Turbulent Pipe Flow", Soc. Petrol. Engineers J., Vol. 4, 203-2.14 (1964). 
37. Schlichting, H., Boundary Layer Theory, McGraw-Hill Book Co. (1960).

38. Scrivastava, A. C., "The Flow of a Non-Newtonian Liquid Near a Stagnation Point", ZAMP, Vol. 9, 80 (1958).

39. Sharma, S. K., "Flow of a Visco-Elastic Liquid Near a Stagnation Point", J. Phy. Soc. Japan, Vol. 14, No. 10, 1421 (1959).

40. Shaver, R. G., and Merrill, E. W., "Turbulent Flow of Pseudoplastic Polymer Solutions in Straight Cylindrical Tubes", AlChE J., Vol. 5, 181 (1959).

41. Shin, H. , "Reduction of Drag in Turbulence by Dilute Polymer Solutions", Sc. D. Thesis, M. I. T. (1959).

42. Tanford, C., Physical Chemistry of Macromolecules, John Wiley and Sons, (1963).

43. Toms, B. A., "Some Observations on the Flow of Linear Polymers through Straight Tubes at Large Reynolds Numbers", Proc. Int'1 Cong. Rheol. Part II, 135 (1949).

44. Townes, H. W., "Flow Over a Rough Surface", Ph. D. Thesis, Calif. Inst. of Tech. (1965).

45. Van Dyke, M. , Perturbation Methods in Fluid Mechanics, Academic Press (1964).

46. Virk, P. S., "The Toms Phenomenon - Turbulent Pipe Flow of Dilute Polymer Solutions", Digest of Sc. D. Thesis, M.I.T. (1966).

47. Weissberg, S. G., Simha, R., and Rothman, S. , "Viscosity of Dilute and Moderately Concentrated Polymer Solutions", J. Res. Nat'1 Bur. Stds., Vol. 47, 298-314 (1951).

18. Wicoeloberger, C., Ergebnisse der Aerodynamischen Versuchsanstalt zu Göttingen, II Lieferung, 24, (1923).

49. Wu, Jin; "Experiments on Eree Turbulence in Visco-Elastic Fluids", Technical Rept. 353-1, Hydronautics Inc. (1965).

50. Zimm, B. H., "Dynamics of Polymer Molecules in Dilute Solution: Viscoelasticity, Flow Birefringence and Dielectric Loss", J. Chem. Phys., Vol. 24, 269 (1956). 


\section{APPENDIX I \\ CALIBRATION OF THE ANEMOMETER}

The description of the heat transfer equipment has made reference to the fact that the anemometer could not maintain the sensor at a constant temperature for all velocities. This handicap in an allegedly constant-temperature device resulted from the low overheat ratios that were required for measurements in water. To overcome this difficulty, the anemometer was calibrated.

The calibration scheme involved, essentially, comparing the anemometer ammeter readings when the set was balanced at all velocities with those when it was balanced at one velocity. More specifically, the procedure was as follows: a .006 inch sensor was inserted in the probe holder, and the ensemble mounted on the tow tank carriage. Any size of sensor could have been employed here, of course, since the anemometer, and not the sensor, was being tested. The anemometer was balanced while the carriage moved at a fixed speed. This procedure was repeated for 16 velocities, ranging from 0.01 to $1.0 \mathrm{ft} / \mathrm{sec}$, and the ammeter current was recorded for each. The ammeter data were plotted as current vs. velocity, and the smooth curve through the data points defined $I_{c}$, the correct current. 
The anemometer was then rebalanced at one of the 16 velocities. The ammeter current at this "balance" velocity is designated $I_{b}$, and, of course, is cqual to $I_{c}$ at this vclocity. Without rebalancing, the ammeter readings were recorded for the remaining 15 velocities; the measurements of these currents were termed I, and are not equal to $I_{C}$ at the corresponding velocity. If the velucily in quesliun was less than the balance velocity, then $I>I_{c} ;$ and if higher, then $I<I_{c}$. The difference of the currents, $I-I_{c}$, increased in magnitude as the $I$ moved away from the balance current $I_{b}$, i. e. as $\left|I-I_{b}\right|$ increased. It was observed that, for a particular velocity, the current correction, $\Delta I=I_{c}-I_{C}$, depended on the overheat ratio, and on the value at the balance current $I_{b}$. Accordingly, the above procedure was repeated for several overheat ratios, and for several balance conditions at each overheat ratio. These overheat ratios and balance conditions were chosen to be comparable to those encountered in the heat transfer runs.

It was found that for every overheat ratio, O. R. , and balance current, $I_{b}$, the correction $\Delta I$ was always linearly related to $I-I_{b}$, the displacement of the current from the balance condition. This linear relationship is shown in Figure 41, a representative plot of the data for $0 . R_{.}=2.0, I_{b}=127 \mathrm{ma}$. The line through the data points on the graph has a slope, $k,\left(=\Delta I /\left(I-I_{b}\right)\right)$, which is dependent on $O . R$. and $I_{b}$. The general relationship $k=k\left(O . R ., I_{b}\right)$ was found by trial and error, and the results are summarized in Table 6. 
Thus the equation $\quad \frac{\Delta I}{I-I_{b}}=\frac{I_{c}-I}{I-I_{b}}=0 . I\left(\frac{300}{I_{b}}\right)^{\frac{2.92}{O . R}}$

was employed to compensate for the electronic shortcomings of the anemometer circuitry.

The inherent error in applying this correction equation can be estimated by examining Table 6 for the variance in the product $k\left(I_{b} / 300\right)^{2.92 / O . R . ~ E x c e p t ~ f o r ~ t h e ~ l a s t ~ r u n, ~ w h i c h ~ i s ~ a c t u a l l y ~ o u t ~ o f ~}$ the range of interest, the numerical value for the product varies between . 089 and . 106; consequently, the error in $k$ is \pm 10 percent. This error can also be estimated directly by examining the data in the $\triangle I$ vs. $\left(I-I_{b}\right)$ graphs. In each graph, the straight line through the data points was considered to be the best fit. As shown in Figure 41 , the slope $\mathrm{k}$ may be varied to pass through some data points which are not close to the "hest-fit" line. The difference in the slope by this procedure is a measure of the error in $k$, and was found to be about \pm 10 percent for each of the 12 data plots. Consequently, the inherent error of \pm 10 percont in the above equation is considered to be realistic.

It is necessary to investigate how a 10 percent error in $\Delta I$ affects the accuracy of the Nusselt Number, since $N u=I_{C}^{2} R / \pi L k \Delta T$. The value of the current $I_{C}$ substituted in $\mathrm{Nu}$ is the measured current, I, plus the correction, $\Delta I$. Each of the graphs was examined to find the maximum error in $\Delta I / I$ when the error in $\Delta I$ was 10 percent. The errors in $\Delta I / I$ varied between 1 percent and 2 percent for the 12 graphs. Consequently, the maximum error in $\mathrm{Nu}$, due to inaccuracies in the anemometer calibration, is \pm 4 percent. 


\section{APPENDIX II}

\section{DRIFT CORRECTIONS}

In order to use the heat transfer data which were recorded while the sensor resistance was changing, a correction curve was found which was applied in all cases where the vultage readings had drifted.

Collecting data for the drift corrections required the use of an unstable sensor. An appropriate sensor was found by noting that near the end of a regular heat transfer run, the reference voltage began to fall off, indicating a changing sensor resistance. After the completion of the heat transfer data, four additional runs were made while the magnitude of the drift increased. The voltages recorded prior to the onset of drift were considered to be the correct voltages, $e_{c}$. for this drift calibration procedure. During the four subsequent runs, the voltage readings, e, at eight given velocities, $V$, were recorded. Table 7 presents the data for $e_{c}$ and $e$ for each velocity, as well as the correction voltage $\Delta \mathrm{e}$, defined as $e_{c}-e$, in each instance.

It was found that the corrections were simply correlated by

$$
\frac{\Delta e}{\Delta e_{\max }}-\left(\frac{V}{v_{\max }}\right)^{0.30}
$$


All the data from Table 7, except that for zero velocity, have been plotted in Figure 42. Applying this equation to 'drifted' voltages recorded during a regular heat transfer run merely requires knowledge of the voltage shift, $\Delta \mathrm{e}_{\max }$, at the reference velocity, $V_{\text {max }}$ The voltage correction $\Delta \theta$ is then easily calculated for any other velocity.

It must be noted that the preceding equation does not apply for the zcro-volocity corrcction, $\Delta o_{0} \ldots$. It was found that $\Delta c_{\max }$ correlated all the correction data much better than any combination of $\Delta \mathrm{e}_{\max }$ and $\Delta \mathrm{e}_{\mathrm{o}} ;$ consequently, the correction curve is proscnted without reference to the zcro-velocity correction. The computation of $\Delta \mathrm{e}_{\mathrm{o}}$ is unnecessary since its value can always be read easily from the voltmeter; viz., the electronic network was always arranged to give a zero voltage readout at zero velocity, and, therefore, the corresponding correction, $\Delta \mathrm{e}_{0}$, is simply the voltage deviation from zero. A check of the heat transfer data which was corrected by the preceding equation showed that the minimum correction computed from the equation was always greater than the corresponding $\Delta \mathrm{e}_{\mathrm{o}}$. In this sense, therefore, the correclion equalion was cunsisteal will $\Delta e_{0}$, evea though the equation does not incorporate $\Delta \mathrm{e}_{\mathrm{O}}$

The generality of the correction curve may be questioned because the overheat ratio and balance conditions were not varied for the correction data. This is not considered a serious flaw because the functional form of the correction curve was the primary 
goal. Since the corrections at the end points, $V-V_{\max }$ and $\mathrm{V}=0$, are known exactly, the present test was concerned with finding some guideline for intermediate corrections.

It will now be shown that even a large error in an intermediate correction results in a relatively small error in the computation of the Nusselt number, Nu. The voltage readings were arranged, by means of the electronic network, to be proportional to $I^{2}-I_{0}^{2}$, i.e.,

$$
\begin{aligned}
e_{c}=e+\Delta e & =a\left(I^{2}-I_{0}^{2}\right) \\
& =b\left(N u-N u_{0}\right)
\end{aligned}
$$

Conseguently

$$
d(\Delta e)=b d(N u)
$$

With some rearranging

$$
\frac{d N u}{N u}=\frac{\left(1-\frac{N u_{0}}{N u}\right)}{\left(1+\frac{e}{\Delta e}\right)} \frac{d(\Delta e)}{\Delta e}
$$

As an example of an intermediate voltage, consider the halfway point:

$$
\mathrm{e}=\frac{1}{2} \mathrm{e}_{\max }
$$

For the heat transfer results in polymer solutions, $\mathrm{Nu}_{\max } \sim 2 \mathrm{Nu}{ }_{0}$, and thus

$$
1-\frac{N u_{0}}{N u} \sim \frac{1}{2}
$$


Consider the worst drift, $30 \%$, tolerated in the heat transfer data,

$$
\text { i.e. } \Delta c_{\max }=0.30 e_{\max }
$$

Finding the corresponding drift for the above-mentioned intermediate voltage requires the use of King's Law. The heat transfer data employing the correction equation will not be for values on the "flat" portion of the heat transfer curves for polymer solutions, but rather for values on the "sensitive" portion where the heat loss is dependent on velocity. In this range, the heat transfer can be approximated by King's Law:

$$
\begin{aligned}
\mathrm{Nu}-\mathrm{Nu}_{0} & =\mathrm{BRe} \\
& =\text { const } \mathrm{V}^{\frac{1}{2}} \\
\text { since } \quad & =\mathrm{b}\left(\mathrm{Nu}-\mathrm{Nu}_{\mathrm{o}}\right) \\
\frac{\mathrm{e}}{\mathrm{e}_{\max }} & =\left(\frac{V}{\mathrm{~V}_{\max }}\right)^{1 / 2 .}
\end{aligned}
$$

Thus for the intermediate voltage mentioned above, $e=\frac{1}{2} e_{\max }$,

$$
\frac{V}{V_{\max }}=\frac{1}{4}
$$

From the correction equation

$$
\begin{aligned}
\frac{\Delta \mathrm{e}}{\Delta \mathrm{e}_{\max }} & =\left(\frac{\mathrm{V}}{V_{\max }}\right)^{.30} \\
& =\frac{1}{(4)^{.30}} \\
& =0.66
\end{aligned}
$$

Thus the term $\left(1+\frac{e}{\Delta e}\right)$ for equation (1) is found by 


$$
\begin{aligned}
& -98- \\
1+\frac{e}{\Delta e} & =1+\frac{\frac{1}{2} e_{\max }}{.66 \Delta e_{\max }} \\
& =1+\frac{\frac{1}{2} e_{\max }}{.66\left(.30 \mathrm{e}_{\max }\right)} \\
& =3.5
\end{aligned}
$$

In this case,

$$
\begin{aligned}
\frac{\mathrm{d} \mathrm{Nu}}{\mathrm{Nu}} & =\frac{1-\frac{\mathrm{Nu}_{0}}{\mathrm{Nu}}}{1+\frac{\mathrm{e}}{\Delta \mathrm{e}}} \frac{\mathrm{d}(\Delta \mathrm{e})}{\Delta \mathrm{e}} \\
& =\frac{1}{7} \frac{\mathrm{d}(\Delta \mathrm{e})}{\Delta \mathrm{e}}
\end{aligned}
$$

Consequently an error in $\Delta e$ of 15 percent results in an error of about 2 percent for Nu. The values used in the foregoing example must be considered an extreme case, and consequently the error in $\mathrm{Nu}$, due to the use of the correction equation, can be neglected. 
APPENDIX III

\section{LOAD FUNCTION FOR THE CANTILEVER WIRE}

Standard textbooks on strength of materials do not give the deflection of a cantilever beam uniformly loaded along a portion of its length, and consequently the calculation of this straightforward problem will be presented in this section. The standard notation for beam problems will be used:

$$
\begin{aligned}
& \mathrm{q} \text { = uniform load } \\
& \mathrm{b}=\text { loaded length of beam } \\
& l=\text { total length of beam } \\
& \mathrm{V}=\text { shearing force } \\
& M=\text { bending moment } \\
& \mathrm{y}=\text { deflection } \\
& \text { E } \quad \text { - modulus of elasticity } \\
& \text { I = moment of inertia }
\end{aligned}
$$


The following diagram indicate the load and shearing force distributions for the present problem.

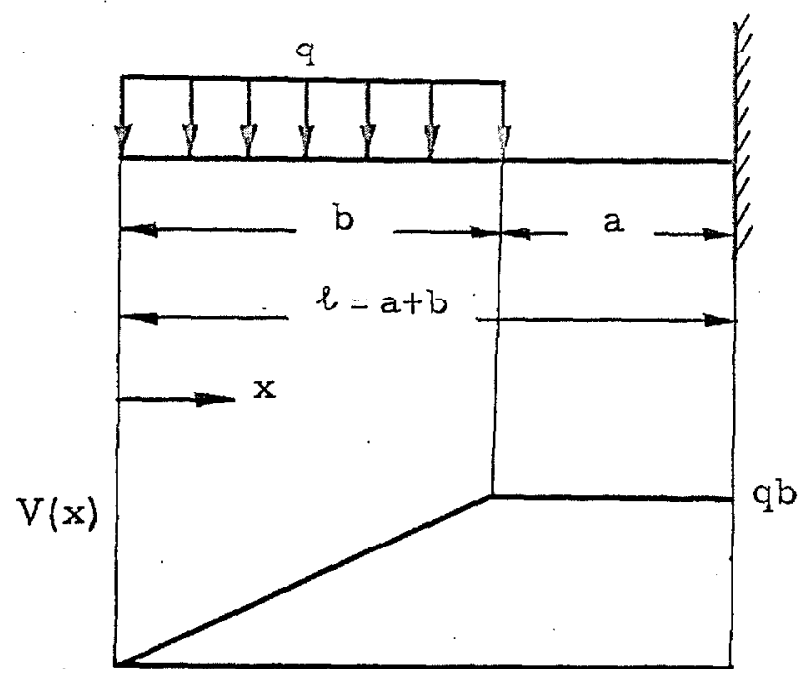

The shearing force varies along the beam as

$$
\begin{aligned}
V(x) & =q x & & 0 \leq x \leq b \\
& =q b & & b \leq x \leq a+b
\end{aligned}
$$

Since there is a discontinuity in the shear force distribution, the problem will be worked by parts: the subscript 1 designates the interval $0 \leq x \leq b$, and 2 designates $b \leq x \leq a+b$. 


$$
\begin{aligned}
& b \leq x \leq a+b \quad M_{2}(x)-\int_{0}^{x} V(y) d y \quad \text { by definition, } \\
& =\int_{0}^{b} q y d y+\int_{b}^{x} q b d y \\
& =q h\left[x-\frac{b}{z}\right]
\end{aligned}
$$

The deflection equation for a laterally loaded beam is given by

$$
E I \frac{d^{2} y_{2}}{d x^{2}}=M_{2}(x)
$$

Integrating once gives

$$
E I \frac{d y_{2}}{d x}=\frac{q b x}{2}[x-b] \div A
$$

at $x=l, \frac{d y}{d x}=0, \quad \therefore A=-\frac{q b l a}{2}$

consequently

$$
E I \frac{d y_{2}}{d x}=\frac{y b}{2}\left[x(x-b)-l_{a}\right]
$$

Integrating again,

$$
\text { EI } y_{2}=\frac{q b}{2}\left[\frac{x^{3}}{3}-\frac{b x^{2}}{2}-i a x+B\right]
$$

$$
\text { at } x=l, y=0, \quad \therefore B=l^{2}\left(a+\frac{b}{2}-\frac{l}{3}\right)
$$

so that

$$
\text { EI } y_{2}=\frac{q b}{2}\left[\frac{b^{3}}{3}-\frac{b^{3}}{2}-l a b+l^{2}\left(a+\frac{b}{2}-\frac{l}{3}\right)\right]
$$


This equation must be used to find the constants of integration when solving for $y_{1}$ in the interval $0 \leq x \leq b$.

$$
\text { For } 0 \leq x \leq b \quad \begin{aligned}
M_{1}(x) & =\int_{0}^{x} q y d y \\
& =\frac{q x^{2}}{2} \\
E I \frac{d^{2} y_{1}}{d x^{2}} & =M_{1}(x)
\end{aligned}
$$

and integrating once gives

$$
\operatorname{EI} \frac{d y_{1}}{d x}=\frac{q x^{3}}{3}+C
$$

The constant $C$ can be found by matching deflections for $y_{1}$ and $y_{2}$ at their common point,

i. e. at $x=b$

$$
\begin{gathered}
\text { EI } \frac{d y_{1}}{d x}=E I \frac{d y_{2}}{d x}=\frac{q i}{2}(-l a) \\
\therefore C=-\frac{q b}{2}\left[l a+\frac{b^{2}}{3}\right]
\end{gathered}
$$

so that

$$
\operatorname{EI} \frac{d y_{1}}{d x}=\frac{q x^{3}}{6}-\frac{q u}{2}\left[\frac{b^{2}}{3}+l a\right]
$$

Integrating again yields

$$
\text { EI } y_{1}=\frac{q x^{4}}{24}-\frac{q b}{2}\left[\frac{b^{2} x}{3}+\ell a x+D\right]
$$

Again matching with $\mathrm{y}_{2}$ at the common point: 


$$
\begin{gathered}
\text { at } x-b \quad \text { EI } y_{1}=\operatorname{EI} y_{2}=\frac{\mathrm{qb}}{2}\left[l^{2}\left(a+\frac{b}{2}-\frac{2}{3}\right)-2 a b-\frac{b^{3}}{16}\right] \\
D=-\frac{b^{3}}{12}-l^{2}\left(\frac{2}{3} l-\frac{b}{2}\right)
\end{gathered}
$$

The end deflection $y_{1}(0)$ is thus

$$
E I y_{1}(0)=-\frac{c b}{2} D
$$

or

$$
y(0)=\frac{1}{\operatorname{EI}} \frac{\mathrm{q} u}{2}\left[\frac{\mathrm{u}^{3}}{12}+l^{2}\left(\frac{2}{3} l-\frac{\mathrm{b}}{2}\right)\right]
$$

Thus the measurement of the wire deflection $y(0)$ provides $q$, the uniform load on the wire:

$$
q=\frac{2 E I}{v} y(0) \frac{1}{\left[\frac{b^{3}}{12}+l^{2}\left(\frac{2}{3} l-\frac{b}{2}\right)\right]}
$$

Two limiting cases will serve to check the validity of the solution for $y(0)$ in equation (1):

a) For a uniform load along the entire beam length, $a=0, b=\ell$; the substitution of these values in $y(0)$ yields

$$
y(0)=\frac{q \ell^{4}}{8 E I}
$$

which is the correct result for a uniformly loaded cantilever beam.

b) For a point load $W$ at the beam end, $a \rightarrow \ell$, and $b \rightarrow 0$ such that $\mathrm{qb} \rightarrow \mathrm{W}$, a constant. Then 


$$
y(0)=\frac{W e^{3}}{3 E I}
$$

the expected result in this case.

It will now bc shown that the deflection y $(0)$ is quite insensitive to the loaded length $b$ for values of $\ell$ and $b$ which were typical in the drag experiments. Differentiating equation (1):

$$
\frac{\mathrm{dy}(0)}{\mathrm{db}}=\frac{\mathrm{q}}{2 \mathrm{EI}}\left[\frac{\mathrm{b}^{3}}{3}+\frac{2}{3} l^{3}-\mathrm{b} l^{2}\right]
$$

with some rearranging

$$
\frac{d y}{y}=4\left(\frac{b^{3}+2 d^{3}-3 b d^{2}}{b^{3}+8 d^{3}-6 b l^{2}}\right) \frac{d b}{b}
$$

Typical values for $\mathrm{b}$ and $\ell$ were 1.5 inch and 2.0 inch respectively. The substitution of these values in the above equation yields

$$
\frac{d y}{y}=\frac{7}{32} \frac{d b}{b}
$$

Since b can easily be measured to \pm .015 inch, or $\pm 1 \%$, the corresponding error in the deflection is only $\pm 0.25 \%$. 


\begin{tabular}{|c|c|c|c|c|}
\hline \multirow{10}{*}{ 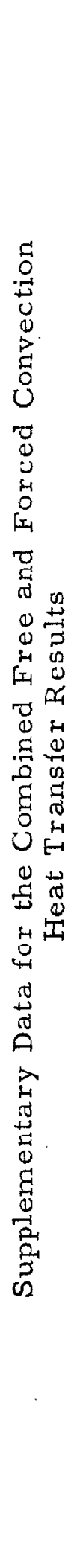 } & 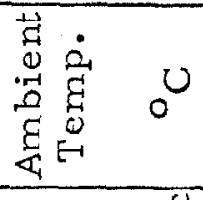 & $\begin{array}{l}\sim \infty N \sim \sim \\
\vec{N} \vec{N} \dot{N} \sim \vec{N} \dot{N}\end{array}$ & 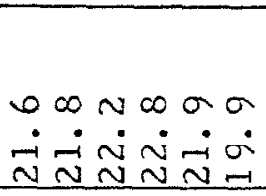 & 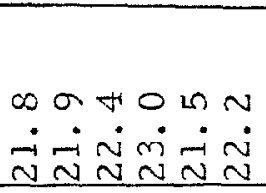 \\
\hline & 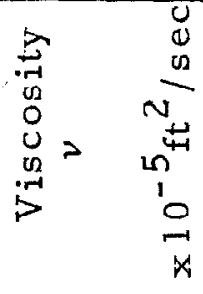 & $\begin{array}{l}\infty \\
\infty m \tilde{N} O N \\
0 \sim \sim\end{array}$ & 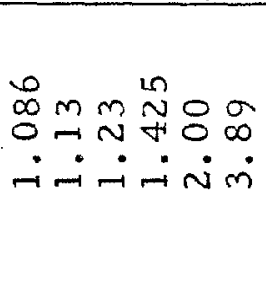 & 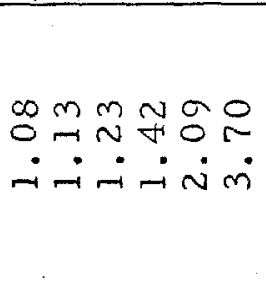 \\
\hline & 悹出出。 & 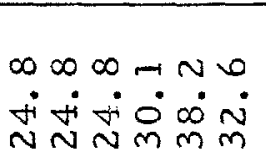 & 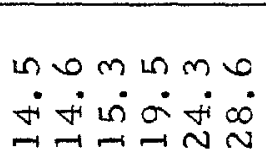 & 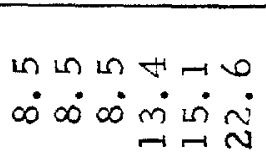 \\
\hline & . & 앆원연언연 & 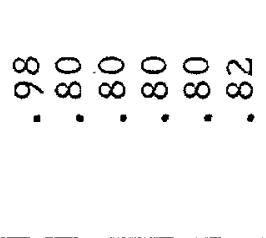 & 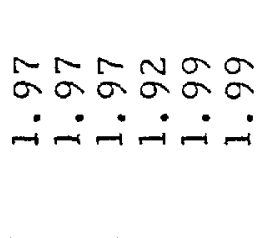 \\
\hline & 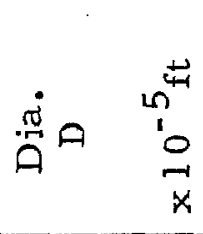 & $\begin{array}{l}000 \sigma \\
\sigma \sigma \sigma \sigma \sigma \sigma \\
\sigma \sigma \sigma\end{array}$ & 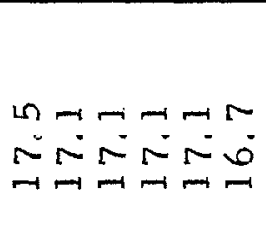 & 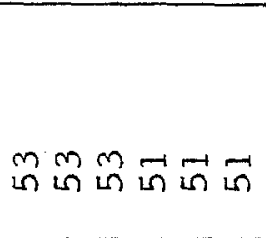 \\
\hline & 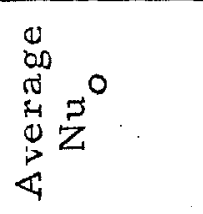 & $\stackrel{\Sigma}{2}$ & + & $\stackrel{\infty}{\sigma}$ \\
\hline & $\vec{z}^{\circ}$ & 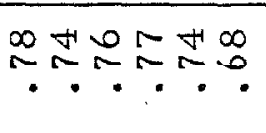 & 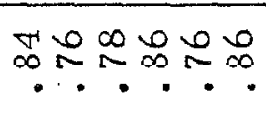 & 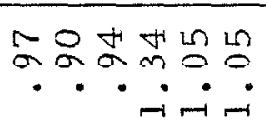 \\
\hline & 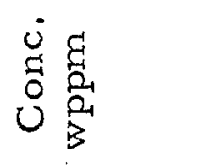 & 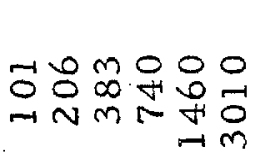 & 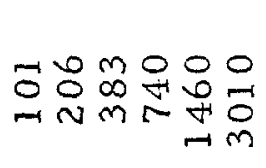 & 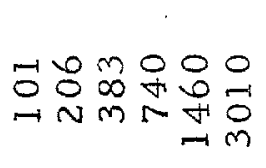 \\
\hline & 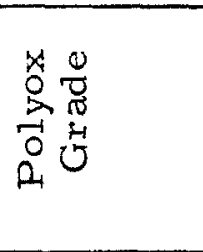 & 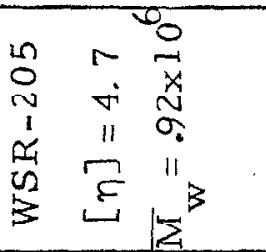 & & \\
\hline & 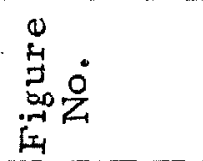 & $\stackrel{\circ}{\sim}$ & 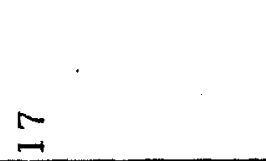 & $\stackrel{\infty}{\sim}$ \\
\hline
\end{tabular}




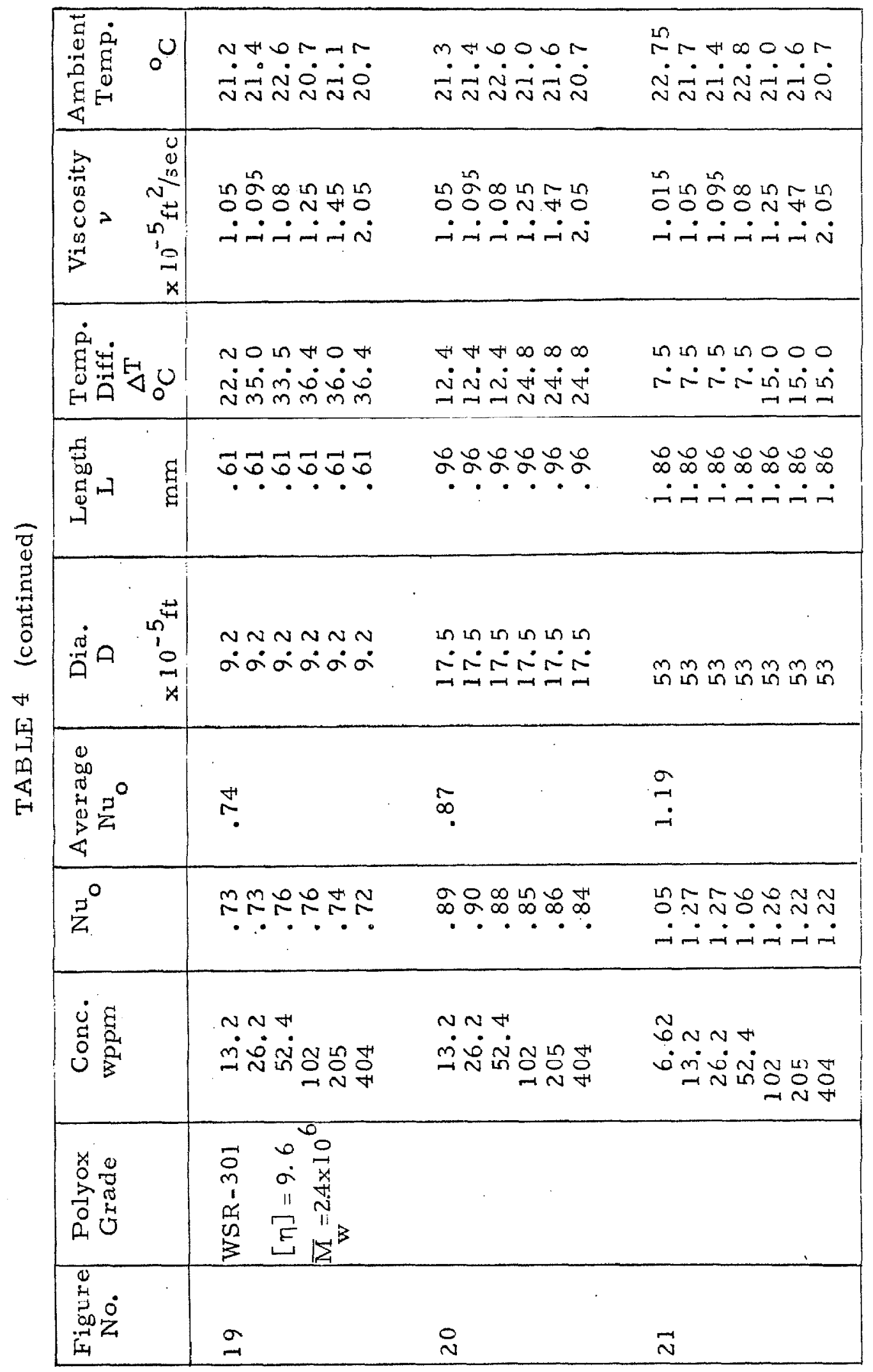




\begin{tabular}{|c|c|c|c|}
\hline 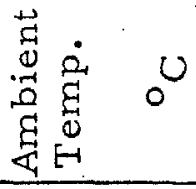 & 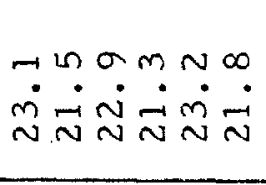 & 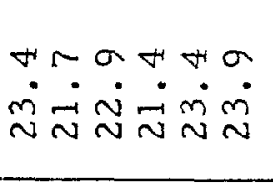 & $\begin{array}{l}\dot{m} \ddot{\sim} \dot{\sim} \dot{\sim} \dot{\sim} \dot{\sim} \dot{\sim} \\
\dot{\sim}\end{array}$ \\
\hline 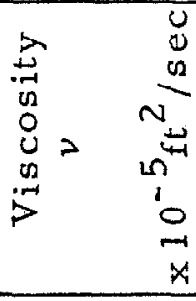 & 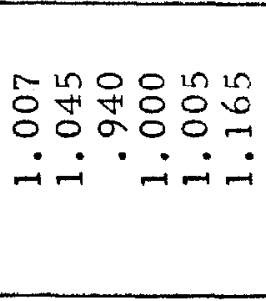 & 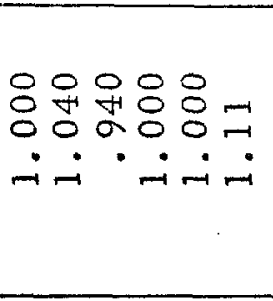 & 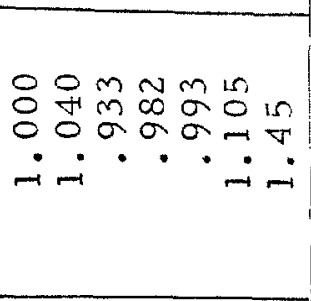 \\
\hline 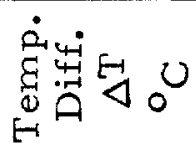 & $\begin{array}{l}N N \sim N O \\
\dot{N} \tilde{N} \dot{N} \dot{m} \dot{m}\end{array}$ & 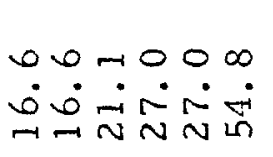 & 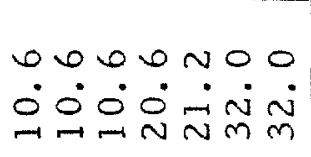 \\
\hline $\begin{array}{l}\frac{1}{4} \\
\text { on } \\
0 \\
0 \\
-1\end{array}$ & $\because$ & 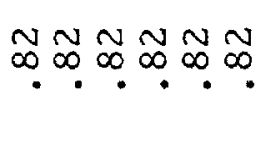 & 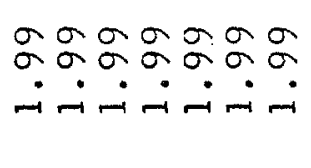 \\
\hline$\stackrel{\dot{\theta}}{a} \quad \stackrel{n^{4}}{i}$ & 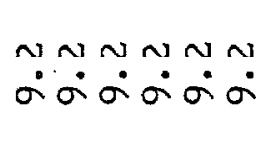 & $\because \tilde{0} \dot{0} \dot{0} \dot{0} \dot{0}$ & 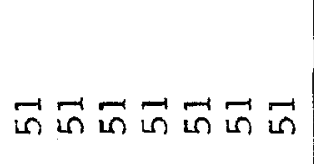 \\
\hline 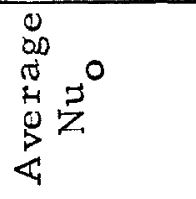 & $\stackrel{\infty}{?}$ & $\stackrel{m}{\infty}$ & $\begin{array}{l}0 \\
0 \\
-i\end{array}$ \\
\hline$\stackrel{5}{Z}^{\circ}$ & 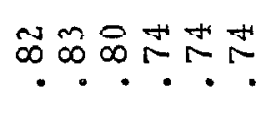 & $\begin{array}{l}\infty \\
\infty \\
\infty\end{array}$. & 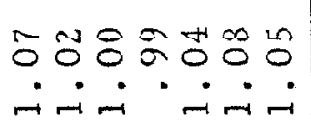 \\
\hline 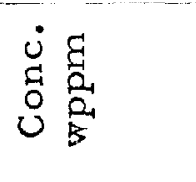 & 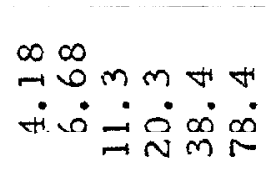 & 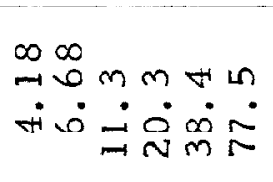 & 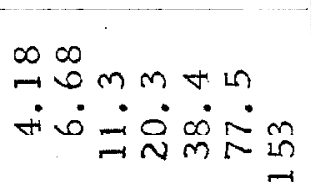 \\
\hline $\begin{array}{l}x \\
0 \\
0 \\
D \\
0 \\
0 \\
0 \\
0 \\
0\end{array}$ & 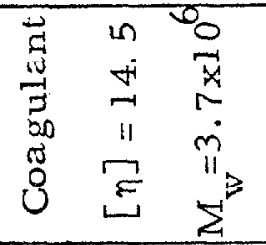 & & . \\
\hline 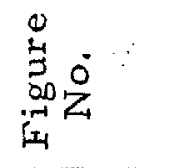 & $N$ & $\stackrel{m}{N}$ & $\stackrel{\leftrightarrow}{N}$ \\
\hline
\end{tabular}


TABLE 5

\section{CALIBRATION OF CANTILEVER WIRE}

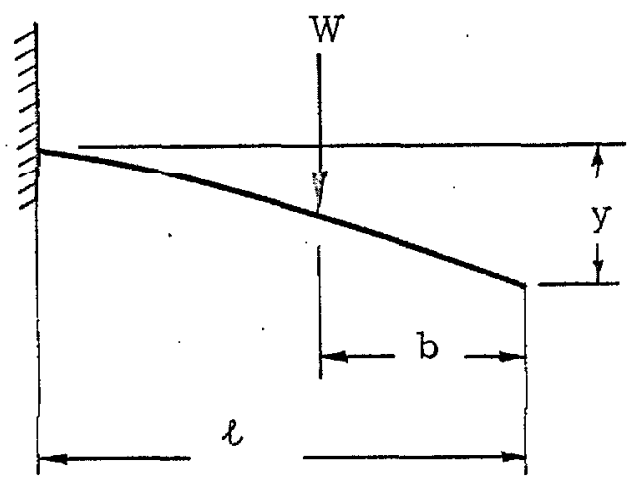

$$
y=\frac{W}{E I} \frac{(2-b)^{2}(a b+b)}{6}
$$

\begin{tabular}{|c|c|c|c|c|c|}
\hline \multirow[b]{2}{*}{$\begin{array}{l}\text { Date } \\
\text { (1967) }\end{array}$} & \multirow{2}{*}{$\begin{array}{l}\text { Weight } \\
\text { W } \\
\text { Ius }\end{array}$} & \multirow{2}{*}{$\begin{array}{c}\text { Deflection } \\
y \\
\text { inch }\end{array}$} & \multicolumn{2}{|c|}{ Lengths } & \multirow[t]{2}{*}{$\begin{array}{l}\text { Flexural Rigidity } \\
E I=\frac{W}{y} \frac{(l-b)^{2}(2 d \div b)}{6}\end{array}$} \\
\hline & & & $\begin{array}{c}\ell \\
\text { inch }\end{array}$ & $\begin{array}{c}b \\
\text { Inch }\end{array}$ & \\
\hline \multirow[t]{4}{*}{$13 \mathrm{Feb}$} & $1.27 \times 10^{-5}$ & .0310 & 1.947 & .0922 & $9.46 \times 10^{-4}$ \\
\hline & 1.77 & .0398 & & .1853 & 9.36 \\
\hline & 4.45 & .0594 & & .6656 & 9.28 \\
\hline & 4.45 & .1119 & & .0606 & 9.35 \\
\hline \multirow[t]{4}{*}{20 Feb } & 1.27 & .0324 & & .037 & 9.37 \\
\hline & 1.77 & .0396 & & .194 & 9.35 \\
\hline & 4.45 & .0706 & & .536 & 9.26 \\
\hline & 4.45 & .1135 & & .053 & 9.25 \\
\hline \multirow[t]{3}{*}{28 Feb } & 1.27 & .0314 & & .080 & 9.25 \\
\hline & 1.77 & .0445 & & .097 & 9.00 \\
\hline & 4.45 & .1136 & & .044 & 9.28 \\
\hline
\end{tabular}


TABLE 6

Summary of data for calibration of anemometer

\begin{tabular}{|c|c|c|c|c|c|}
\hline $\begin{array}{c}\text { Oyerheat } \\
\text { Ratio } \\
\text { O.R. }\end{array}$ & $\begin{array}{c}\text { Balance } \\
\text { Current } \\
\mathrm{I}_{\mathrm{b}}, \mathrm{ma}\end{array}$ & $\begin{array}{l}\text { Slope } k \\
k=\frac{\Delta I}{I-I_{b}}\end{array}$ & $\frac{2.92}{\text { O.R. }}$ & $\frac{I_{b}}{300}$ & $k\left(\frac{I_{b}}{300}\right)^{\frac{2.92}{0 . R}}$ \\
\hline \multirow[t]{5}{*}{ 2. 0} & 104 & .44 & 1.46 & .334 & .089 \\
\hline & 127 & .316 & & .423 & .090 \\
\hline & 137 & .316 & & .457 & .101 \\
\hline & 158 & .248 & & .527 & .097 \\
\hline & 185 & .186 & & .617 & .092 \\
\hline \multirow[t]{4}{*}{4.0} & 150 & .167 & .73 & .500 & .101 \\
\hline & 180 & .146 & & .602 & .101 \\
\hline & 227 & .131 & & .756 & .106 \\
\hline & 265 & .113 & & .884 & .103 \\
\hline \multirow[t]{3}{*}{6.0} & 167 & .13 & .49 & .556 & .097 \\
\hline & 222 & .118 & & .740 & .102 \\
\hline & 250 & .140 & & .833 & .127 \\
\hline
\end{tabular}


$-110-$

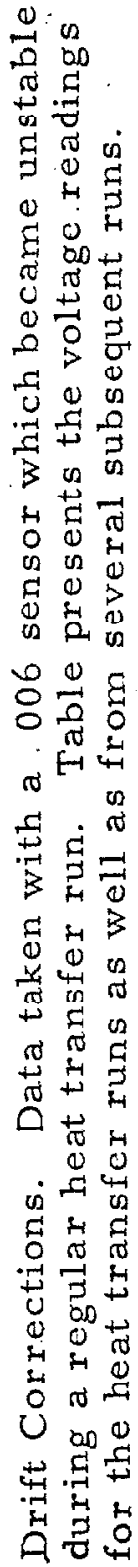

\begin{tabular}{|c|c|c|c|c|c|c|c|c|c|c|}
\hline$\underset{\widetilde{A}}{\Xi}$ & $\left|\begin{array}{cc}0 & 0 \\
0 & 0 \\
0 & 1 \\
0 & 0 \\
0 & 0 \\
0 & 1 \\
0 & 0 \\
0 & 0 \\
U & 0\end{array}\right|$ & $\begin{array}{l}\infty \\
\dot{\sim}\end{array}$ & $\underset{\sim}{\sim}$ & $\begin{array}{l}N \\
\beth\end{array}$ & $\stackrel{-1}{\circ}$ & $\vec{\sigma}$ & $\begin{array}{l}N \\
\infty\end{array}$ & $\stackrel{H}{r}$ & م. & $m$ \\
\hline $\begin{array}{l}\text { f5 } \\
+ \\
+4\end{array}$ & 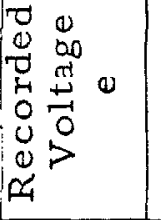 & $\stackrel{r}{\circ}$ & $\begin{array}{l}n \\
\sigma^{\circ}\end{array}$ & $\begin{array}{r}\dot{H} \\
\stackrel{2}{*}\end{array}$ & $\begin{array}{l}N \\
\dot{N}\end{array}$ & $\underset{\sim}{\sigma}$ & $\stackrel{r}{0}$ & $\begin{array}{c}0 \\
-i \\
i\end{array}$ & $\underset{\mathbf{i}}{\vec{j}}$ & $\begin{array}{l}m \\
\dot{\nabla}\end{array}$ \\
\hline 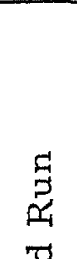 & 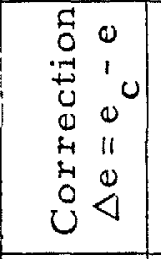 & $\stackrel{\sim}{\infty}$ & $\vec{\infty}$ & $\begin{array}{l}0 \\
\therefore\end{array}$ & in & $\begin{array}{l}0 \\
0\end{array}$ & $\begin{array}{l}\infty \\
\text { in }\end{array}$ & $\begin{array}{l}4 \\
\dot{1}\end{array}$ & $\begin{array}{l}0 \\
\dot{t}^{\circ}\end{array}$ & $\dot{m}$ \\
\hline$m_{1}$ & 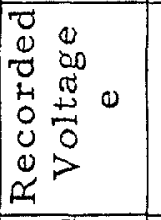 & $\begin{array}{l}\infty \\
\stackrel{1}{\sim}\end{array}$ & $\begin{array}{r}-1 \\
\dot{I}\end{array}$ & $\begin{array}{l}0 \\
\stackrel{-}{\Rightarrow}\end{array}$ & $\begin{array}{l}\infty \\
\infty\end{array}$ & $\begin{array}{l}0 \\
\dot{0}\end{array}$ & $\vec{m}$ & $\begin{array}{l}0 \\
-i\end{array}$ & $\begin{array}{l}0 \\
0\end{array}$ & $\vec{r}$ \\
\hline$\stackrel{\stackrel{3}{3}}{\mathscr{3}}$ & $\mid$\begin{tabular}{ll|} 
& 0 \\
0 & 0 \\
0 & 1 \\
0 & 0 \\
0 & 0 \\
4 & 1 \\
5 & 0 \\
0 & 0 \\
0 & 0
\end{tabular} & فَ & $\begin{array}{l}0 \\
\text { 'م }\end{array}$ & $\begin{array}{l}\infty \\
\dot{\nabla}\end{array}$ & $\begin{array}{l}m \\
\dot{\nabla}\end{array}$ & $\begin{array}{l}0 \\
\dot{\nabla}\end{array}$ & $\begin{array}{l}\infty \\
\dot{m}\end{array}$ & $\begin{array}{l}n \\
\dot{m}\end{array}$ & $\begin{array}{l}0 \\
\dot{m}\end{array}$ & $\begin{array}{l}n \\
\sim \\
\sim\end{array}$ \\
\hline $\begin{array}{l}q \\
\sim \\
N\end{array}$ & $\begin{array}{lll}0 & 0 \\
0 & 0 \\
0 & 0 \\
4 & 0 & 0 \\
0 & \pm & 0 \\
0 & 0 & 0 \\
0 & 0 \\
0 & 7 & \\
0 & 0\end{array}$ & $\begin{array}{l}+ \\
\infty \\
\infty\end{array}$ & $\begin{array}{l}0 \\
0 \\
=1\end{array}$ & $\begin{array}{l}\infty \\
\stackrel{\sim}{\sim}\end{array}$ & $\begin{array}{l}0 \\
\stackrel{-}{\sim}\end{array}$ & $\begin{array}{l}0 \\
\infty\end{array}$ & $\vec{n}$ & $\begin{array}{l}\sigma \\
\sim\end{array}$ & $\begin{array}{l}0 \\
-i\end{array}$ & $\begin{array}{l}n \\
\sim \\
i\end{array}$ \\
\hline 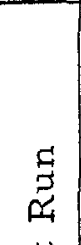 & $\begin{array}{|cc|} & 0 \\
0 & 0 \\
-1 & 1 \\
0 & 0 \\
0 & 0 \\
4 & 11 \\
-1 & 0 \\
0 & 0 \\
0 & 0 \\
\end{array}$ & $\begin{array}{l}\dot{m}_{3} \\
\dot{m}\end{array}$ & $\dot{m}$ & $\stackrel{i}{N}$ & $\begin{array}{l}u \\
N\end{array}$ & $\stackrel{i v}{N}$ & $\begin{array}{l}0 \\
\sim\end{array}$ & $\begin{array}{l}\infty \\
-i\end{array}$ & $\begin{array}{l}\vec{H} \\
-i\end{array}$ & : \\
\hline $\begin{array}{l}\Delta \\
\omega \\
-1\end{array}$ & 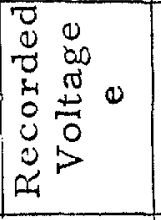 & $\begin{array}{l}0 \\
\underset{N}{N}\end{array}$ & $\begin{array}{l}0 \\
\sigma \\
\sigma\end{array}$ & $\begin{array}{l}\sigma \\
\stackrel{1}{\sigma}\end{array}$ & $\begin{array}{l}\infty \\
\stackrel{\sim}{\sim}\end{array}$ & $\begin{array}{l}\infty \\
\sigma^{\circ}\end{array}$ & $\begin{array}{l}\sigma \\
\dot{0}\end{array}$ & $\begin{array}{l}\varphi \\
+\end{array}$ & $\stackrel{N}{\dot{m}}$ & $\stackrel{5}{0}$ \\
\hline 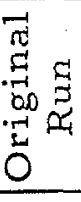 & 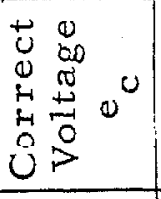 & $\begin{array}{l}n \\
\dot{J}\end{array}$ & $\begin{array}{l}N \\
N\end{array}$ & $\begin{array}{l}0 \\
\infty \\
\infty\end{array}$ & $\begin{array}{l}m \\
\dot{n} \\
\stackrel{n}{n}\end{array}$ & $\begin{array}{l}0 \\
\stackrel{1}{*}\end{array}$ & $\begin{array}{l}\sigma \\
\infty\end{array}$ & ف & $\begin{array}{l}0 \\
\dot{H}\end{array}$ & $\begin{array}{l}0 \\
0\end{array}$ \\
\hline 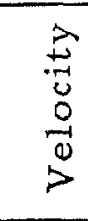 & 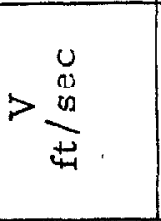 & 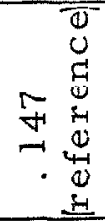 & $\Rightarrow$ & 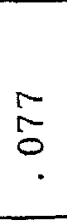 & $\begin{array}{l}\text { in } \\
\text { in } \\
0\end{array}$ & $\begin{array}{l}\infty \\
\sigma \\
\tilde{r} \\
0 \\
0\end{array}$ & $\underset{\sim}{\stackrel{L}{N}}$ & $\begin{array}{l}\stackrel{2}{\sigma} \\
\stackrel{5}{0} \\
.\end{array}$ & $\stackrel{\stackrel{H}{n}}{\stackrel{4}{0}}$ & 8 \\
\hline
\end{tabular}


$-111-$

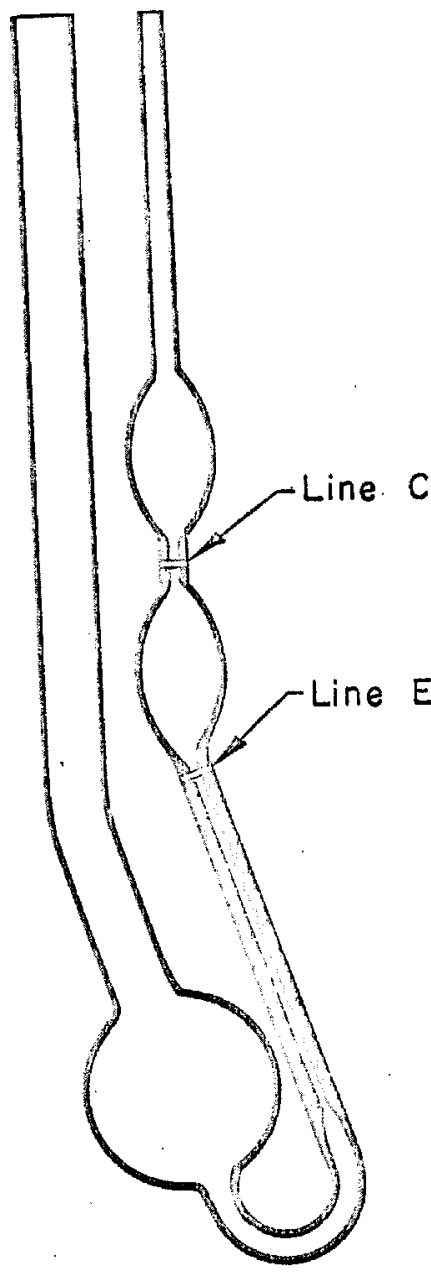

Fig. 1. Cannon-Fenske Viscometer. 


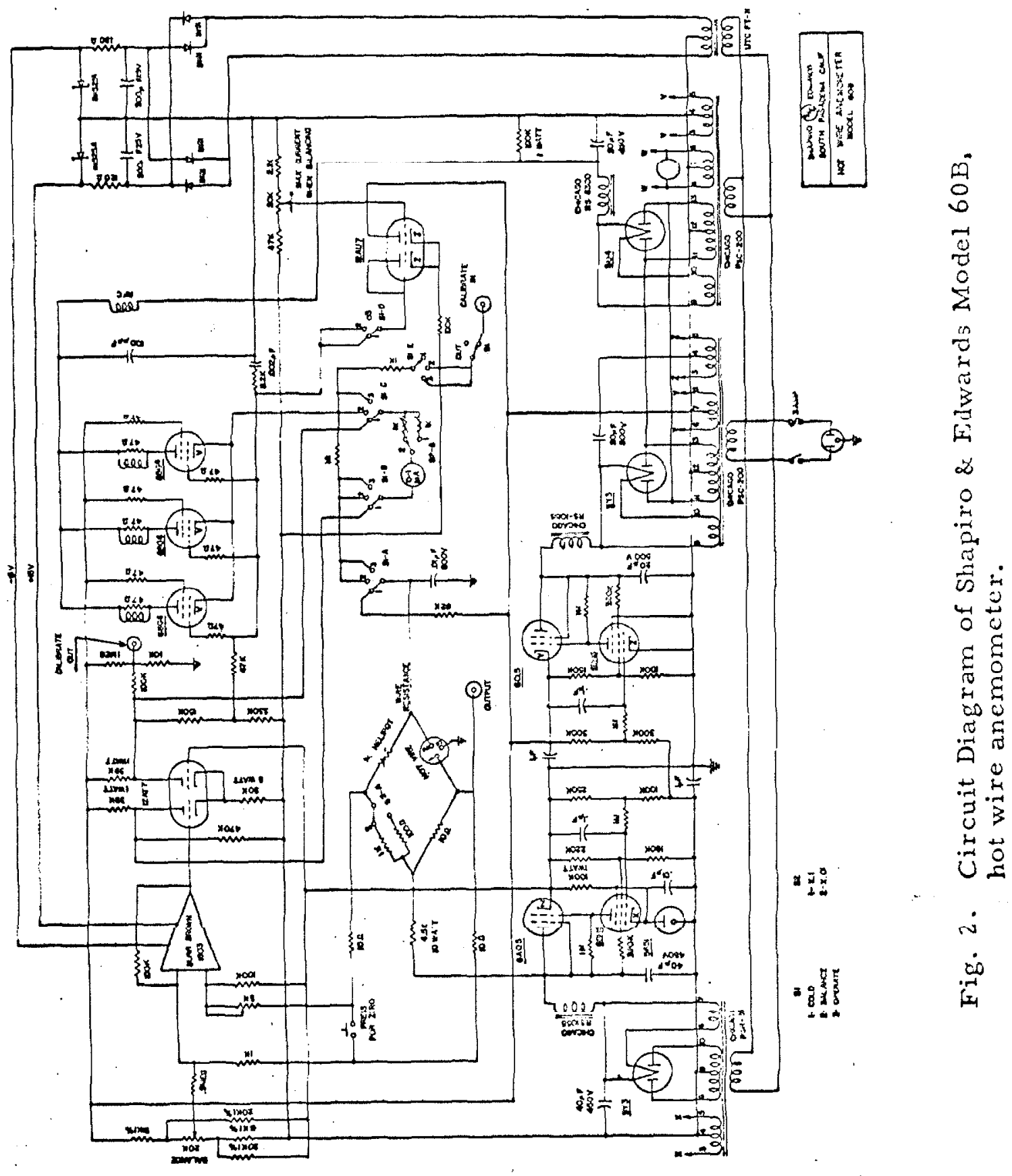




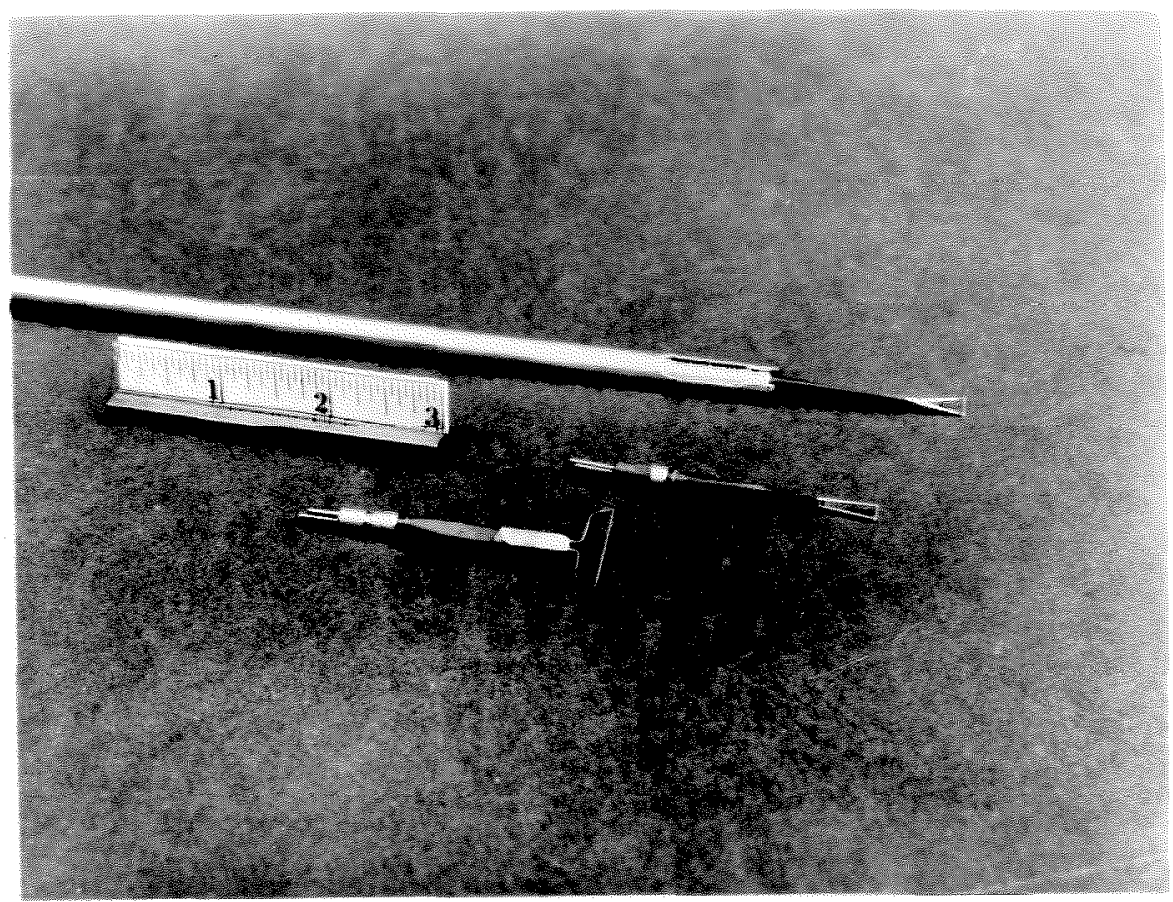

Fig. 3. Photograph of probe equipment. At the rear, a 0,006 inch sensor assembled with a probe and locking sleeve; in the middle, a standard 0.006 inch sensor and holder; in the foreground, the custom-made sensor with a length-to-diameter ratio of $96: 1$. 


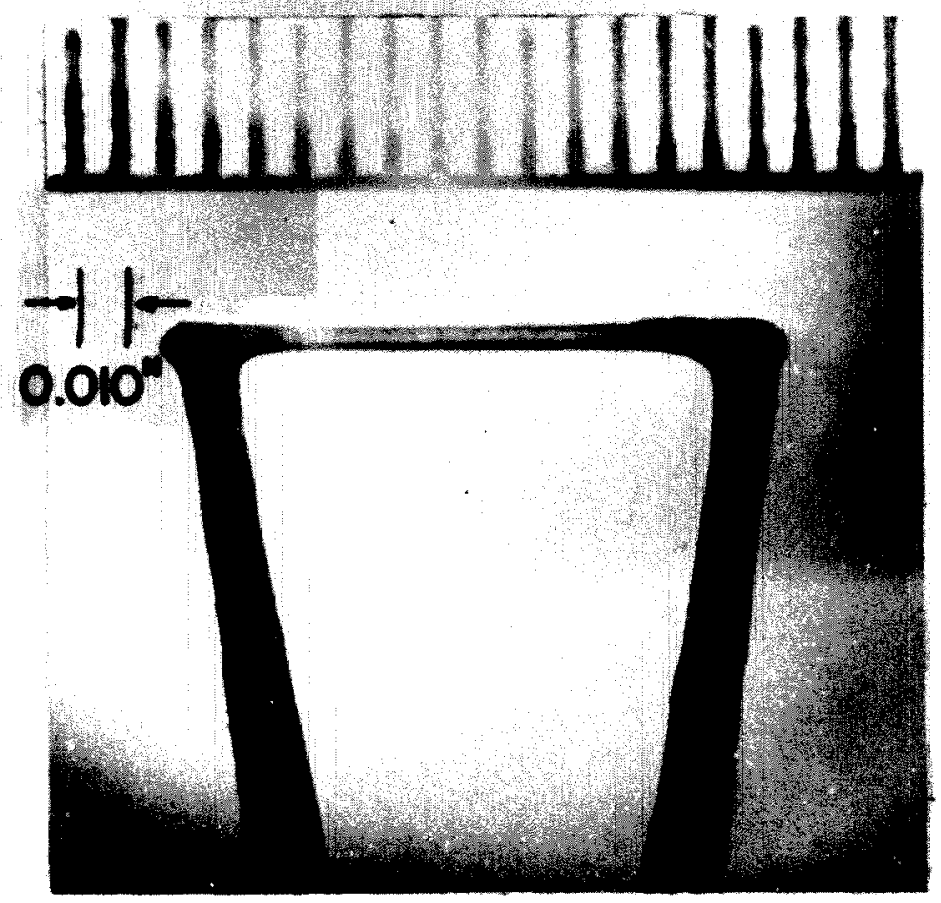

Fig. 4. Photograph of 0.006 in. dia. platinum hot film probe. 


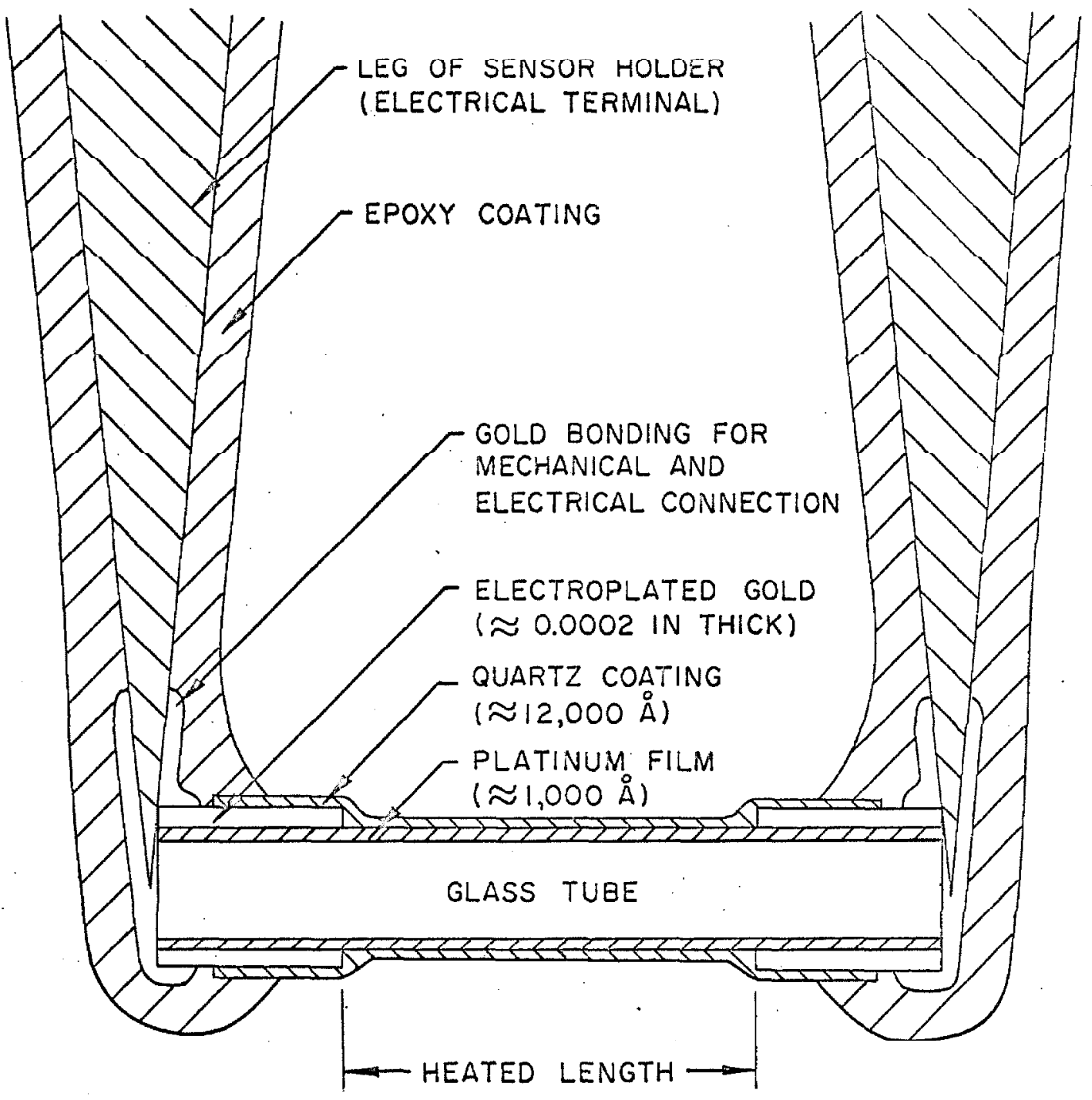

Fig. 5. Drawing of commercial hot film semsor. The drawing is not to scale and the specified distances are given by the manufacturer. 


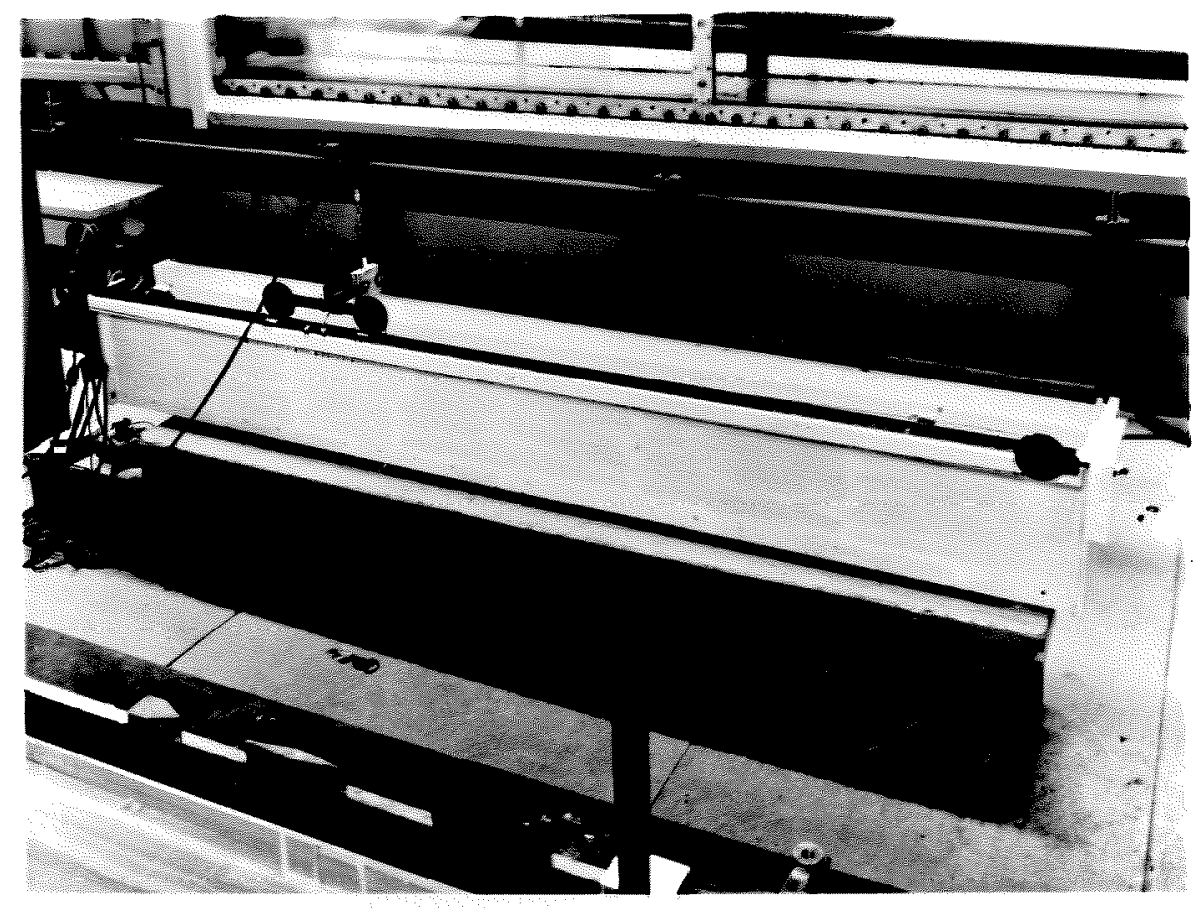

Fig. 6. Photograph of tow tank and carriage. 


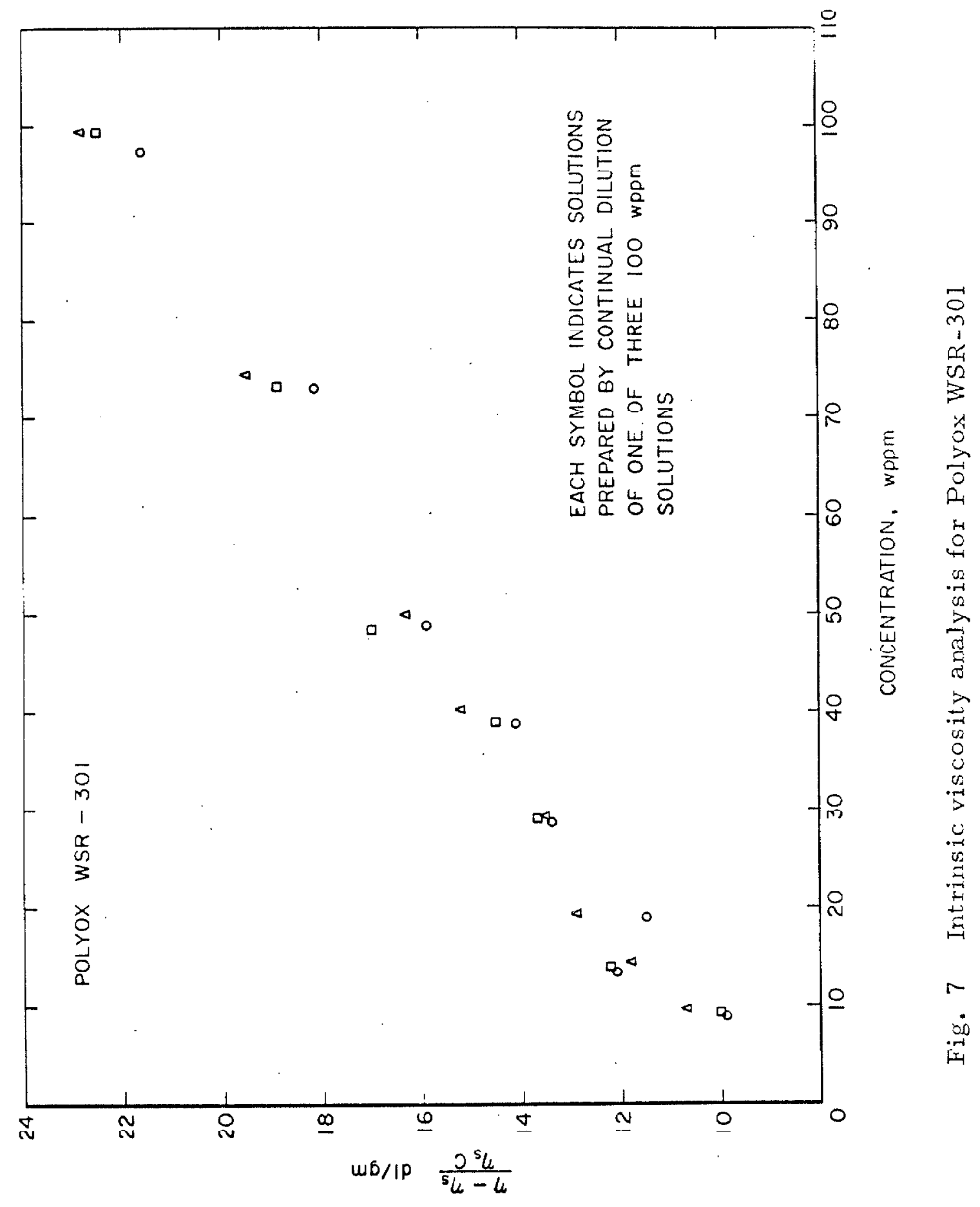




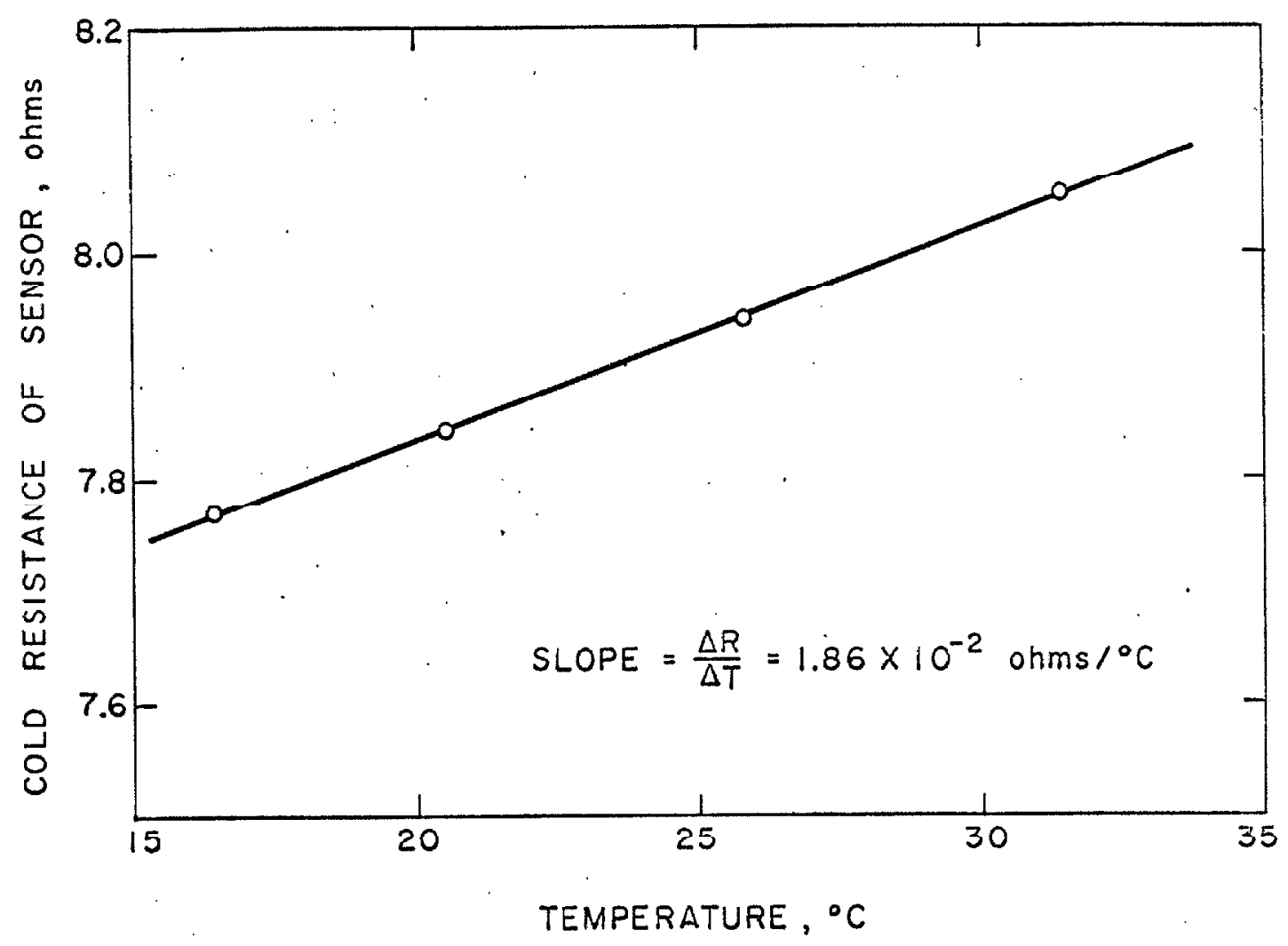

Fig. 8. Representative data relating resistance and temperature for a given sensor. The data are used lo delermine ile coefficient of resistivity for that sensor. 


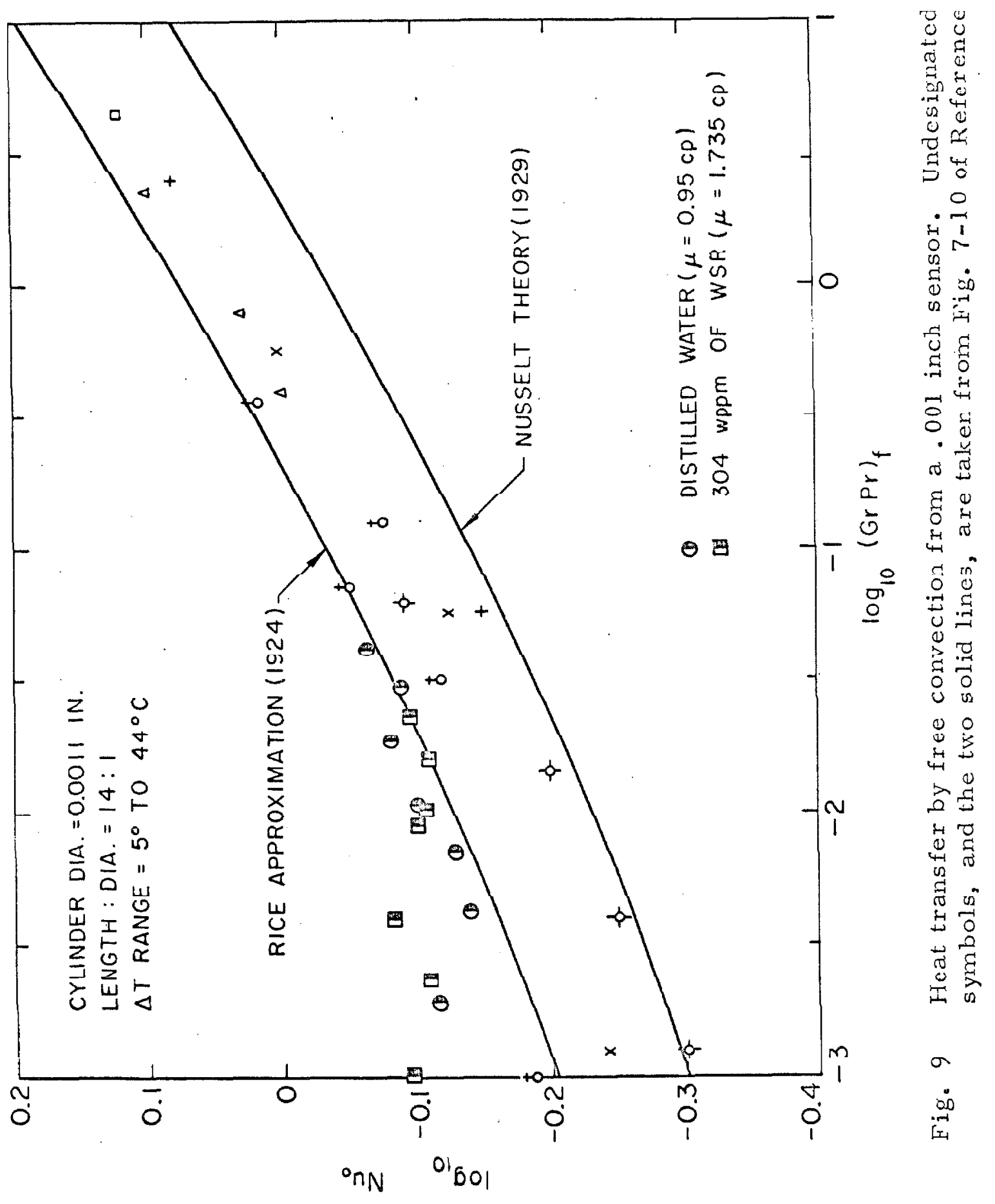




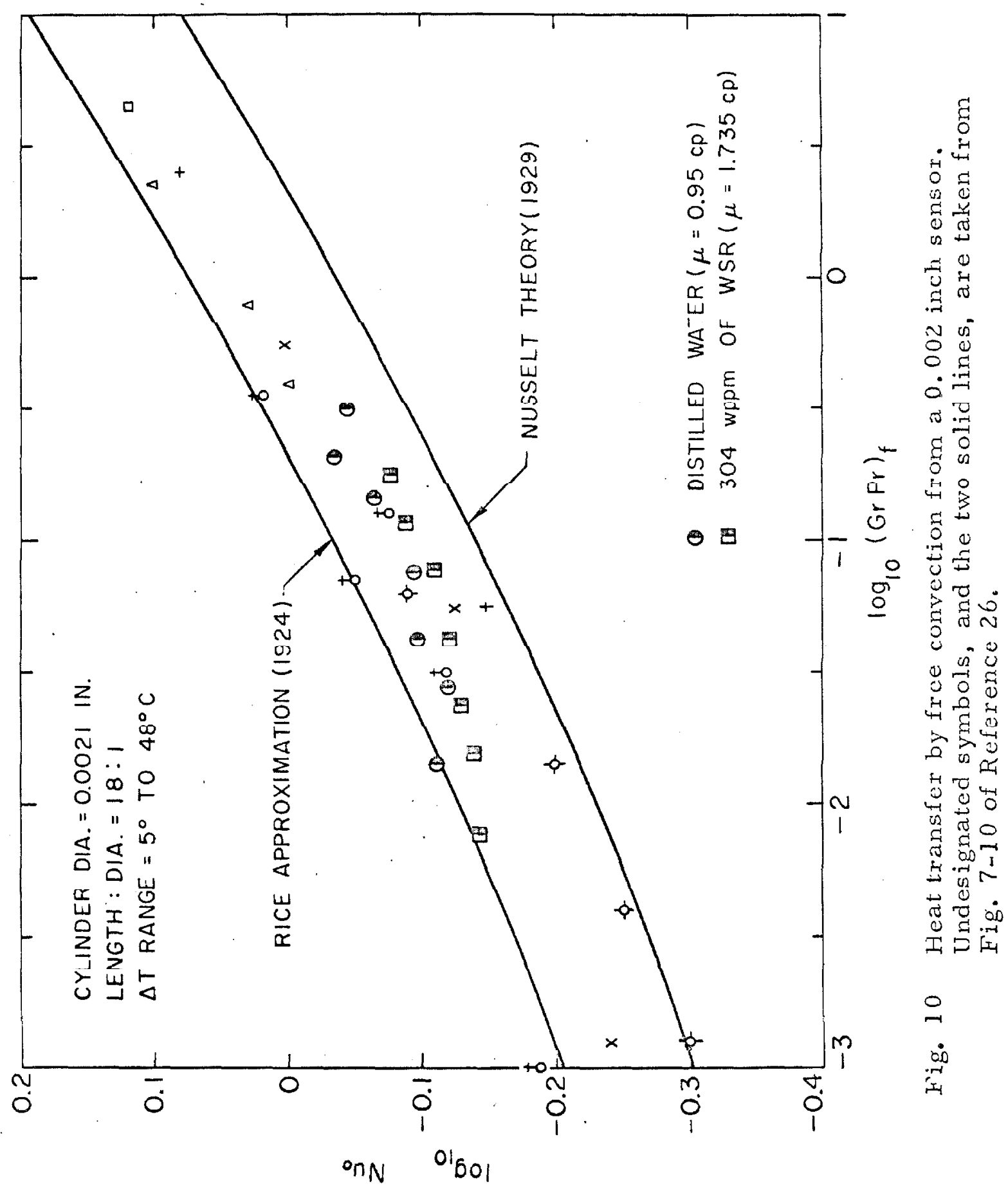




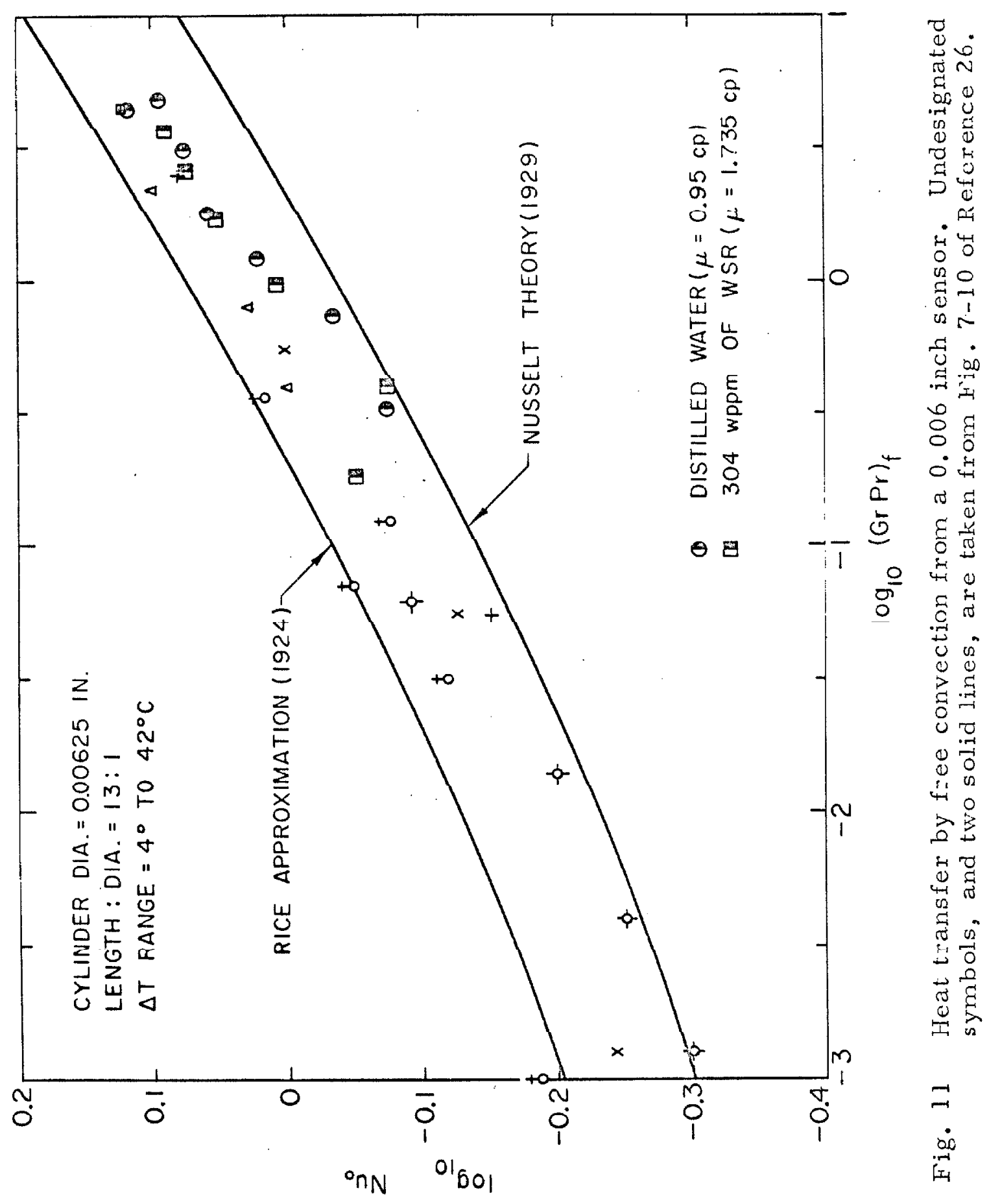




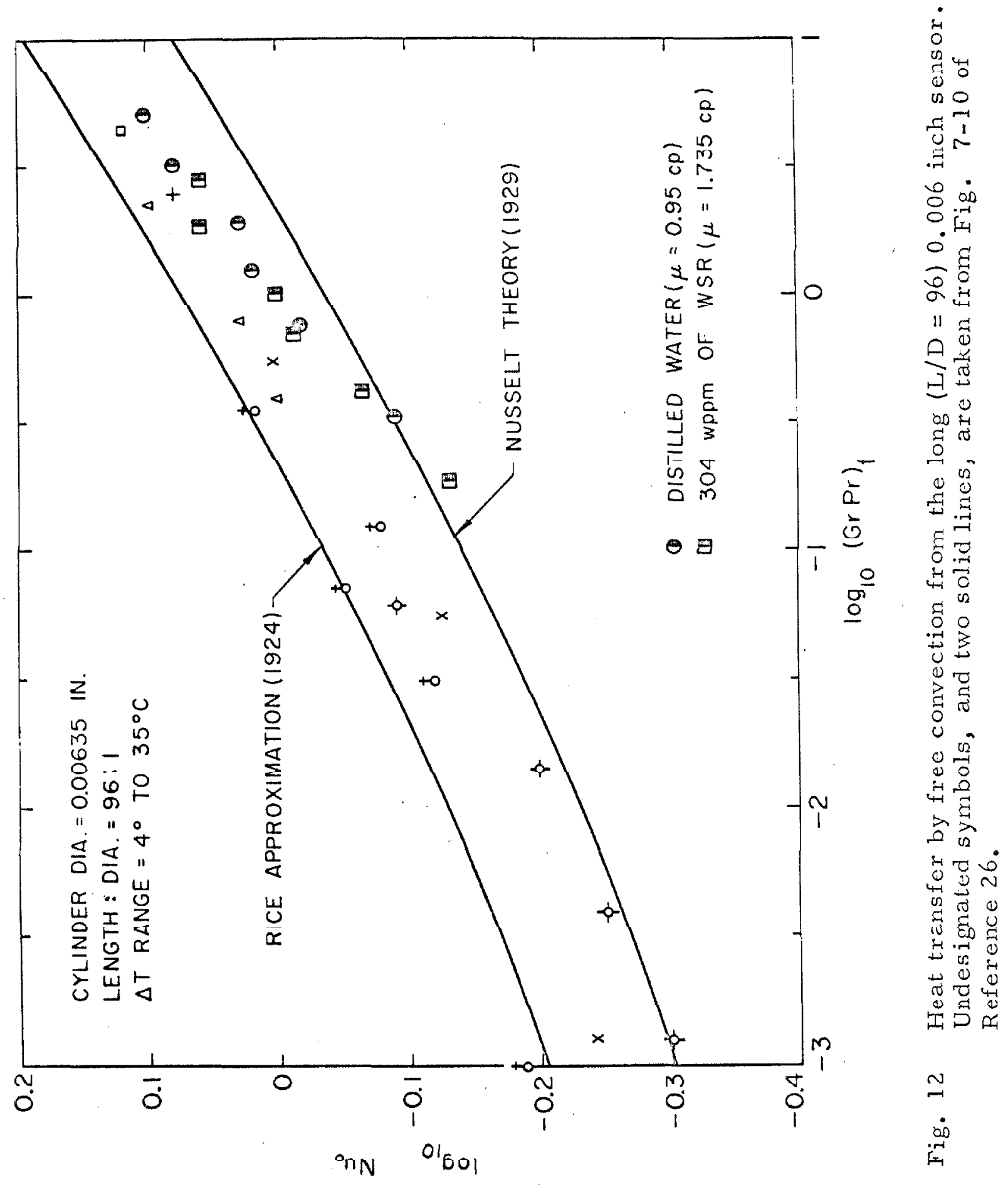




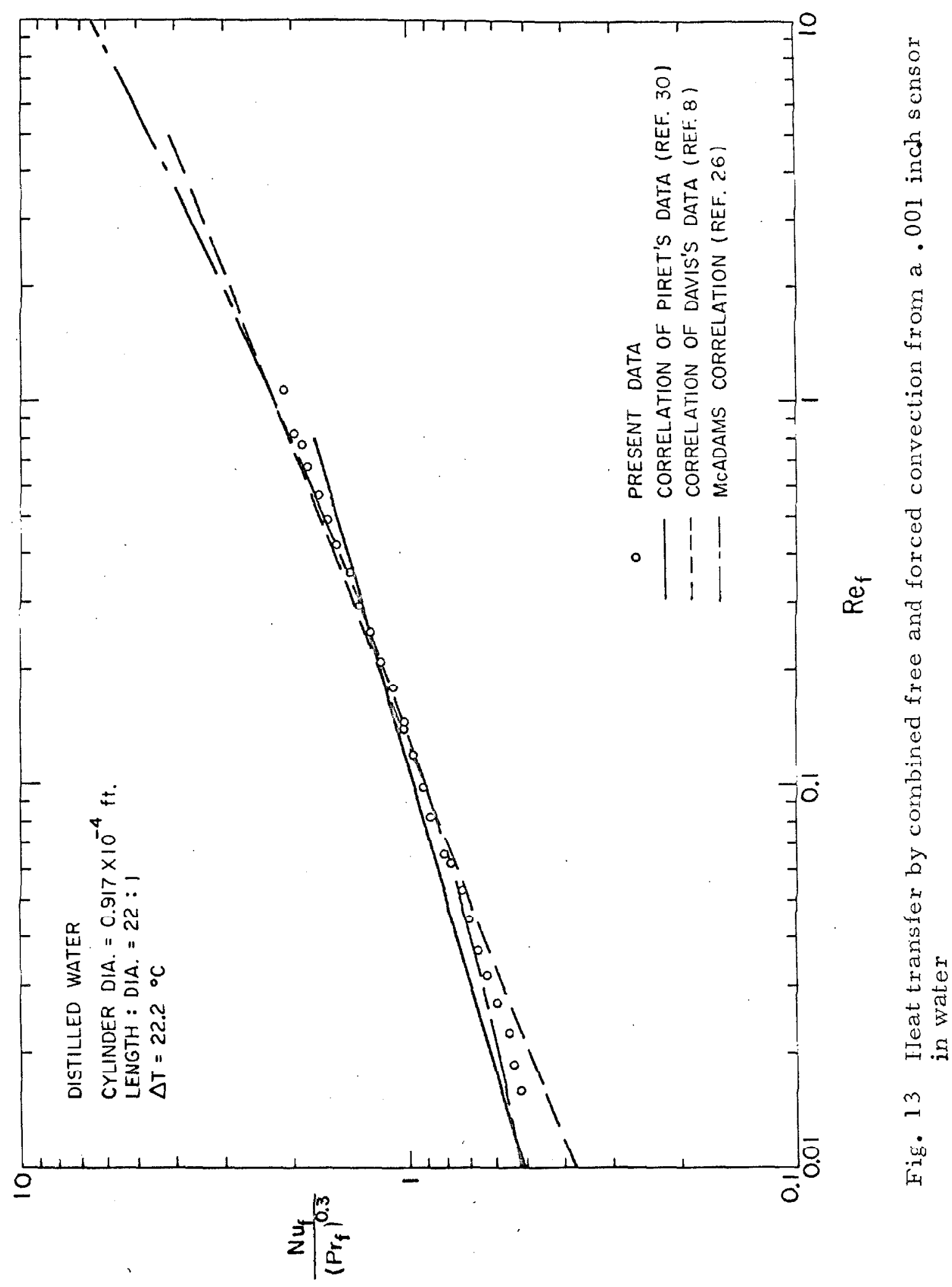




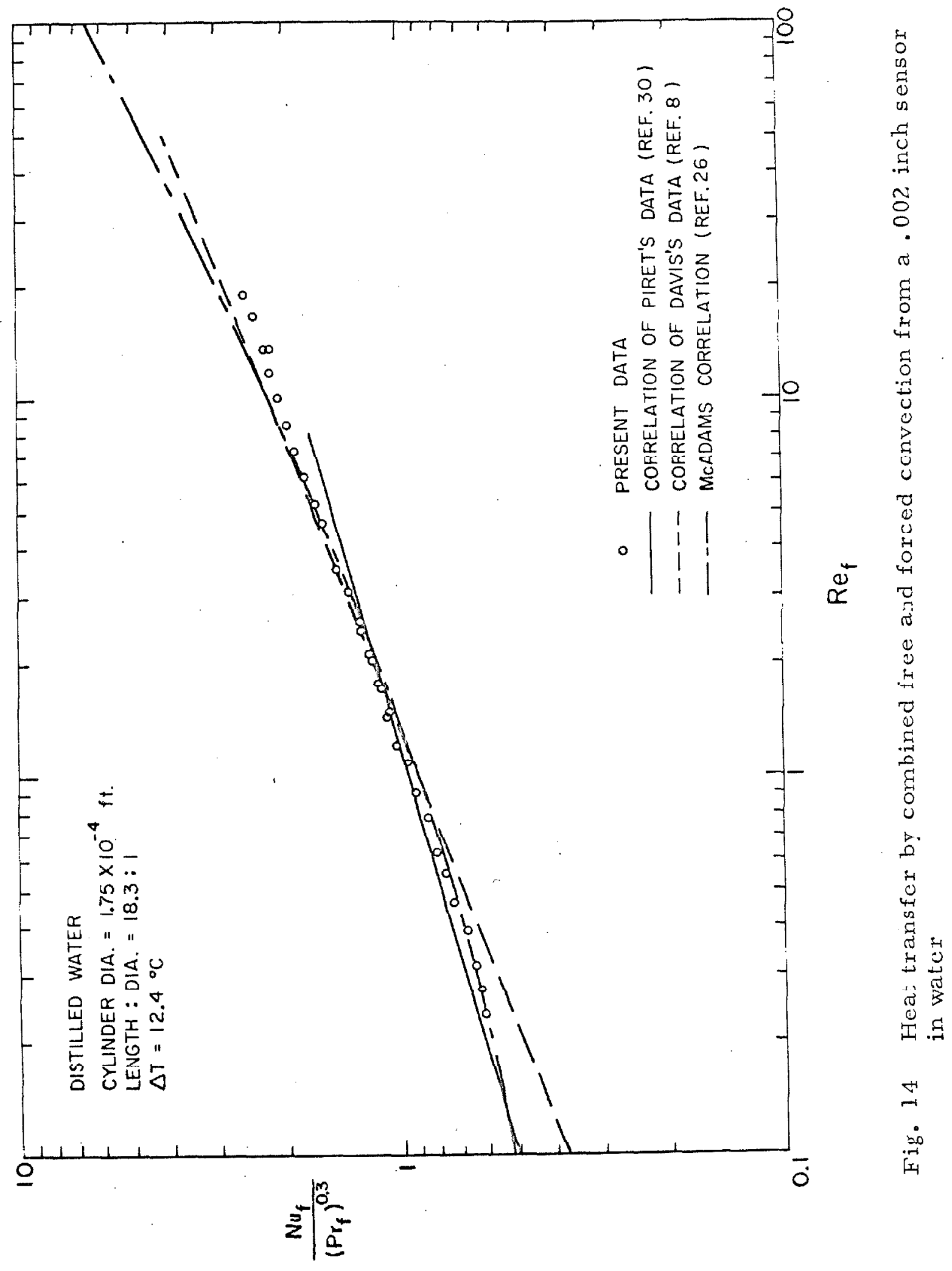




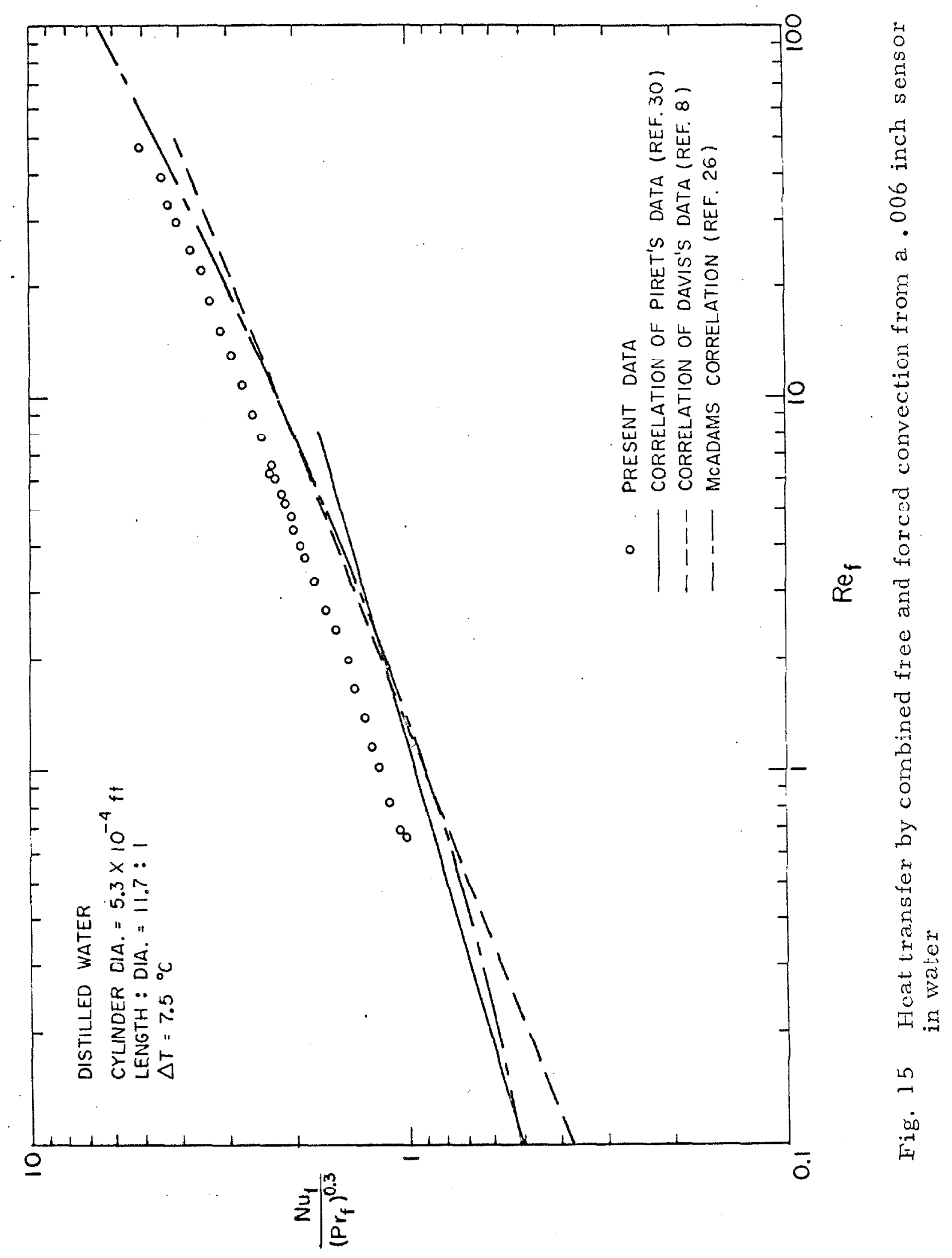




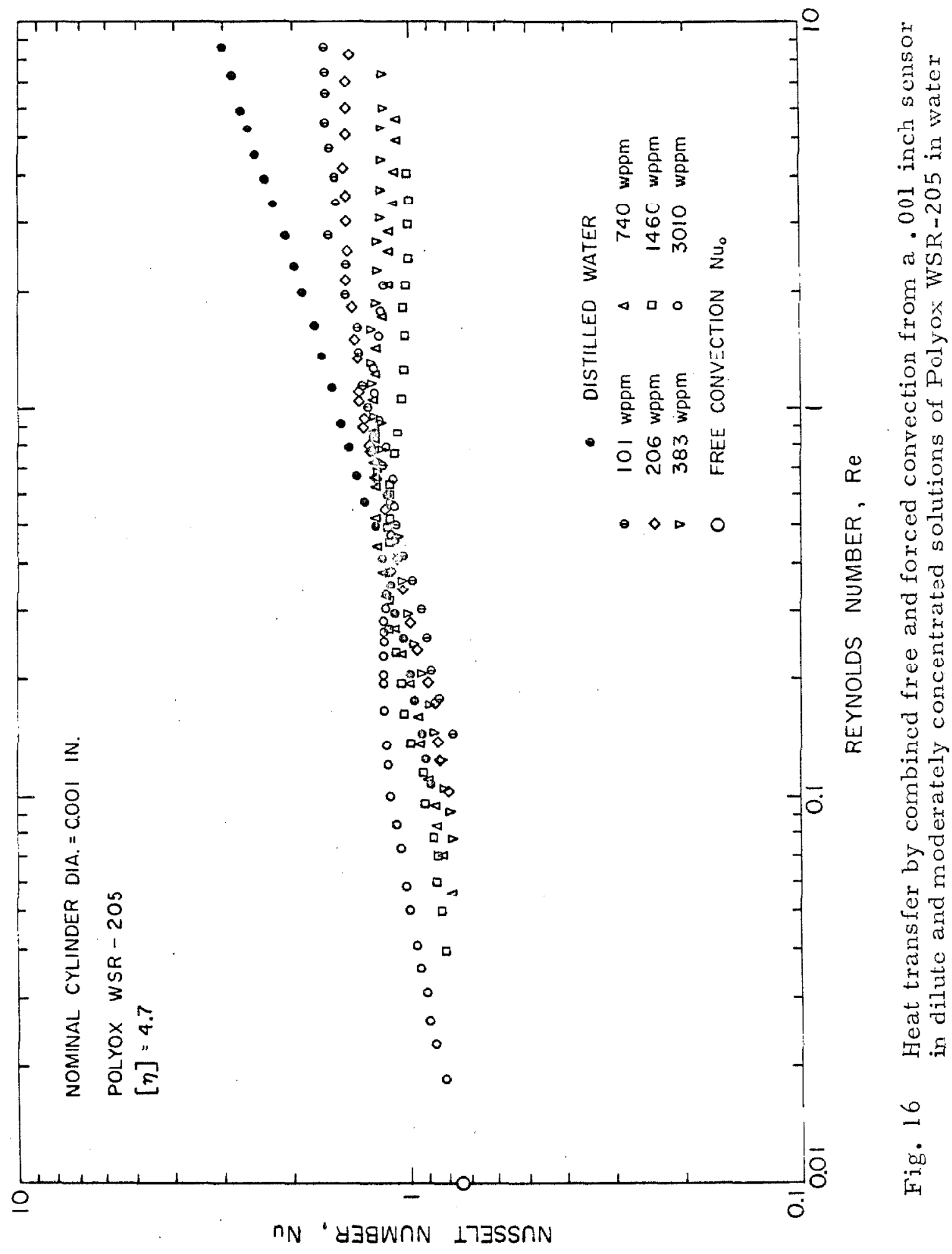




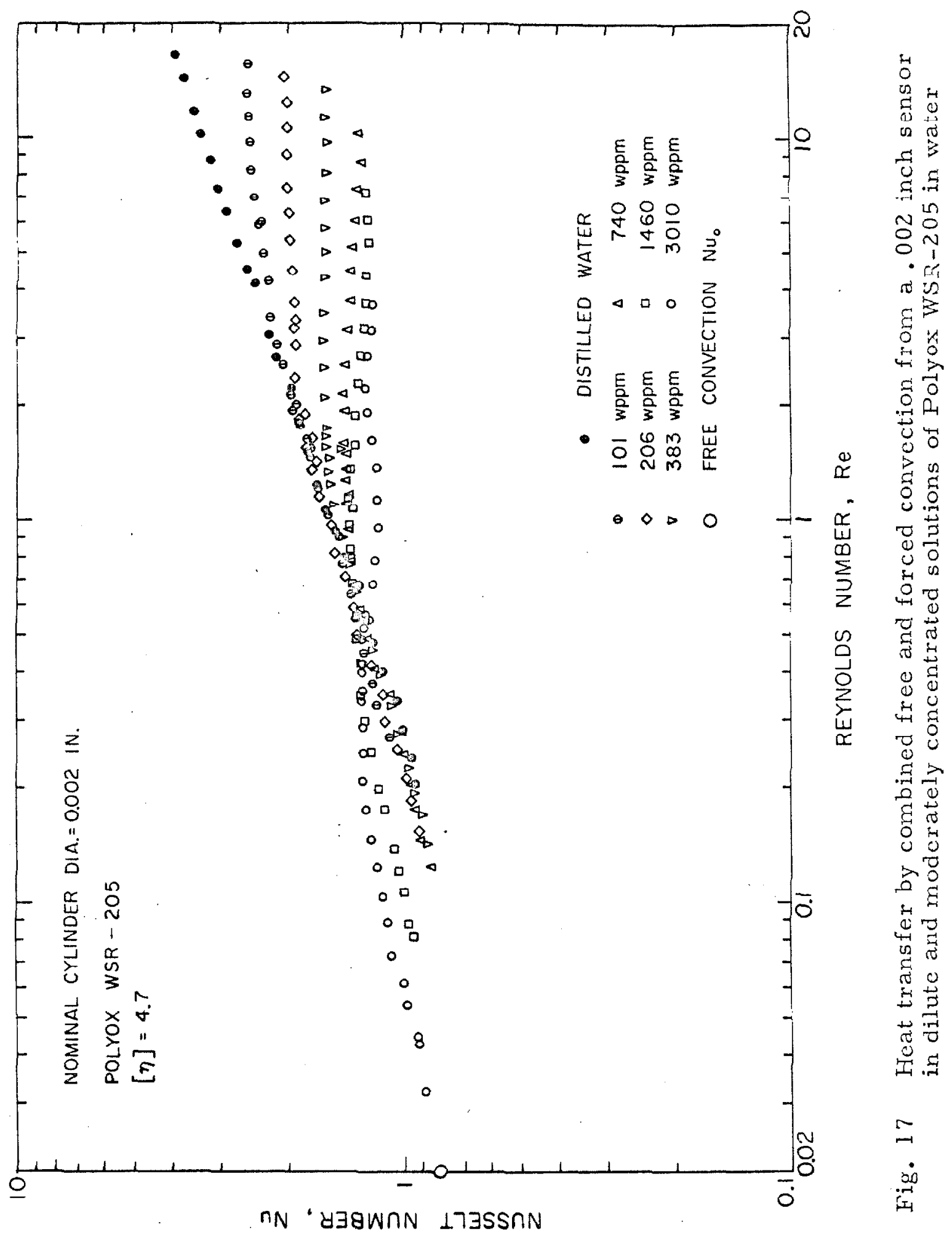




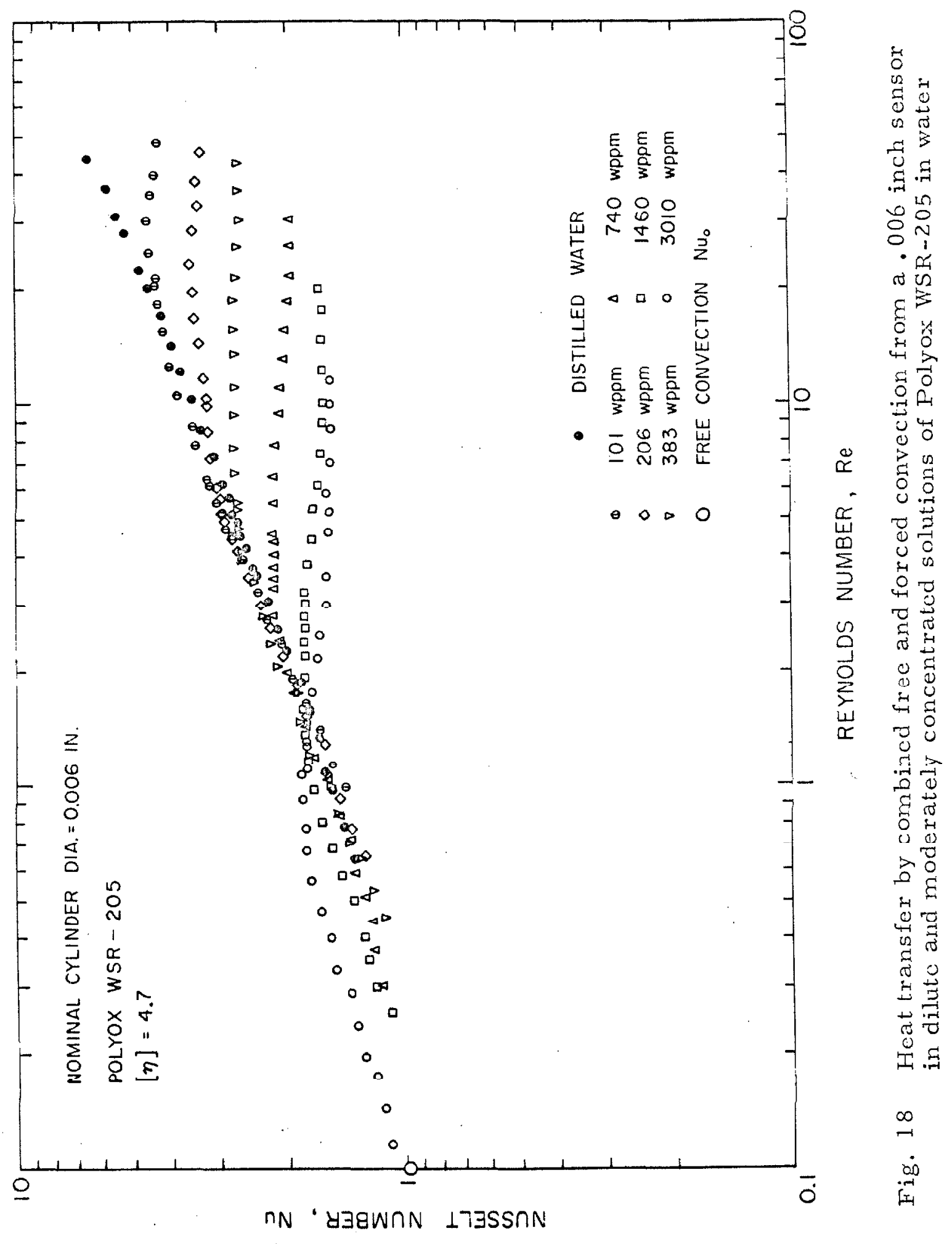




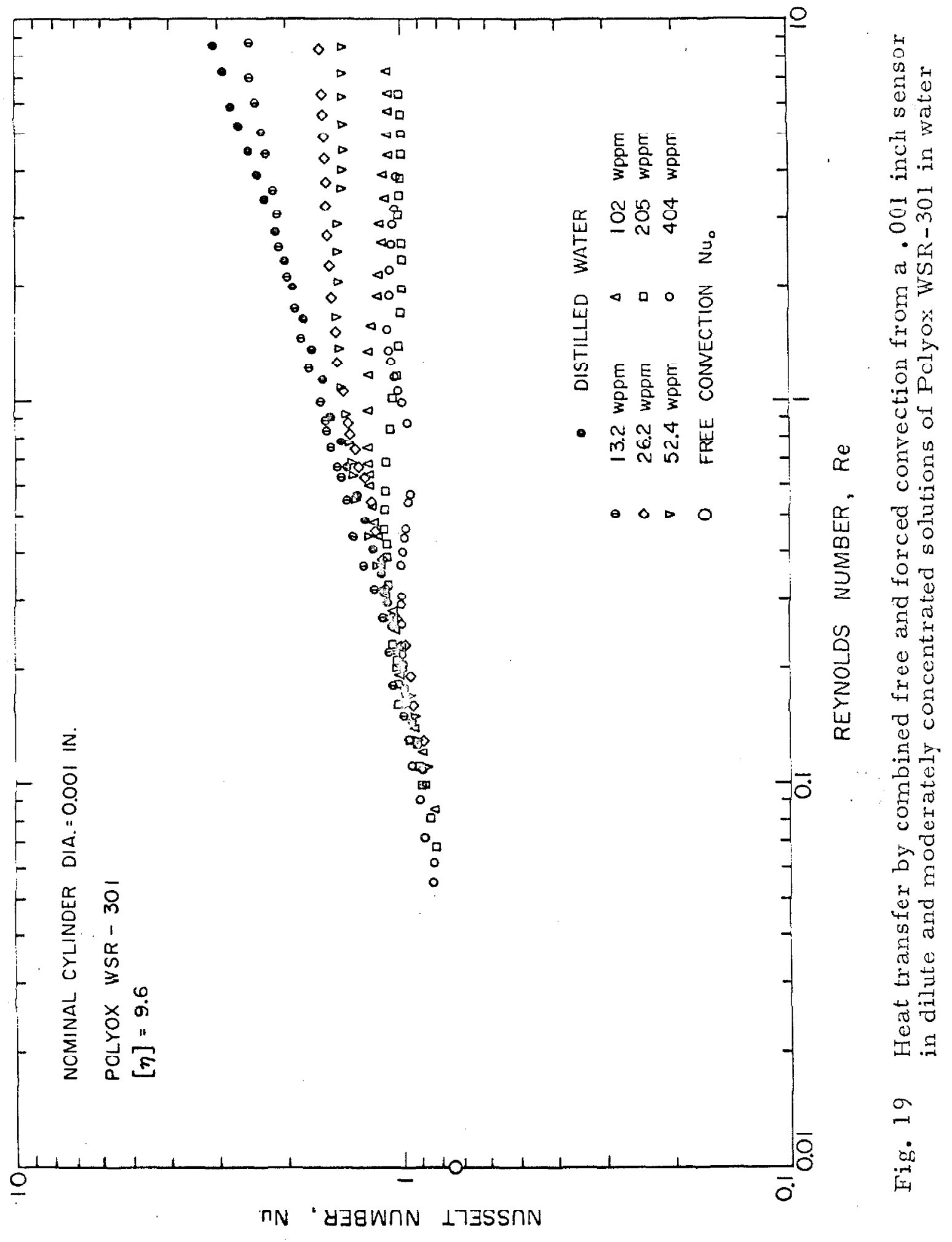




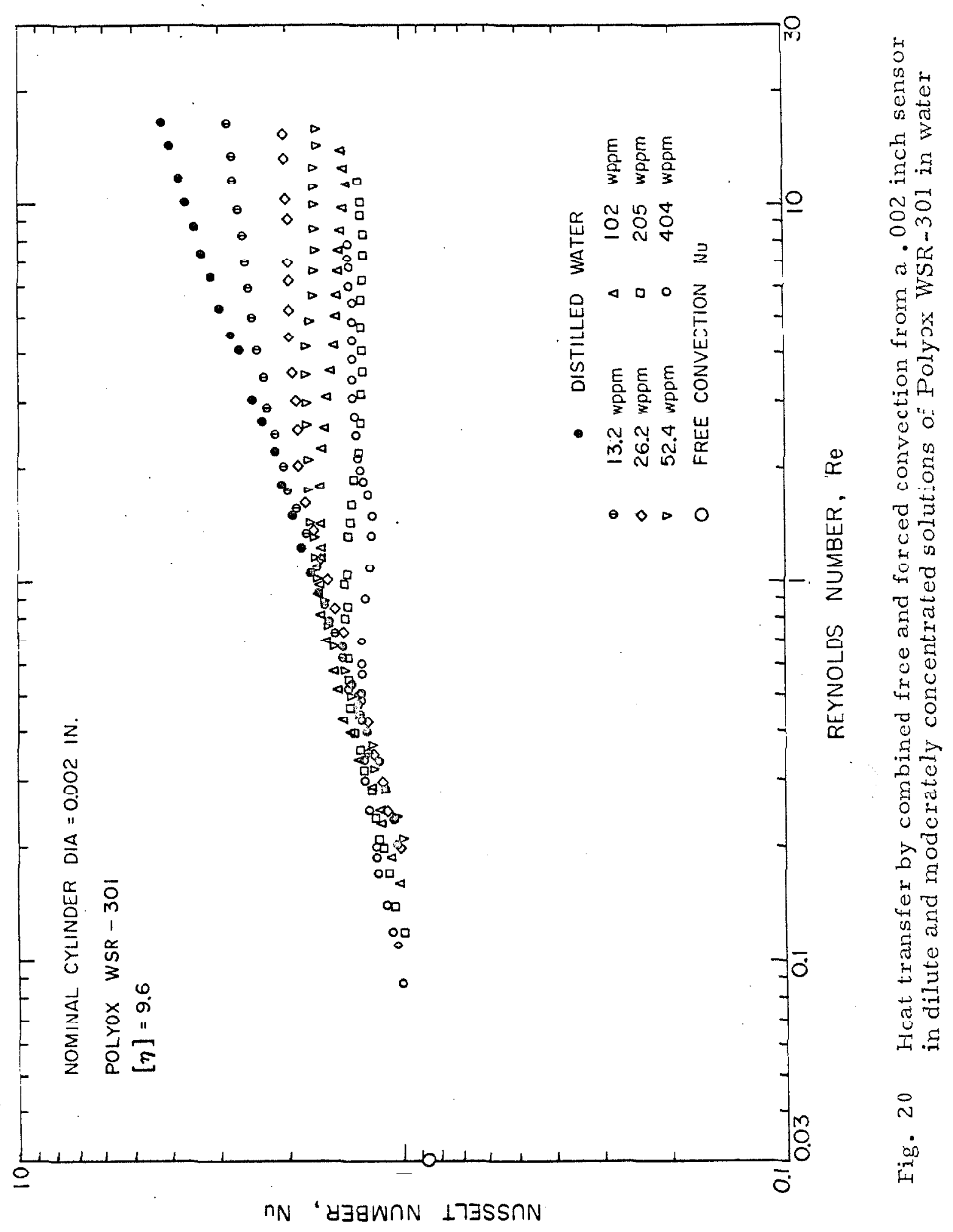




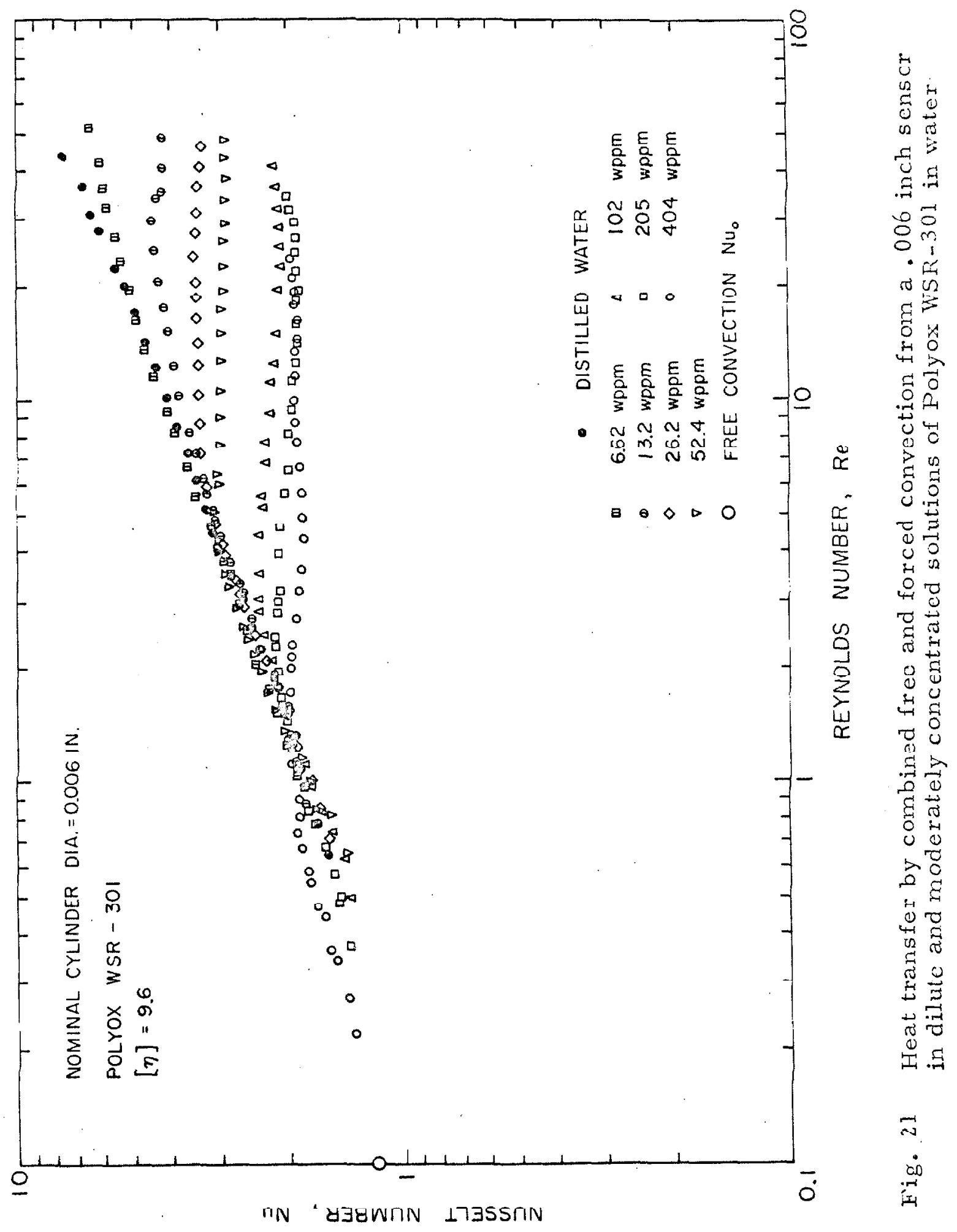




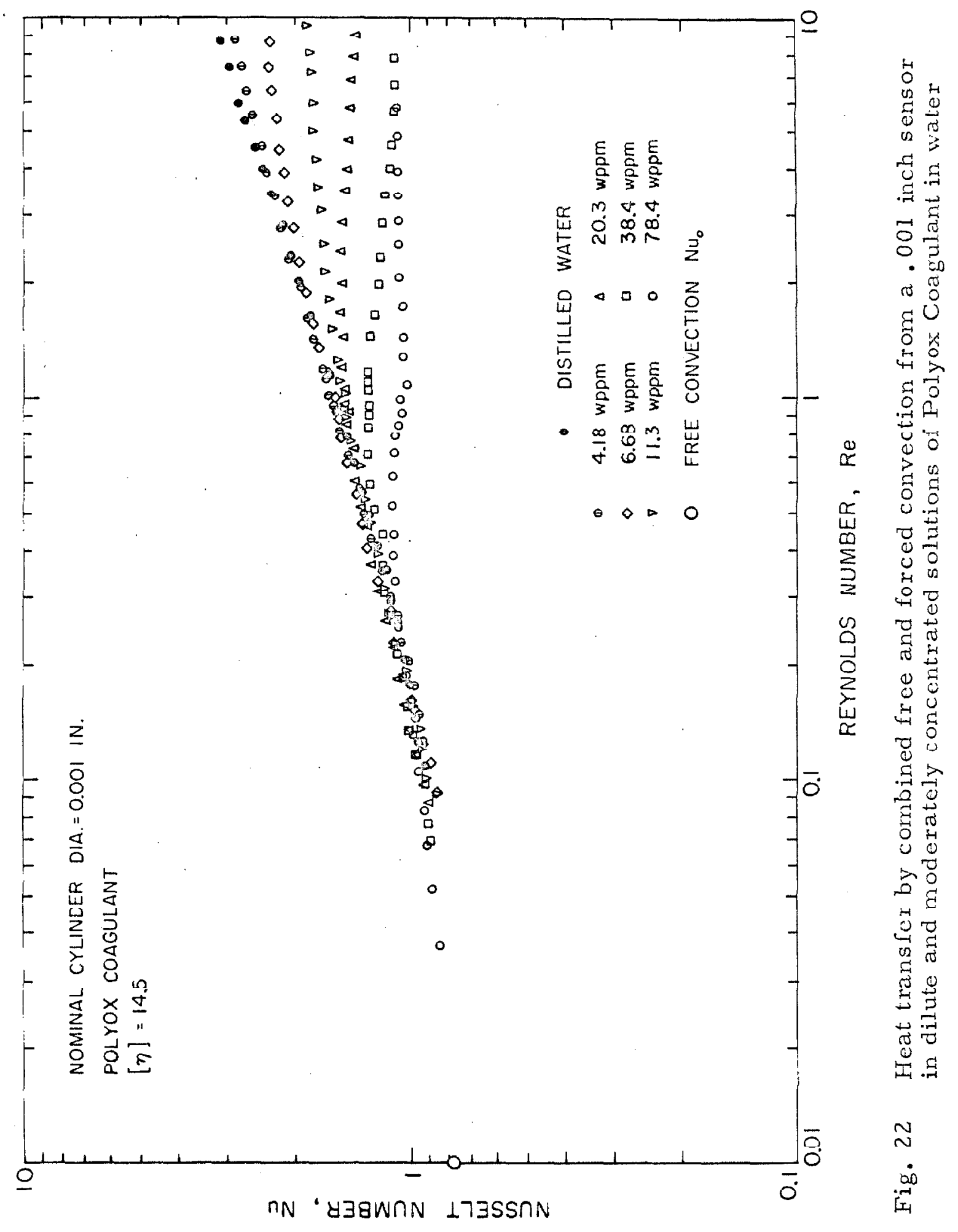




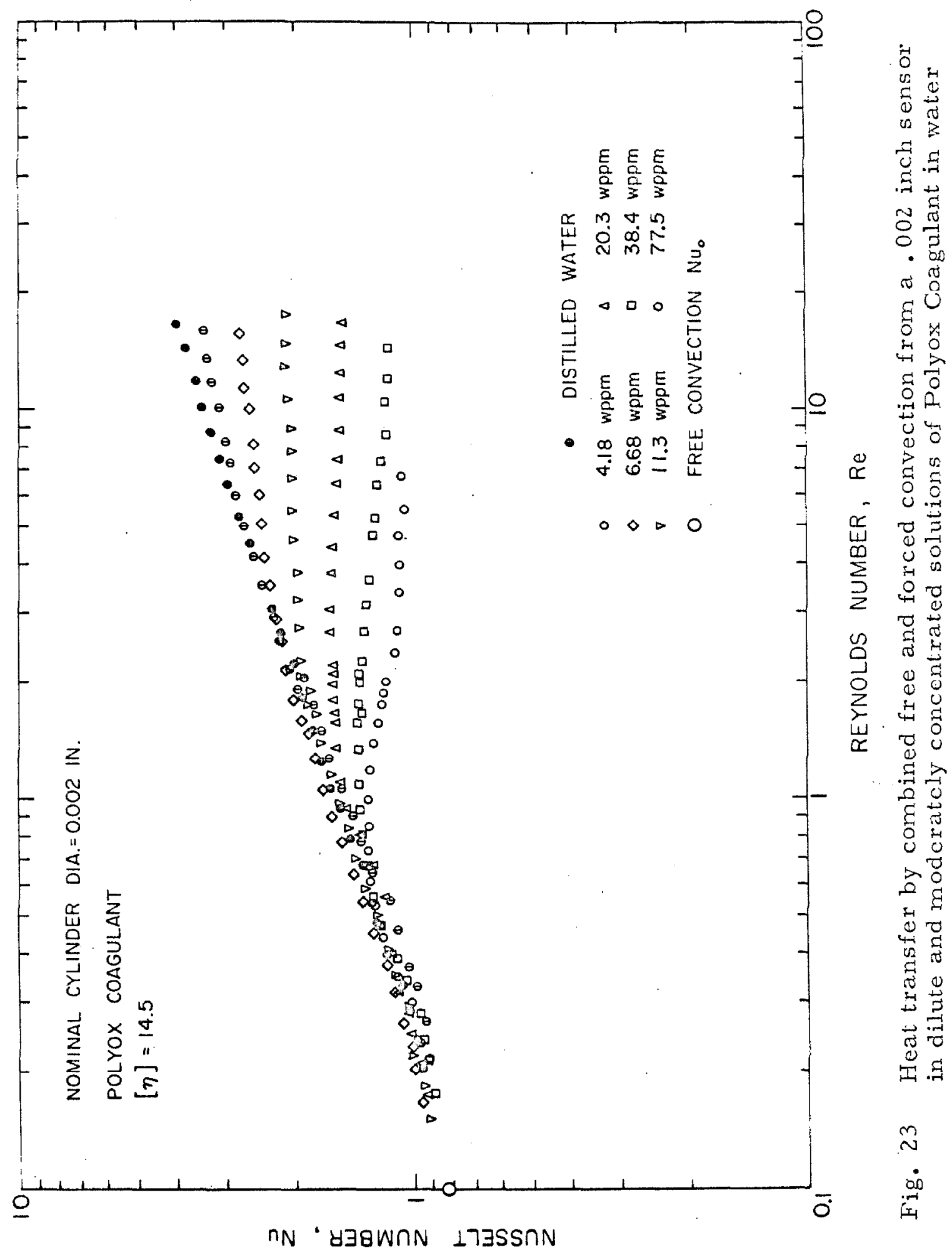




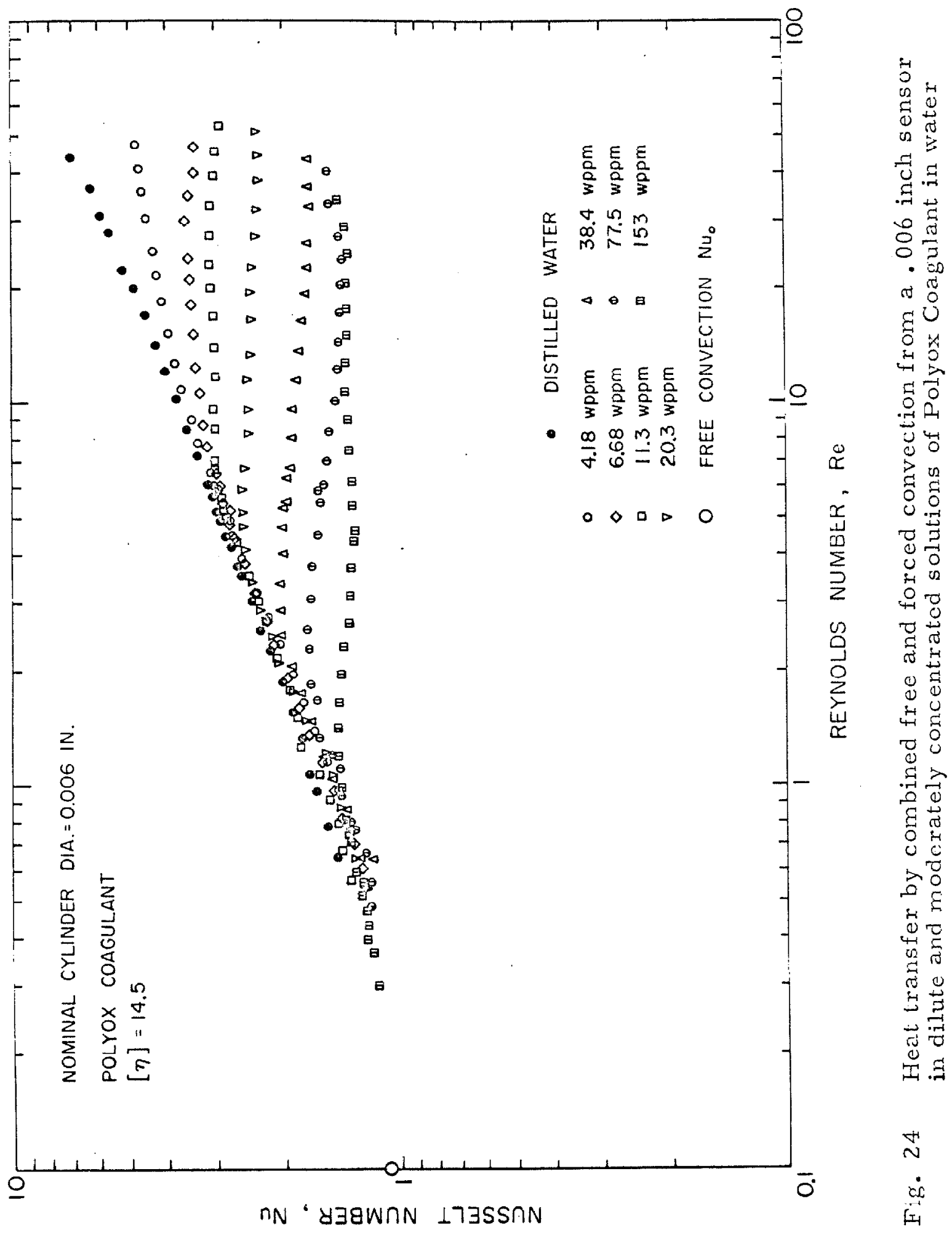




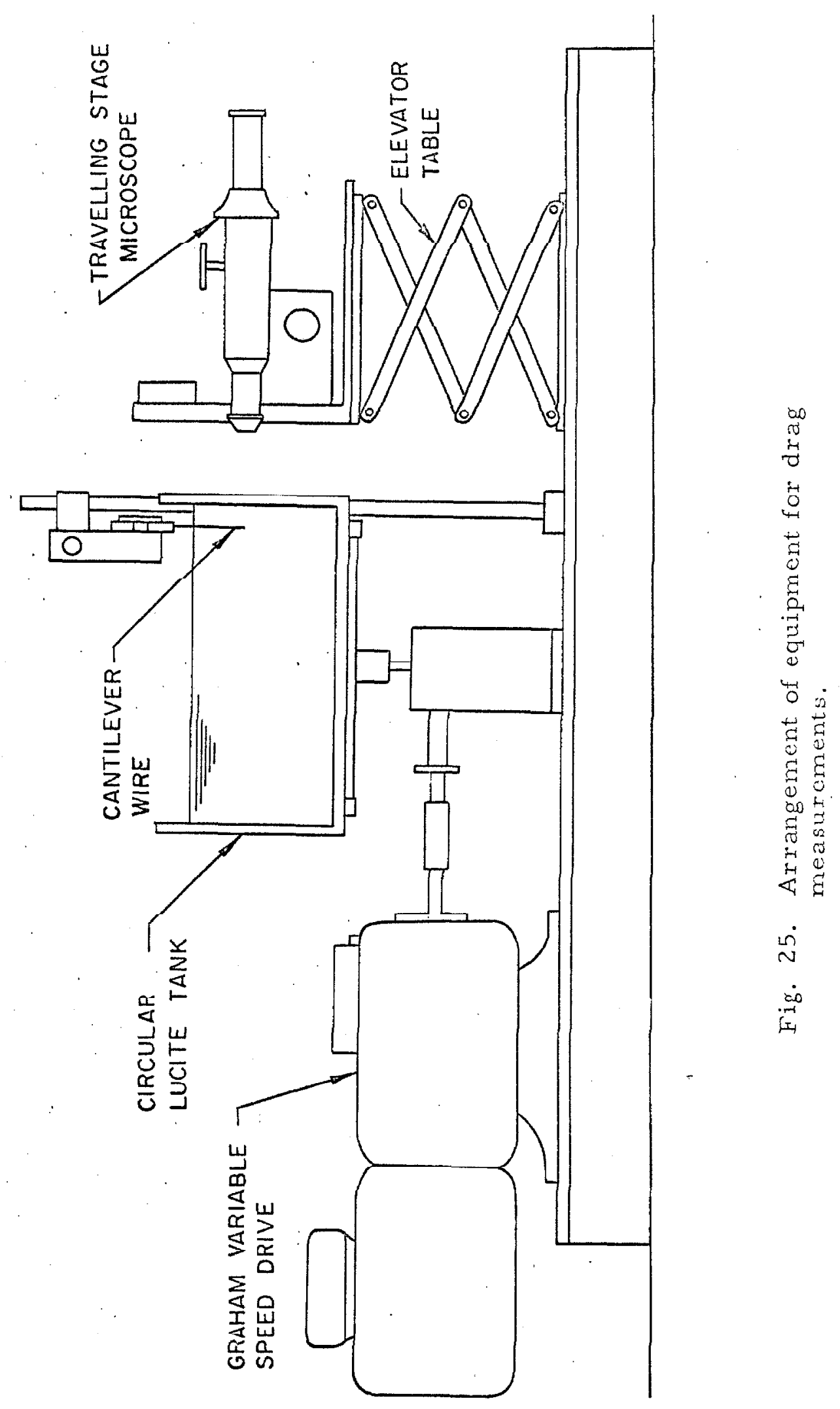




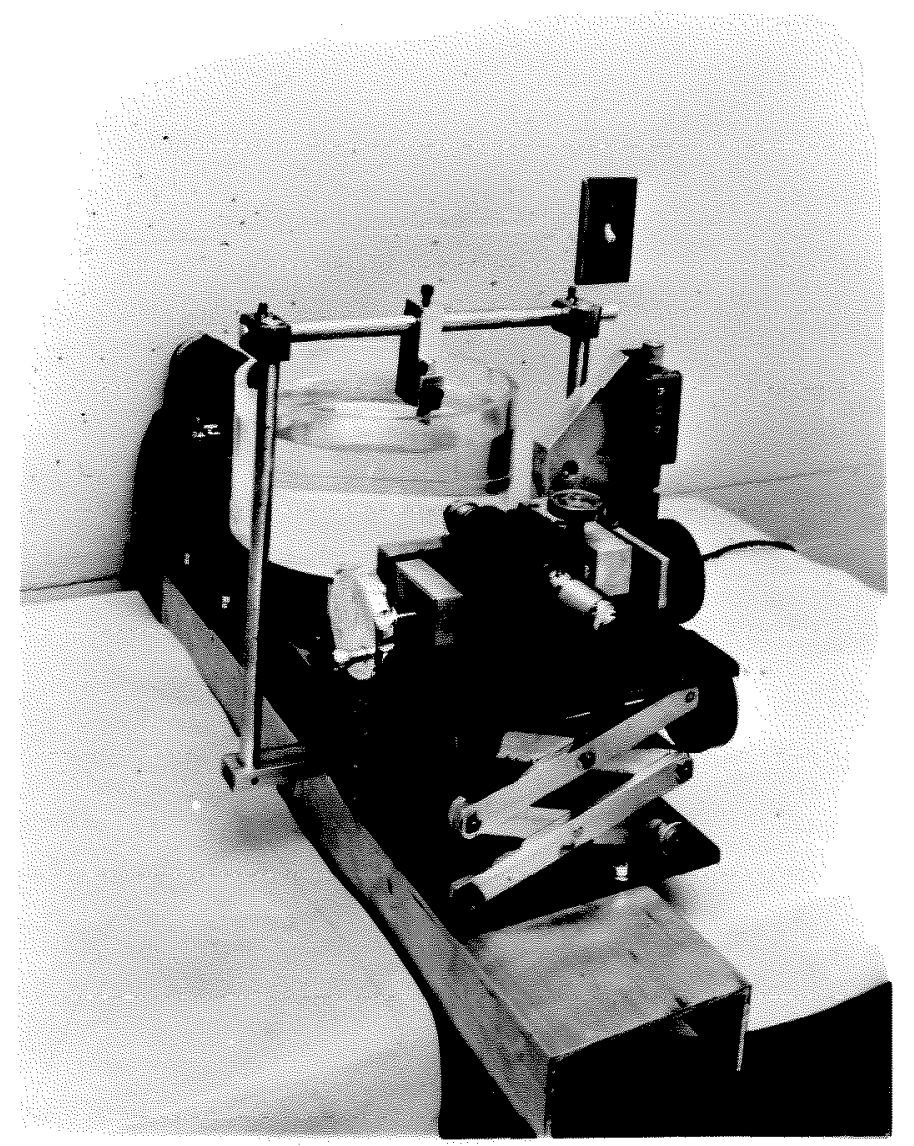

Fig. 26. Photograph of equipment for drag measurements . 


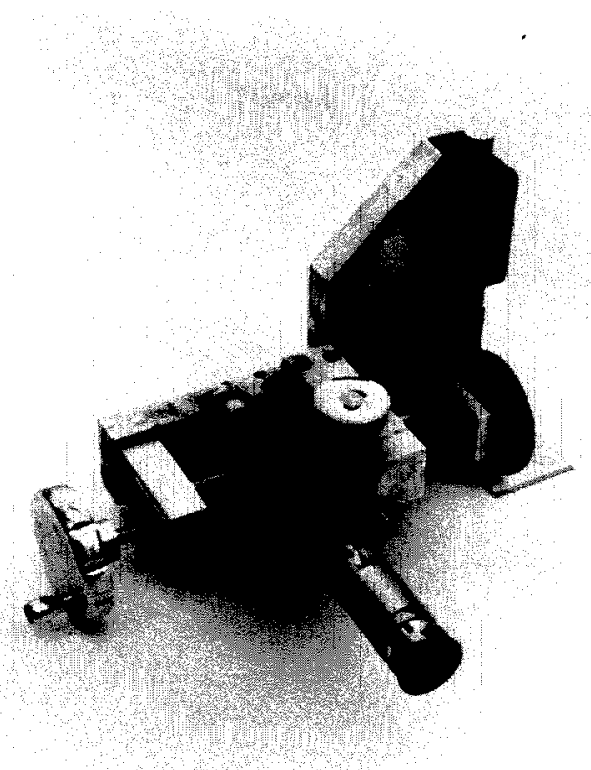

Fig. 27. The travelling stage microscope. 


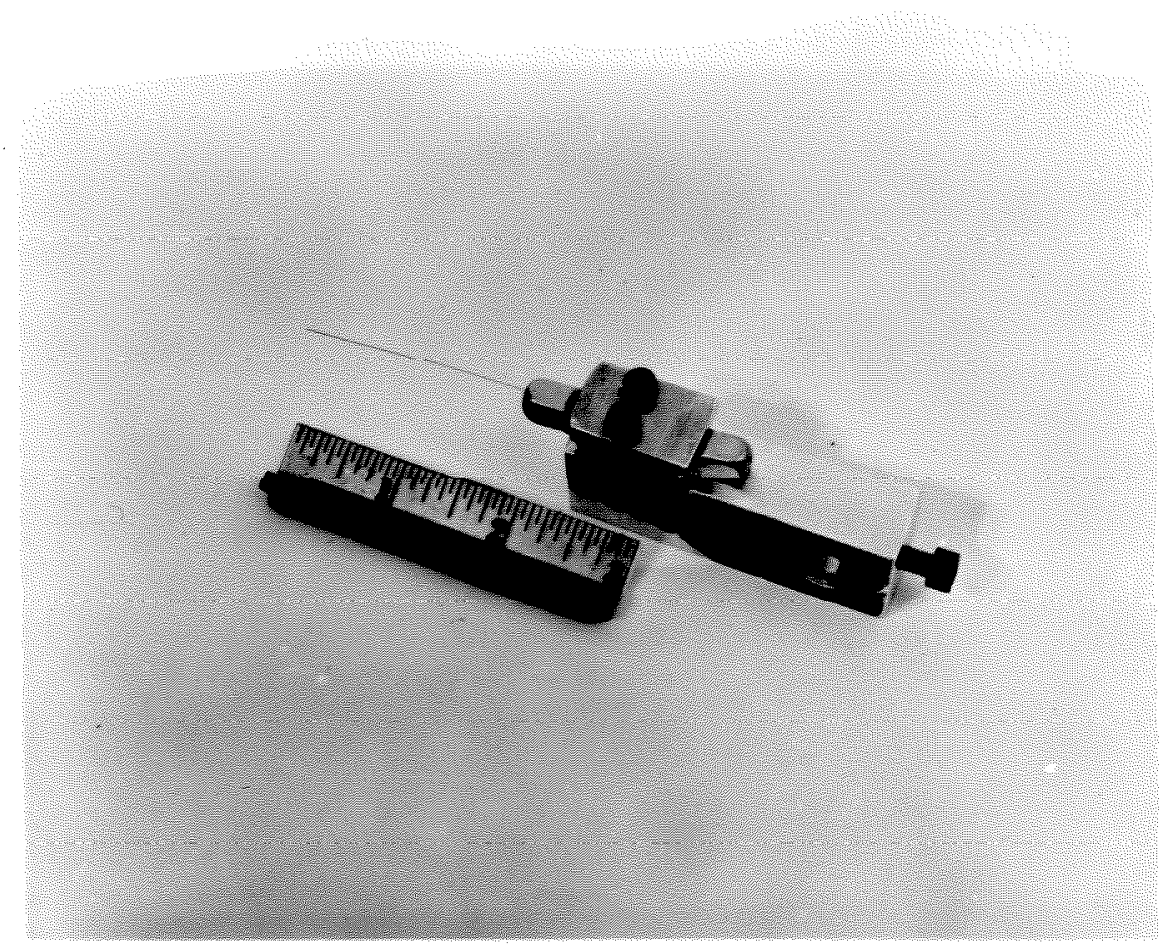

Fig. 28. Photograph of cantilever wire and its mounting support. 


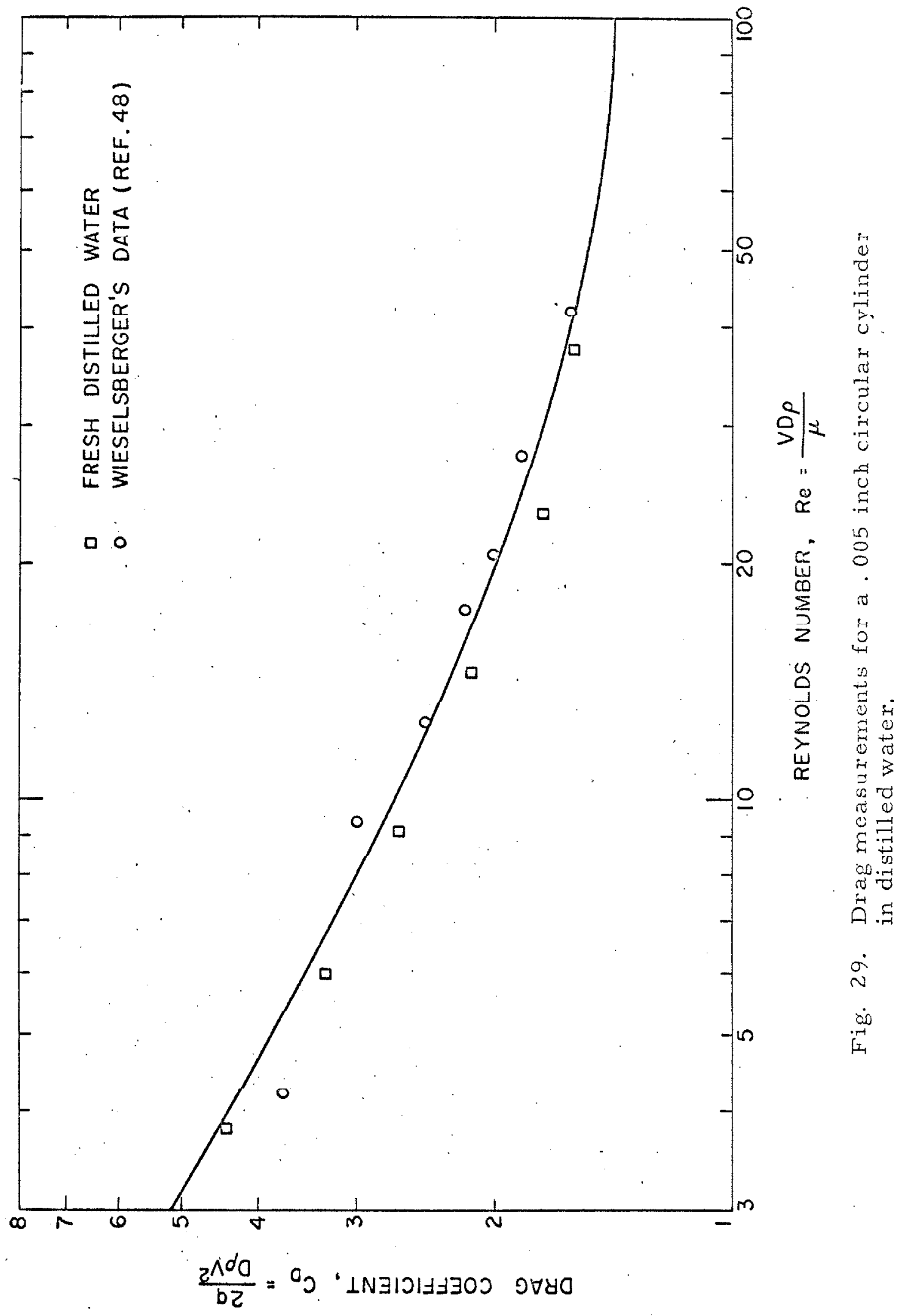




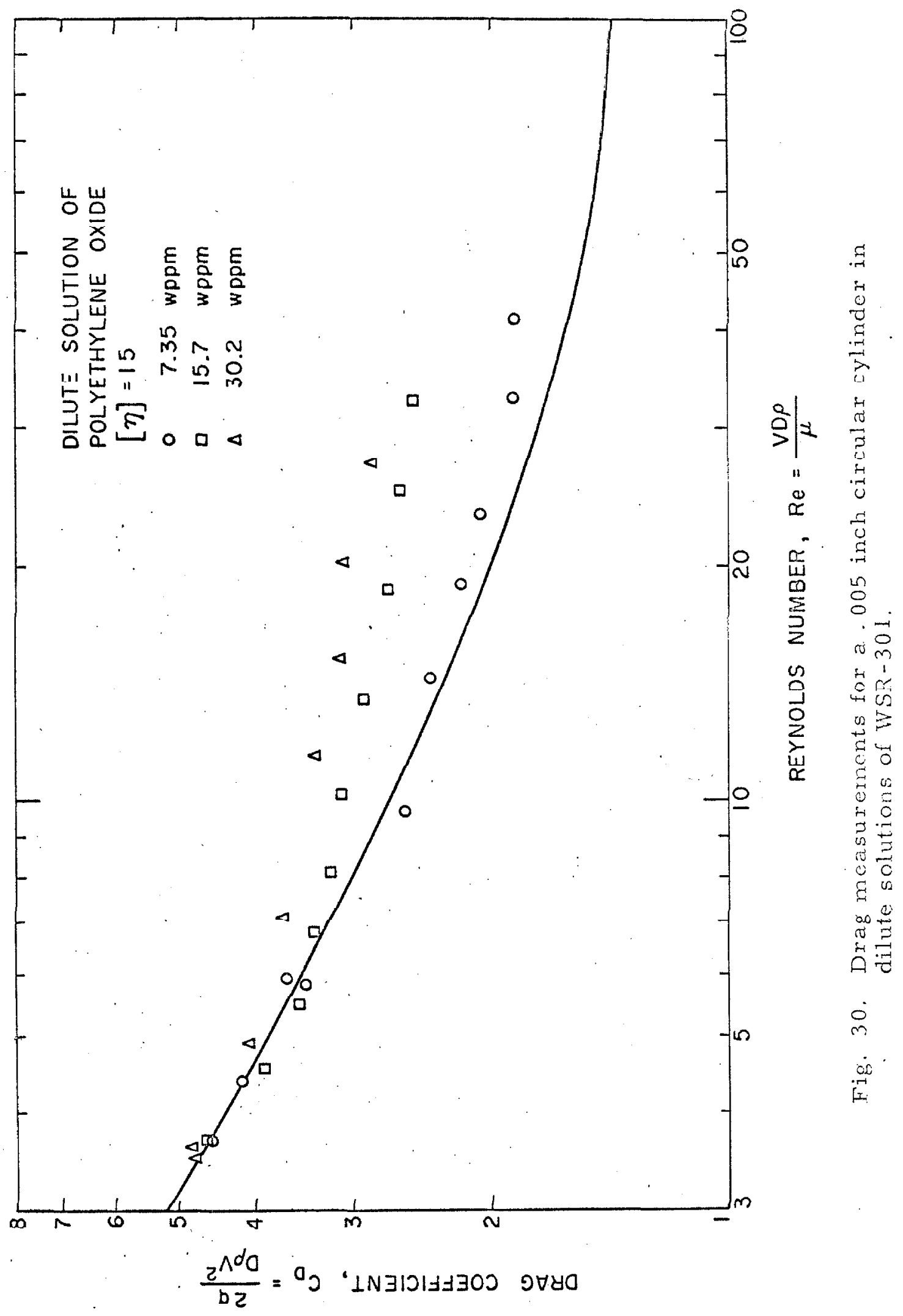




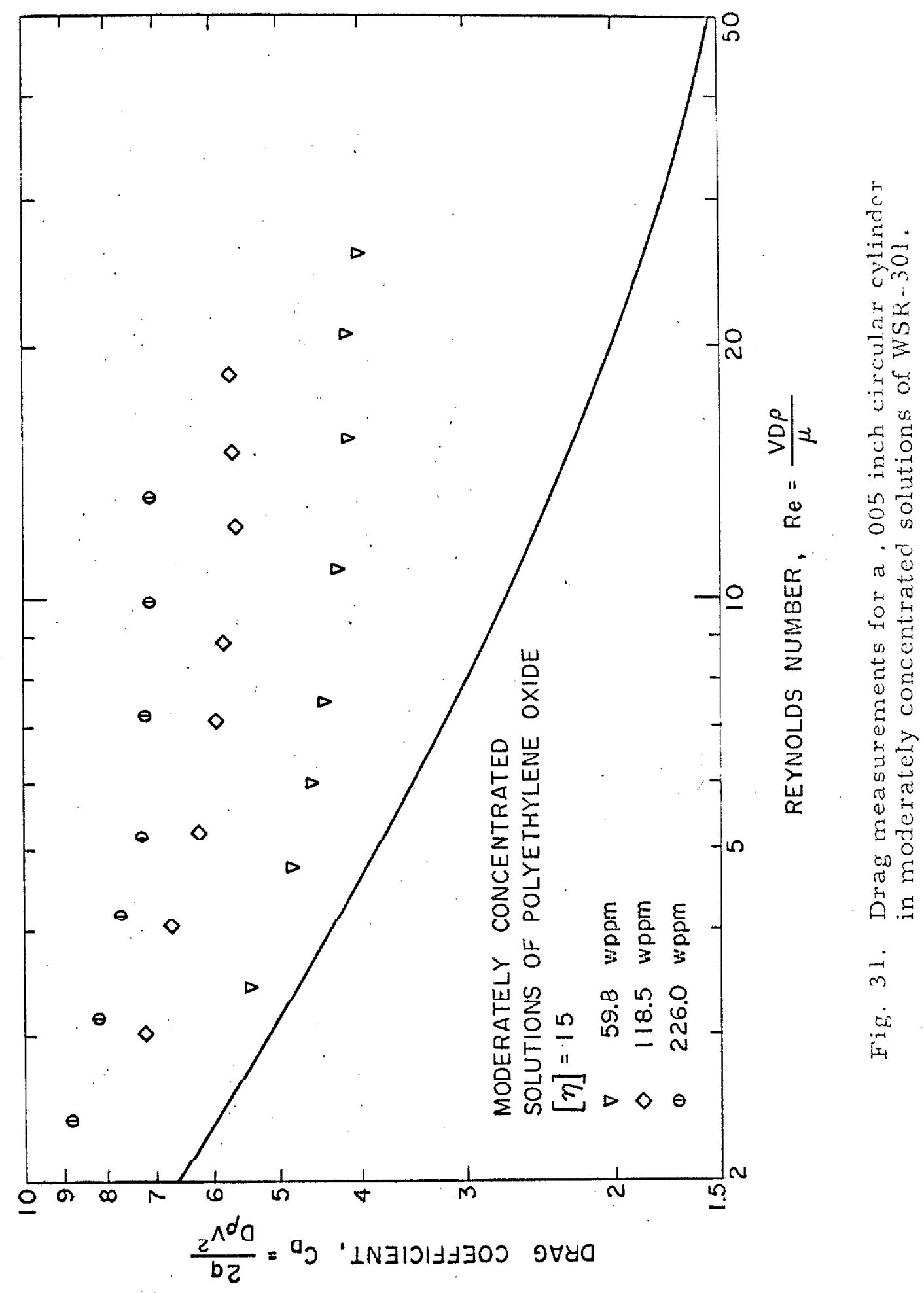




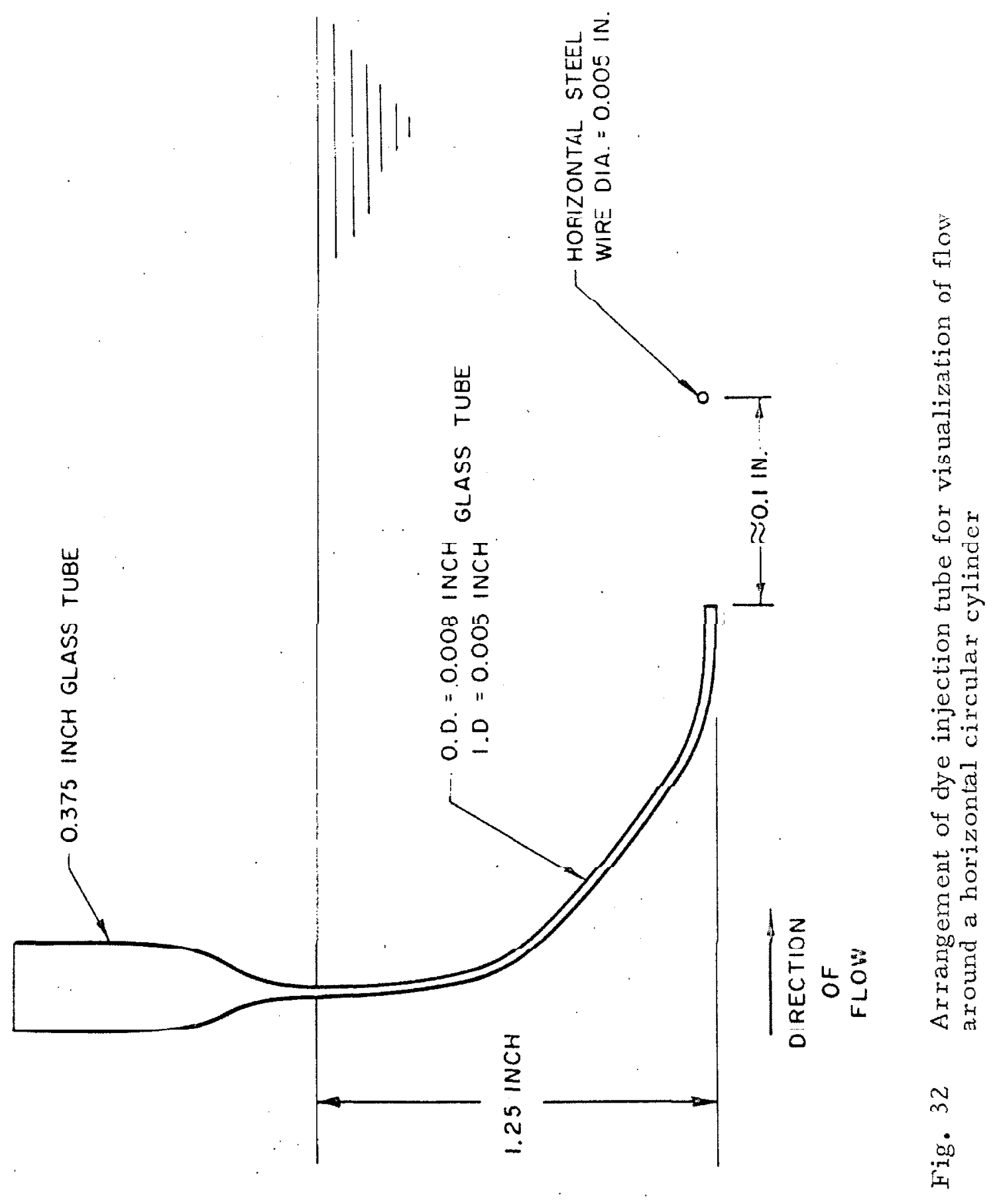




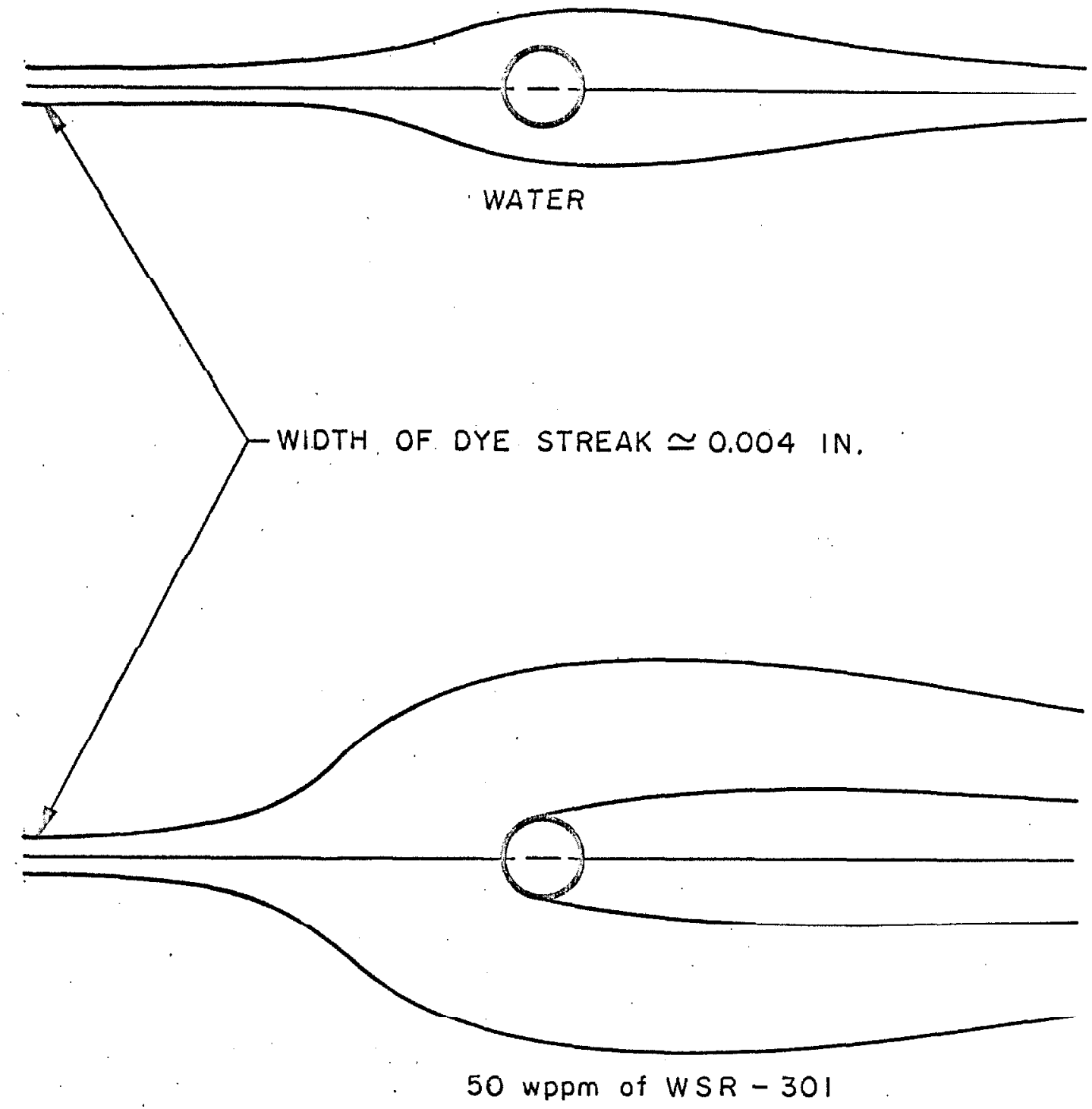

Fig. 33. Observed dye patterns around a 0.05 inch circular cylinder. Fluid velocity is $0.5 \mathrm{ft} / \mathrm{sec}(\mathrm{Re}=20)$. 


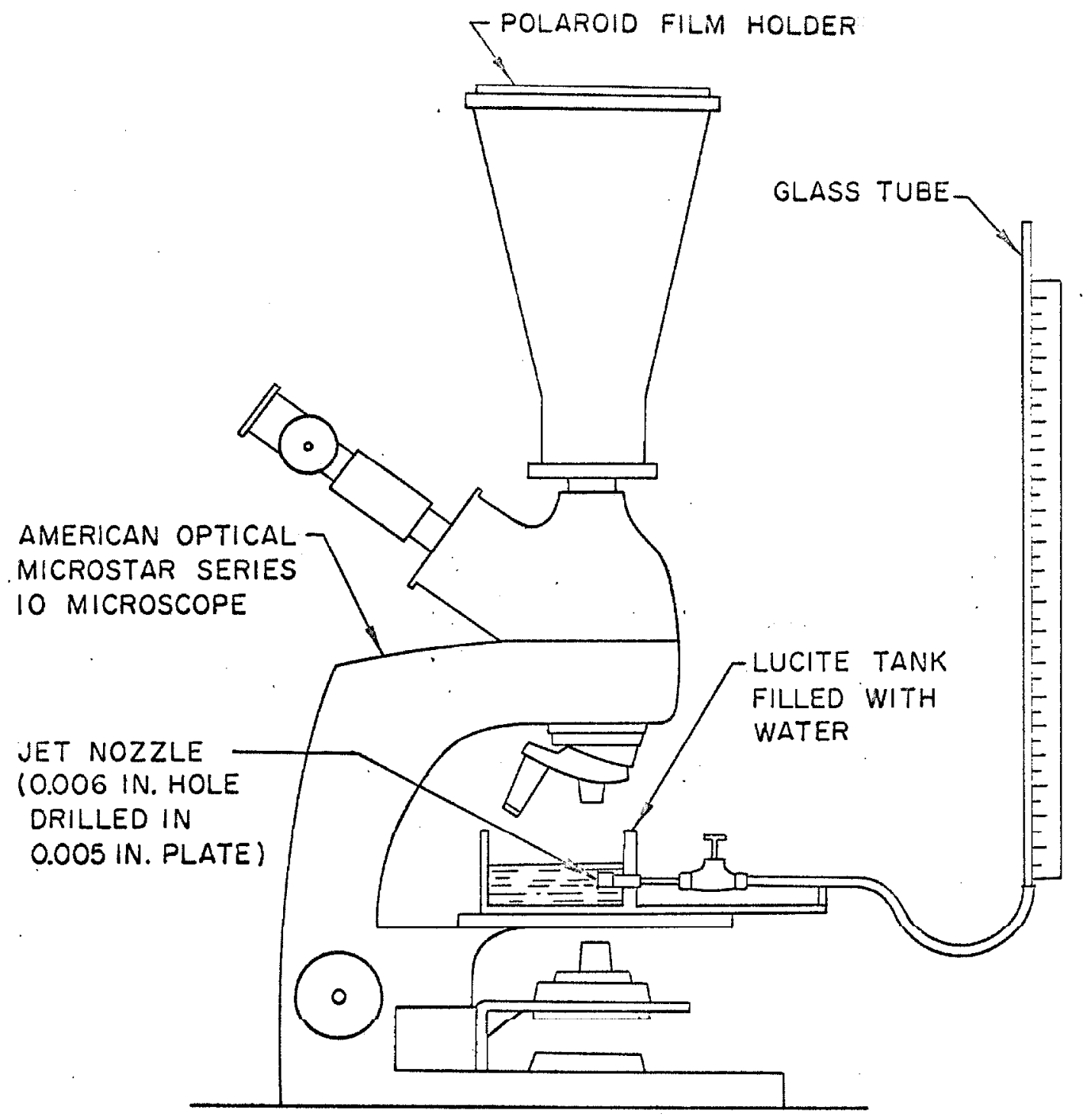

Fig. 34. Arrangement of equipment for jet experiment. 
$-145-$

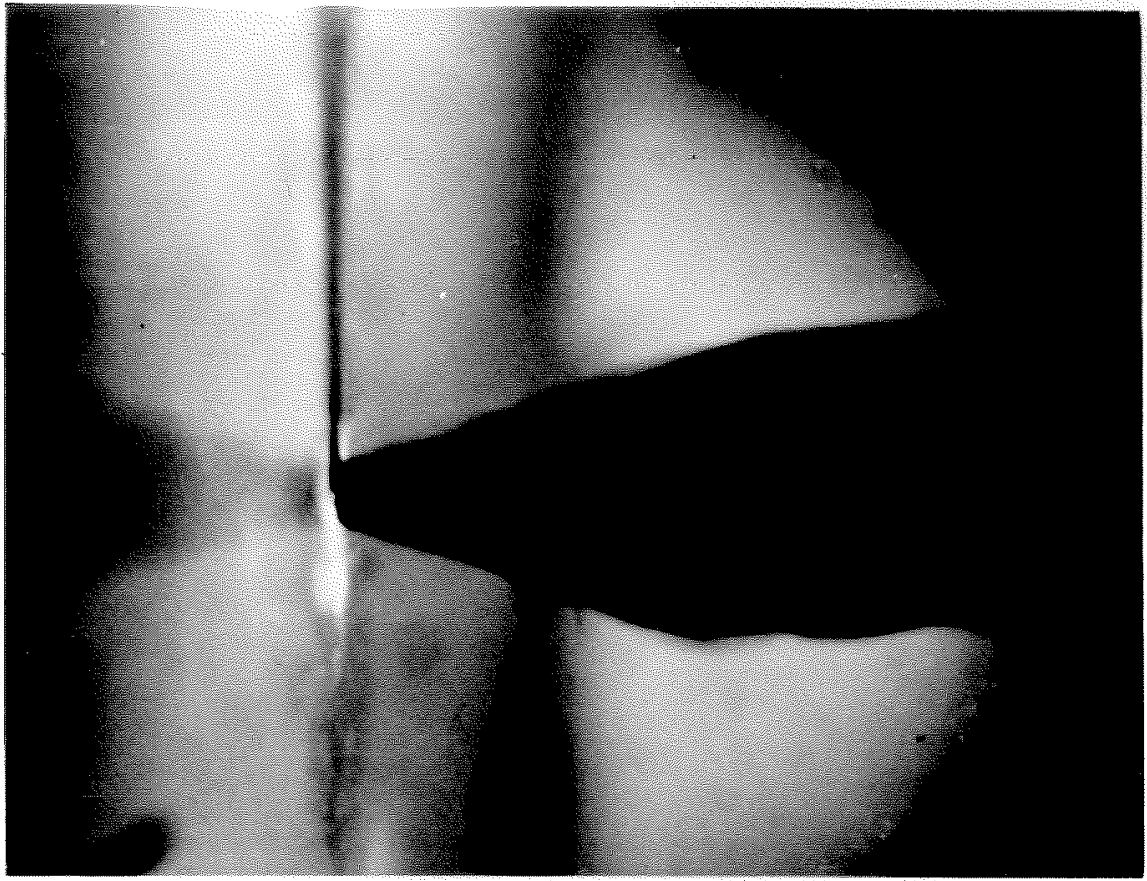

Fig. 35. Laminar jet of water. Mean velocity $=0.2 \mathrm{ft} / \mathrm{sec}$.

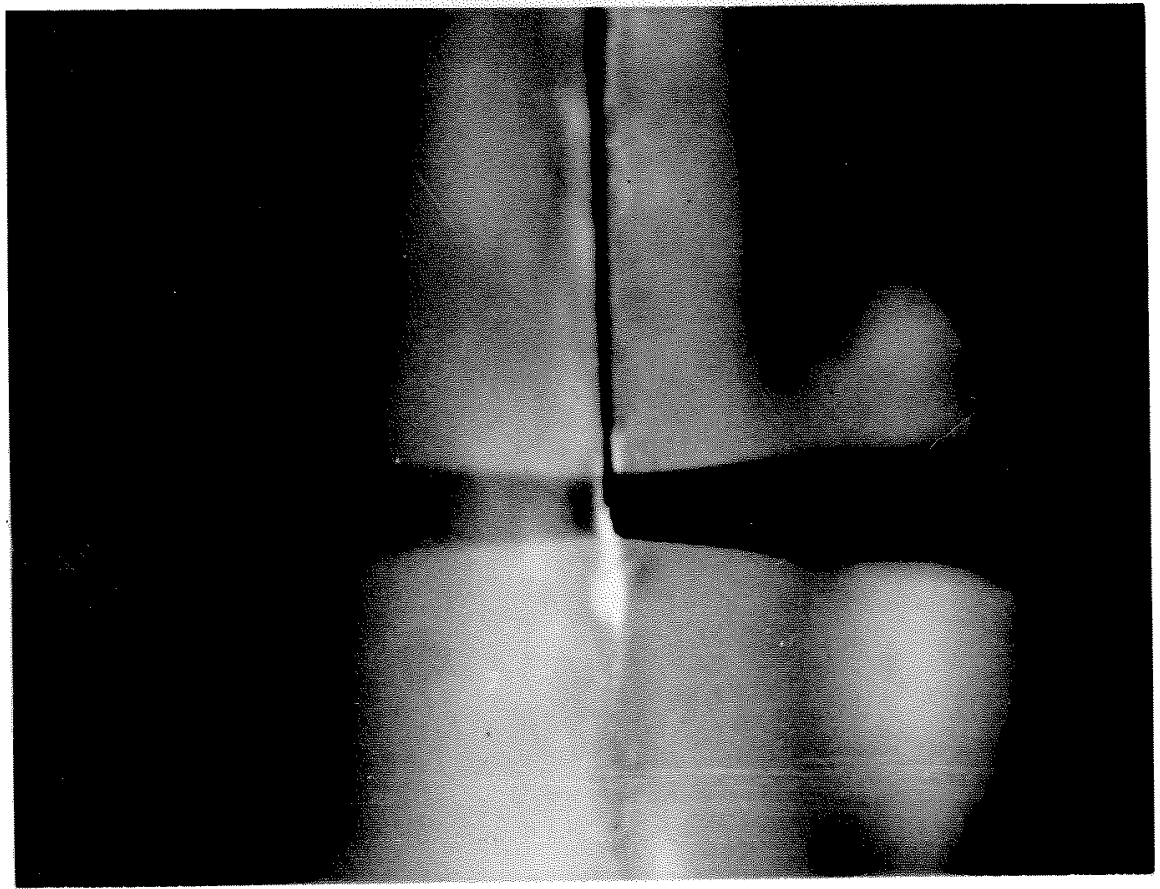

Fig. 36. Laminar jet of water. Mean velocity $=0.4 \mathrm{ft} / \mathrm{sec}$. 


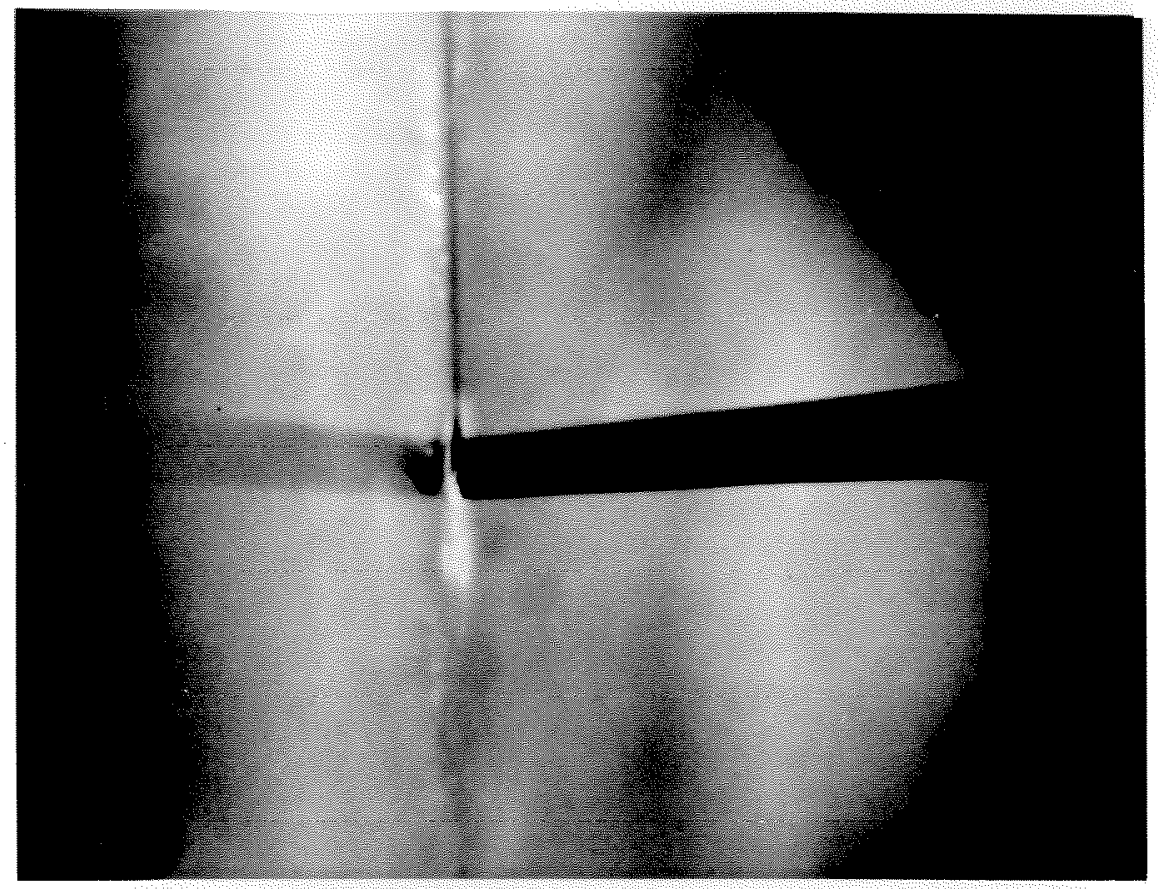

Fig. 37. Laminar jet of water. Mean velocity $=1.5 \mathrm{ft} / \mathrm{sec}$.

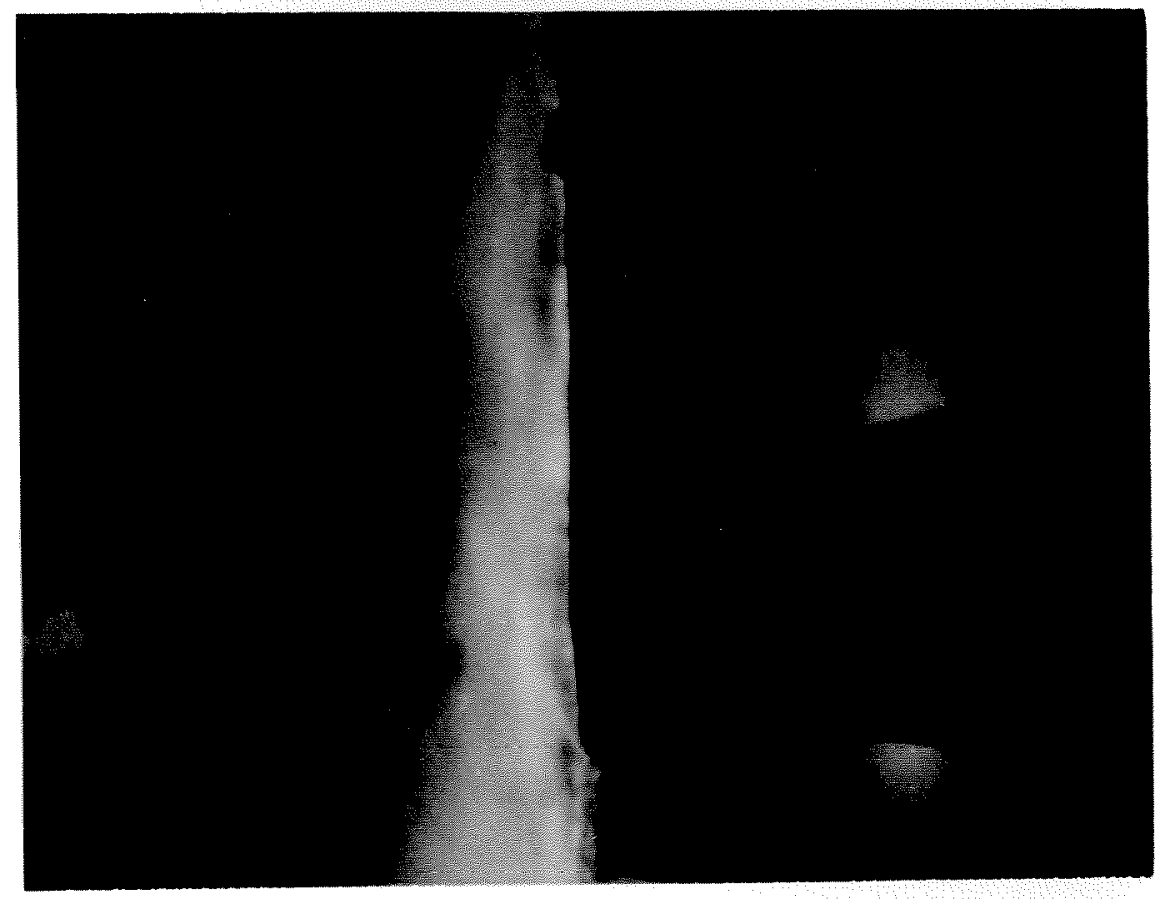

Fig. 38. Laminar jet of a dilute polymer solution. Mean velocity $=1.0 \mathrm{ft} / \mathrm{sec}$. 


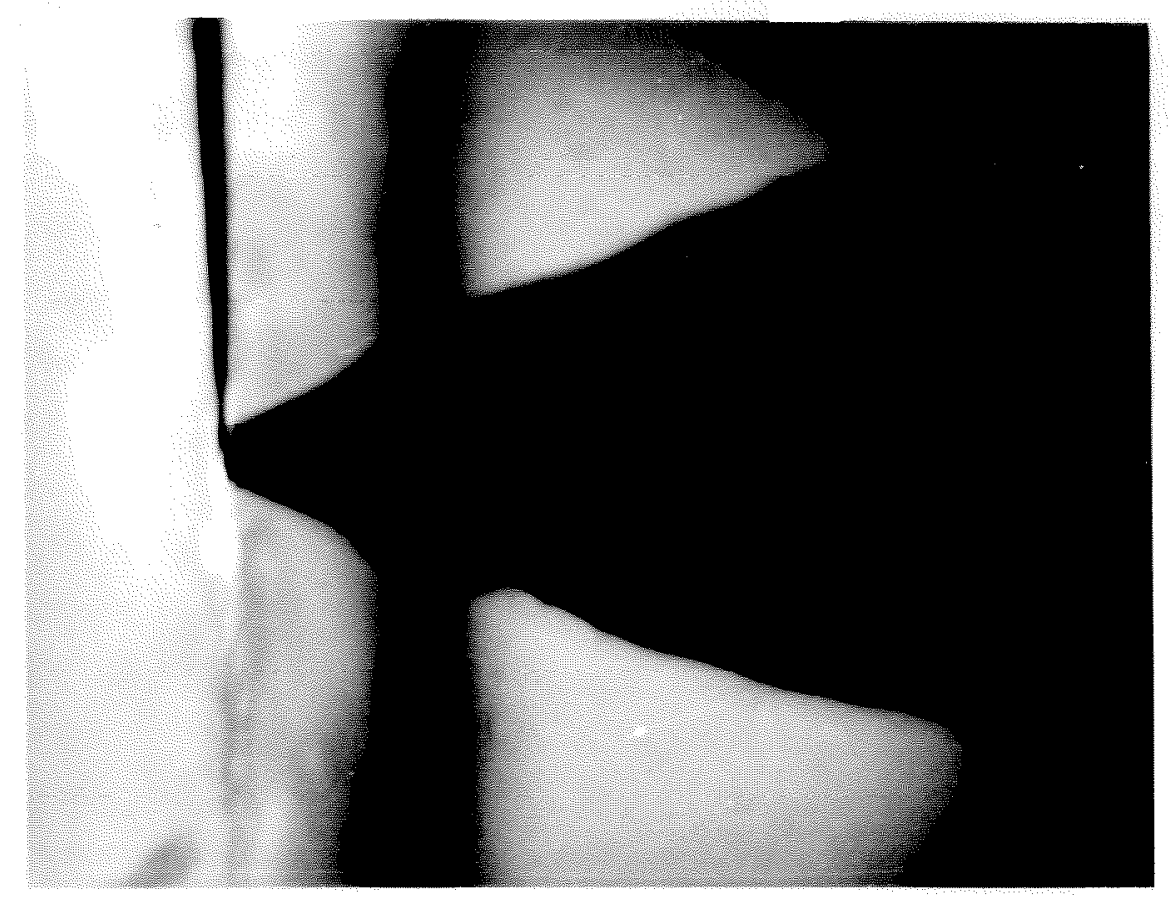

Fig. 39. Laminar jet of a dilute polymer solution. Mean velocity $=0.4 \mathrm{ft} / \mathrm{sec}$.

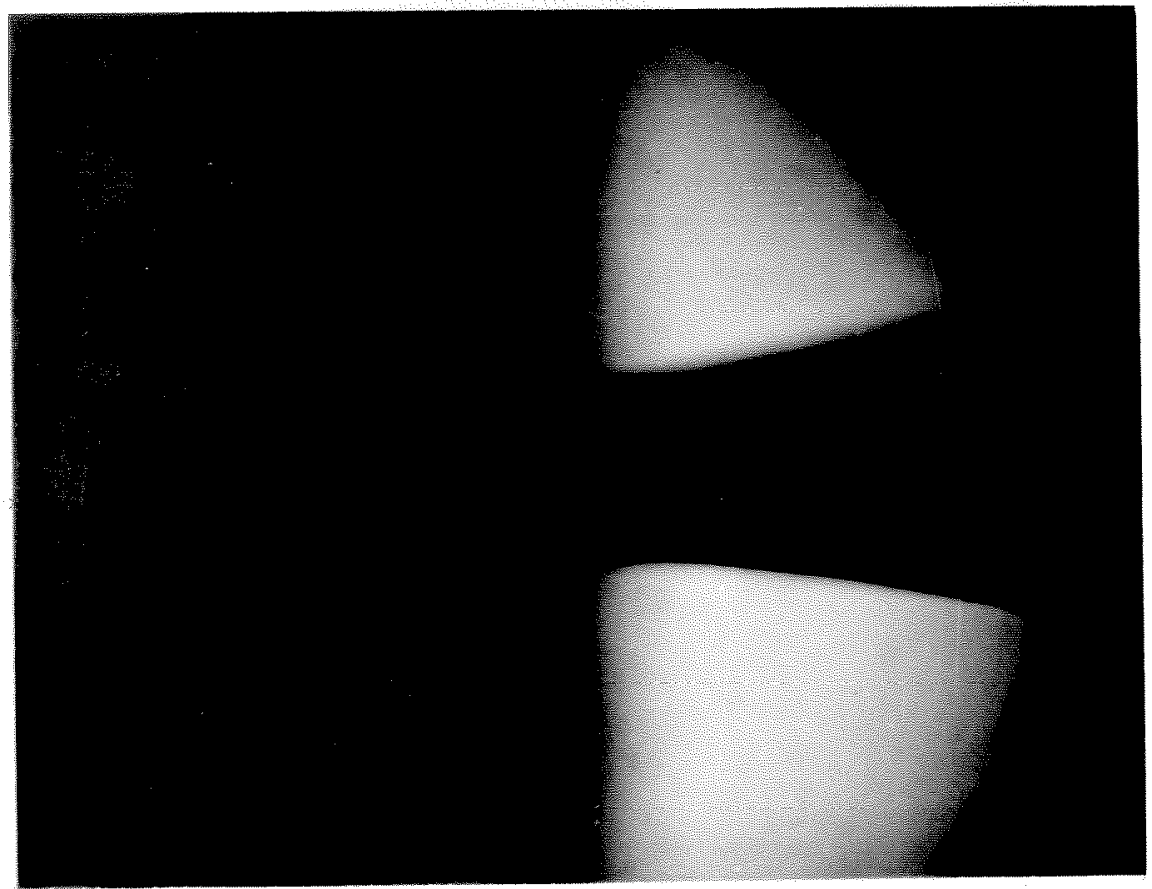

Fig. 40. Laminar jet of a dilute polymer solution. Mean velocity $=2.6 \mathrm{ft} / \mathrm{sec}$. 


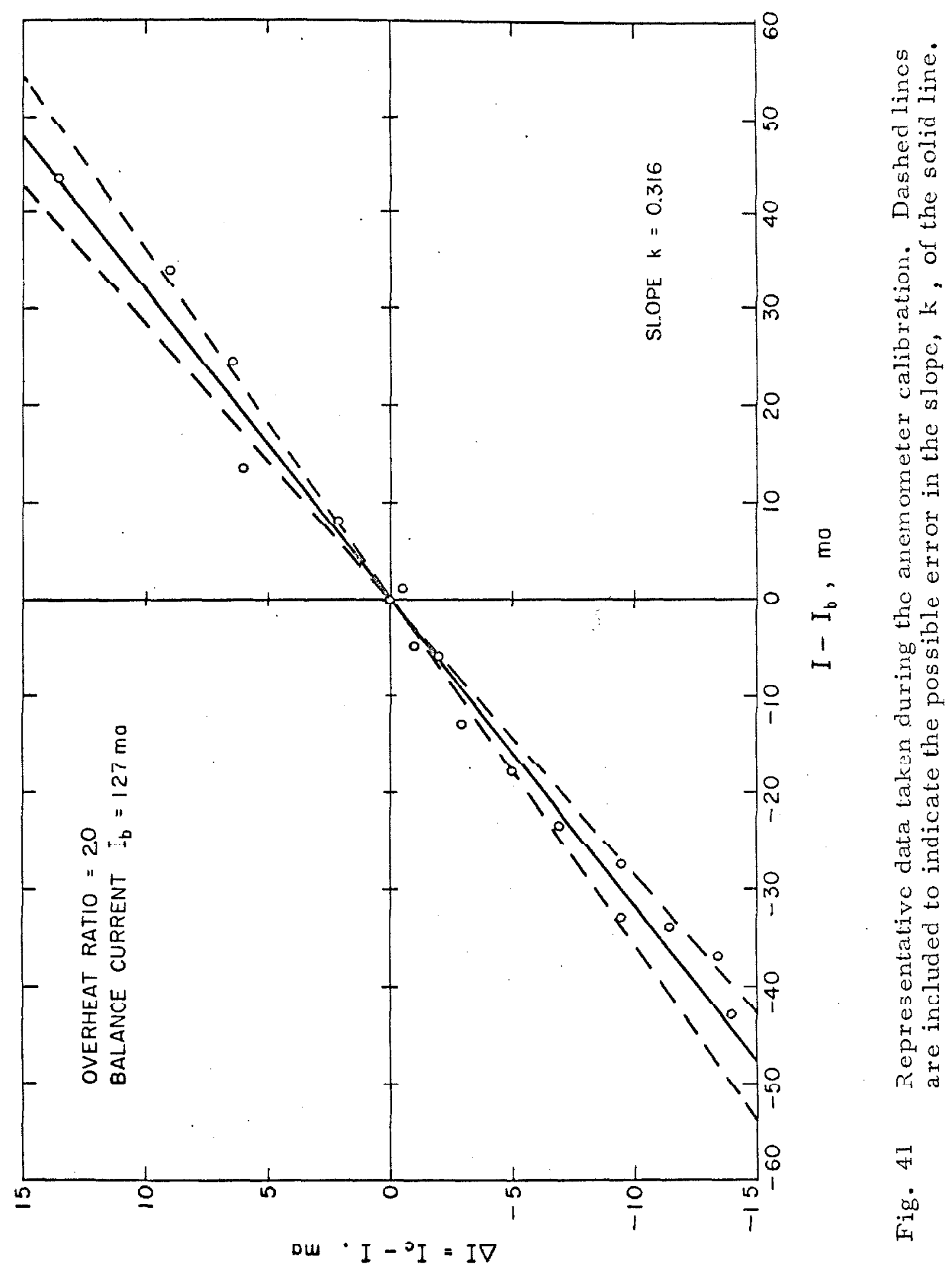




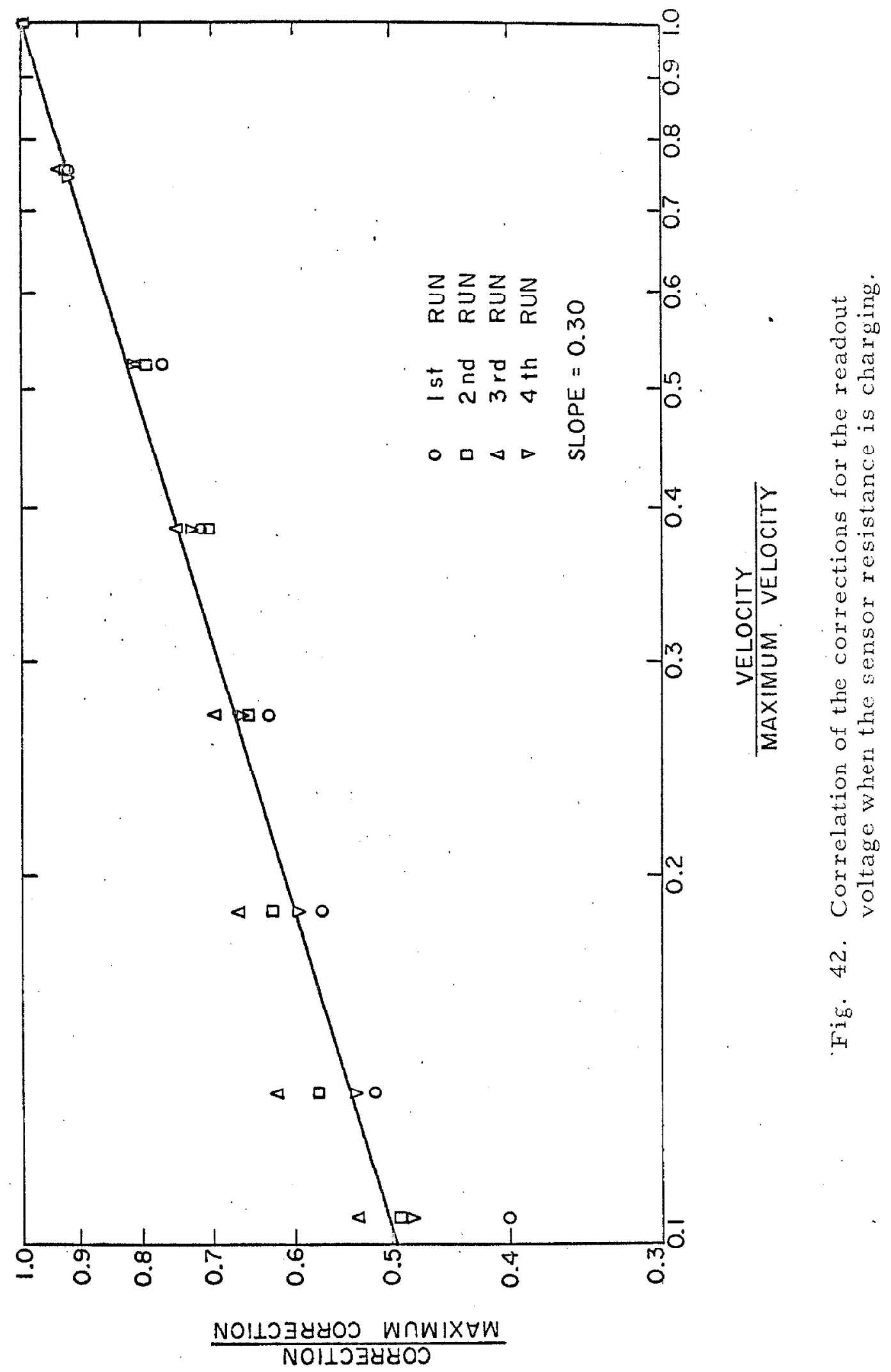

